Review

\title{
Thermostable Vaccines in Veterinary Medicine: State of the Art and Opportunities to Be Seized
}

\author{
Angela Fanelli ${ }^{1,2}\left(\right.$, Luca Mantegazza ${ }^{1}\left(\mathbb{D}\right.$, Saskia Hendrickx ${ }^{3}$ and Ilaria Capua ${ }^{1, *(1)}$ \\ 1 One Health Center of Excellence, University of Florida, Gainesville, FL 32603, USA; \\ angela.fanelli@uniba.it (A.F.); mantegazza@ufl.edu (L.M.) \\ 2 Department of Veterinary Medicine, University of Bari, 70010 Valenzano, Italy \\ 3 Feed the Future Innovation Lab for Livestock Systems, University of Florida, Gainesville, FL 32603, USA; \\ scjhendrickx@ufl.edu \\ * Correspondence: icapua@ufl.edu
}

check for updates

Citation: Fanelli, A.; Mantegazza, L.; Hendrickx, S.; Capua, I.

Thermostable Vaccines in Veterinary

Medicine: State of the Art and

Opportunities to Be Seized. Vaccines 2022, 10, 245. https://doi.org/

$10.3390 /$ vaccines 10020245

Academic Editor: Romain Paillot

Received: 22 December 2021

Accepted: 28 January 2022

Published: 5 February 2022

Publisher's Note: MDPI stays neutral with regard to jurisdictional claims in published maps and institutional affiliations.

Copyright: (C) 2022 by the authors. Licensee MDPI, Basel, Switzerland. This article is an open access article distributed under the terms and conditions of the Creative Commons Attribution (CC BY) license (https:// creativecommons.org/licenses/by/ $4.0 /)$.

\begin{abstract}
The COVID-19 pandemic has highlighted the weakness of the vaccine supply chain, and the lack of thermostable formulations is one of its major limitations. This study presents evidence from peer-reviewed literature on the development of thermostable vaccines for veterinary use. A systematic review and meta-analysis were performed to evaluate the immunogenicity and/or the efficacy/effectiveness of thermostable vaccines against infectious diseases. The selected studies $(n=78)$ assessed the vaccine's heat stability under different temperature conditions and over different periods. Only one study assessed the exposure of the vaccine to freezing temperatures. Two field studies provided robust evidence on the immunogenicity of commercial vaccines stored at temperatures far in excess of the manufacturer's recommended cold-chain conditions. The drying process was the most-used method to improve the vaccine's thermostability, along with the use of different stabilizers. The pooled vaccine efficacy was estimated to be high $(\mathrm{VE}=69 \%)$, highlighting the importance of vaccination in reducing the economic losses due to the disease impact. These findings provide evidence on the needs and benefits of developing a portfolio of heat- and freeze-stable veterinary vaccines to unleash the true potential of immunization as an essential component of improved animal health and welfare, reduce the burden of certain zoonotic events and thus contribute to economic resilience worldwide.
\end{abstract}

Keywords: thermostable; heat-stable; freeze-stable; vaccines; COVID-19 legacy; vaccine efficacy

\section{Introduction}

Global vaccine availability and equity is a goal advocated by global leaders and by 170 Nobel Laureates [1]. Nevertheless, the current COVID-19 pandemic has highlighted that the global vaccine coverage is highly inequitable and skewed, with a high vaccine uptake concentrated in selected countries, predominantly the G7 and European ones [2]. Recently, the G20 Summit has underlined the urgent need to intensify efforts to enhance timely, global, and equitable access to safe, effective, and affordable COVID-19 vaccines [3]. In fact, logistical and supply chain system failures have slowed the vaccine availability and have hampered the global efforts to up-scale COVID-19 vaccination coverage. The lack of thermostability has been proven to be one of the major barriers limiting the worldwide distribution of these products [4]. Indeed, the race to develop efficacious SARS-CoV-2 vaccines has resulted in the first available commercial vaccine products to have storage and delivery requirements of temperatures between $+2{ }^{\circ} \mathrm{C}$ and $-70{ }^{\circ} \mathrm{C}$, depending on the product [5-8].

It is surprising that in 2021 the vast majority of vaccines for human and animal diseases are still dependent on cold-chain systems to ensure their potency throughout production, shipment, storage, and administration. In both human and animal health, vaccines resistant 
to damage by heat and freezing could have great economic and health benefits. Heat-freezestable vaccines could help to reduce vaccine wastage and prevent the consequences of administering ineffective vaccines [9]. For these reasons, thermostable vaccines have been named a priority research area in the World Health Organisation's Global Vaccine Action Plan 2011-2020 [10]. Nevertheless, their development and production is not always a prime concern for vaccine developers, industries, and funding entities [2].

Vaccination is an effective preventive measure against infectious diseases. The main objective of livestock vaccines is to improve animal health, reducing the economic losses associated with disease occurrences [11]. The use of vaccines is recognised as an important management option during outbreaks, as it helps to control the spread of infection and reduce the need for the large-scale culling of at-risk animals [12]. Vaccines are also essential to sustain the commercial exchange of animal products between countries. Vaccines have been developed for 53\% (63/117) of the OIE listed diseases (Appendix A: Table A1) $[13,14]$, while the production of vaccines has been historically reported by members to the World Organisation for Animal Health (OIE) for 68 diseases. When considering these data, it should be noted that only the laboratories under national veterinary services are requested to provide information to the OIE on the vaccines produced (e.g., vaccines produced by private firms are not reported to the OIE) (Appendix A: Table A2).

Most vaccines require continuous storage at $2-8{ }^{\circ} \mathrm{C}$ from manufacturing through to administration, requiring a cold-chain system for their transportation [15]. Vaccination campaigns for several OIE-listed diseases (e.g., Foot-and-mouth disease (FMD) and Rabies) are highly encouraged in endemically infected countries to combat disease outbreaks and reduce their economic burden [16]. These are generally low- and middle-income countries which do not have widespread access to a stable supply of electricity or an effective coldchain system for vaccines. Considering this, thermal stability is a critical issue for most of the available vaccines against animal diseases of international concern.

Similarly, half of the supplied vaccines for human use are wasted as a result of inadequate cold-chain capacities [15]. It has been estimated that this loss accounts for about $80 \%$ of the total cost of vaccination programs, which is roughly \$200-\$300 million per year [17]. In the worst circumstances, the damages may remain undetected, increasing the chance that vaccines with reduced potency are administered, exposing the recipients to a higher risk of becoming infected or even ill [18]. There are no such studies for veterinary vaccines, but we can assume similar figures. For these reasons, it would seem reasonable to invest in solutions that can address the core fragilities which are embedded in most vaccines that are on the market today. Indeed, we have previous experiences which underscore the importance of having heat-stable vaccines.

To date, Rinderpest in cattle, and smallpox in humans, are the only diseases that have been officially eradicated. For both diseases, indispensable to the success of the eradication was the adequate supply of heat-stable and potent vaccines $[19,20]$. The benefits of developing thermostable vaccines for humans were reviewed by several studies $[9,21]$. Additionally, the economic impact of their use was estimated in different case studies in developing countries. For instance, Lee et al. [22] developed a computational model to simulate the effects of making some vaccines thermostable in Niger. They showed that even a single thermostable vaccine would free significant cold storage space for other vaccines, thus alleviating supply chain bottlenecks. In Benin, another study showed that replacing different existing vaccines with thermostable formulations would save medical costs and productivity losses, even with a price two-to-three times higher than the non-thermostable product [23]. Although no study evaluating the economic impact of thermostable vaccines for veterinary use has been carried out, it is reasonable to assume that it would be significant, especially considering how livestock plays an important role in the economy of developing countries, contributing to the livelihoods of about 1.7 billion people [24].

The potential impact of making certain formulations thermostable appears evident when looking at the figures of vaccines commercialized by private companies and authorized by the agencies responsible for the evaluation and supervision of medicines. 
For instance, the USDA Animal and Plant Health Inspection Service (APHIS) licensed more than 700 vaccines, bacterins, and immunomodulators (USDA APHIS: Veterinary biologics, product summaries: https:/ /www.aphis.usda.gov/aphis/ourfocus/animalhealth/ veterinary-biologics / product-summaries, accessed on 25 November 2021), while the European Medicines Agency (EMA) lists more than 400 vaccines approved for animal use (EMA veterinary medicine database: http://vet.eudrapharm.eu/vet/advancedSearch.do, accessed on 25 November 2021). Billions of doses are administered annually to protect the worldwide poultry population (STATISTA: https:/ / www.statista.com/statistics/263962 / number-of-chickens-worldwide-since-1990/, accessed on 25 November 2021).

A vaccine that did not require cold temperatures to be transported and stored would eliminate the costs of maintaining the cold-chain and would address equity issues linked to the unavailability of a reliable electricity supply. The positive impact would be also seen in high-income countries, as thermostable vaccines would be easier and cheaper to store. For example, Porphyre et al. [25] identified the importance of sufficient strategic supplies of vaccines to control FMD outbreaks in Scotland. The easy distribution and storage of thermostable vaccines would greatly influence delivery rates and, thus, the reaction timing for controlling outbreaks in livestock. This is particularly true when considering highly contagious diseases, such as FMD [26]. The general consensus is that vaccination is one of the essential tools to respond to outbreaks of livestock diseases which cannot be controlled by stamping-out policies. In these cases, vaccination is also considered the control option that provides the largest economic benefits $[27,28]$.

As an unsurprising starting point, it should be mentioned that the characteristics of thermostable vaccines are not clearly and specifically defined. The World Health Organization (WHO) encourages the production of thermostable vaccines, considering them, in general terms, as heat- and freeze-stable formulations which can be stored for extended periods of time above $8^{\circ} \mathrm{C}$, as well as not being damaged by freezing temperatures $\left(<0{ }^{\circ} \mathrm{C}\right)$ [29]. The OIE, which sets the standards for the production and quality control of biological products for veterinary use across the globe [30], uses the word 'thermotolerant' to describe the ability of a vaccine to retain a level of infectivity after exposure to heat (Glossary of terms of the OIE Terrestrial Manual https:/ / www.oie.int/app/uploads/2021/03/mailing-oct-2014.pdf, accessed on 25 November 2021). However, it does not provide a clear definition of thermotolerance or thermostability in terms of its shelf-life and its recommended stability, with reference to temperature ranges. Moreover, the Food and Agriculture Organization of the United Nations (FAO) and the Pan American Health Organization (PAHO), which have high-level scientific and technical expertise from around the world in dealing with priority health issues, do not outline a standard for thermostable vaccines [31,32]. The lack of a standard, as well as a unified definition, from the international organisations involved in the fight against human and animal diseases at a global level, contributes to the hinderance in the production of thermostable formulations.

Today, given the evidence of the inequitable access to vaccines, supply chain challenges, and the continuing rise in new cases of COVID-19, particularly in low- and middle-income countries, the world has a perfect opportunity to identify bottlenecks and to reprioritize research. The transformative power of the COVID-19 pandemic calls for major advancements in vaccine development and manufacturing, which would empower decision makers and the scientific community to unleash the full potential of vaccines and immunization. Considering the above, the objective of this study is to gather, assess, and present evidence from the peer-reviewed literature on thermostable vaccines developed for animal diseases and providing examples of their value, as well as discussing their impact on disease prevention and control.

\section{Materials and Methods}

\subsection{Objectives}

This systematic review and meta-analysis focus on a selection of animal infectious diseases with the objective of answering the following guiding questions: 
1. What type of thermostable vaccines have been developed for veterinary use?

2. What are the characteristics of these thermostable vaccines?

3. How immunogenic and effective are these thermostable vaccines?

\subsection{Eligibility Criteria}

The inclusion criteria are: (1) the clinical and field trials evaluating the immunogenicity and/or the efficacy/effectiveness of thermostable vaccine formulations developed against animal infectious diseases (only bacterial and viral diseases); (2) studies testing thermostable vaccines in natural hosts; (3) articles published in peer-reviewed journals after 1990; and (4) an English language full text. Experimental studies using laboratory animals (e.g., mice) and in vitro studies are excluded.

\subsection{Information Sources}

PubMed, CAB Abstracts, and Web of Science databases were used to perform two separate literature searches: a broad search on thermostable vaccines, and a specific search on DNA vaccines, which are the new-generation vaccines that are considered heat-stable on account of their structural character $[11,33,34]$. The first search was done using general keywords and was integrated by screening the reference lists of the identified eligible studies. For the search on DNA vaccines, the terms used to label articles (MeSHterms or Subject category) were implemented, and only the titles of the first 100 returns (sorted by relevance) from each database were retrieved, since the timeframe for this study only allowed for a rapid assessment. The decision of performing two separate searches was for the following reasons:

- Authors may not specify that DNA vaccines do not need the cold-chain, a thermostability is an intrinsic characteristic of these vaccines. Thus, the computerized search would not be able to retrieve the manuscripts if it only used general keywords;

- The use of a unique complex search strategy, combining multiple different terms, would not be an efficient way to identify relevant articles.

The last search was done on 8 September 2021.

Details on the search strategies are provided in Table 1.

Table 1. Computerized literature search using database-appropriate syntax.

\begin{tabular}{|c|c|c|}
\hline Database & Strategy & No. of Publications \\
\hline \multicolumn{3}{|c|}{ Thermostable Vaccines } \\
\hline PubMed & $\begin{array}{c}\text { ("vaccin*"[Title/Abstract] AND ("thermostable"[Title/Abstract] OR "heat } \\
\text { stable"[Title/Abstract] OR "freeze stable"[Title/Abstract] OR ("heat-freeze"[All } \\
\text { Fields] AND "stable"[Title/Abstract]))) AND ((fft[Filter]) AND } \\
\text { (1990:2021[pdat])) }\end{array}$ & 462 \\
\hline CAB Abstracts & $\begin{array}{c}\text { (title:(vaccin*) OR ab:(vaccin*))AND (title:(thermostable) OR ab:(thermostable) } \\
\text { OR title:(heat stable) OR ab:(heat stable) OR title:(freeze stable) OR ab:(freeze } \\
\text { stable) OR title:(heat-freeze stable) OR ab:(heat-freeze stable)) AND } \\
\text { yr:[1990 TO 2021] }\end{array}$ & 500 \\
\hline Web of Science & $\begin{array}{c}\left(\mathrm{TI}=\left(\text { vaccin }^{*}\right) \mathrm{OR} \mathrm{AB}=\left(\text { vaccin }^{*}\right)\right) \mathrm{AND}(\mathrm{TI}=(\text { thermostable }) \mathrm{OR} \\
\mathrm{AB}=(\text { thermostable }) \mathrm{OR} \mathrm{TI}=(\text { heat stable }) \mathrm{OR} \mathrm{AB}=(\text { heat stable }) \mathrm{OR} \\
\mathrm{TI}=(\text { freeze stable }) \mathrm{OR} \mathrm{AB}=(\text { freeze stable }) \mathrm{OR} \mathrm{TI}=(\text { heat-freeze stable }) \mathrm{OR} \\
\mathrm{AB}=(\text { heat-freeze stable })) \\
\text { Timespan: } 1 \text { January } 1990 \text { to } 5 \text { September } 2021 \text { (Publication Date }) \\
\text { Not: Document Types: Proceedings Papers or Editorial Materials or Meeting } \\
\text { Abstracts or Book chapters or Notes or Early access }\end{array}$ & 693 \\
\hline \multicolumn{3}{|c|}{ DNA Vaccines } \\
\hline PubMed & $\begin{array}{l}\text { ("vaccines, dna"[MeSH Major Topic] AND "animals"[MeSH Major Topic]) AND } \\
\text { ((fft[Filter]) AND (english[Filter])) }\end{array}$ & $\begin{array}{c}417 \\
\text { First } 100 \text { sorted by best match }\end{array}$ \\
\hline CAB Abstracts & $\begin{array}{c}\text { title:(DNA vaccine) OR ab:(DNA vaccine) AND up:(Animals) AND } \\
\text { yr:[1996 TO 2021] } \\
\text { Refinements: } \\
\text { Document type = Journal article } \\
\text { AND Language = English }\end{array}$ & $\begin{array}{l}6845 \\
\text { First } 100 \text { sorted by relevance }\end{array}$ \\
\hline Web of Science & $\begin{aligned}(\mathrm{TS} & =(\text { ("DNA vaccine") }) \text { AND }(\mathrm{DT}==(" \mathrm{ARTICLE} ") \text { AND } \\
\text { TASCA } & ==(\text { "VETERINARY SCIENCES") AND LA }==(\text { "ENGLISH") })\end{aligned}$ & $\begin{array}{c}557 \\
\text { First } 100 \text { sorted by relevance }\end{array}$ \\
\hline
\end{tabular}




\subsection{Data Collection Process and Data}

Two data extraction sheets were created in Microsoft Excel, version 2017. In the first database, the following information for each study was recorded: the authors, year of publication, target agent, type of agent (bacterium/virus), animal species, country, product name, vaccine type, strain, market availability (locally produced, commercially available, or experimentally developed), thermostability characteristics, route of administration, type of study (clinical or field trial), assessment (objective), test used, main results, and comments. If the data was not provided, 'N.A.' (NOT AVAILABLE) was written. If some information was difficult to extract, a comment was written to that cell. The second database was created to retrieve quantitative data from clinical and field trials assessing the vaccine efficacy/effectiveness after its challenge with the infectious organism. The vaccine efficacy was measured in the clinical trial, as well as how well the vaccine performed in controlled settings. On the other hand, the vaccine effectiveness was defined as the measure of how well the vaccine works in the real world and was measured in the field trials. Vaccine efficacy/effectiveness can be computed by estimating the incidence rate of the disease among vaccinated and unvaccinated groups and determining the percentage of reduction in the incidence rate of the disease among vaccinated animals, compared to unvaccinated animals (1-risk ratio) $[35,36]$. To build this database we only considered the studies on diseases which are severe and sudden in onset (acute conditions leading to death), while studies assessing the morbidity rate were excluded. The following information was retrieved: the number of deaths after challenging in the vaccinated group, the number of survivals after challenging in the vaccinated group, the number of deaths after challenging in the control group, the number of survivals after challenging in the control group, the challenge time (days post-vaccination, dpv), the relative percent of survival (RPS)/days post-challenge (most of the studies computed the relative percentage of survival (RPS) from the cumulative mortalities in the vaccinated group (Mvac) and unvaccinated control (Munvac): $\mathrm{RPS}=[1-(\mathrm{Mvac} / \mathrm{Munvac})] \times 100 \%)$. If a single study had data for more than one experimental group, then those studies were considered as separate studies according to the number of the vaccinated groups under investigation. All authors checked the quality of the data extracted. Any disagreement in the results were resolved by discussion within the team.

\subsection{Risk of Bias (Quality Assessment)}

To minimize the risk of bias in individual studies, anything that could have potentially affected the interpretation of the study was written in the comments section of the data extraction sheets.

\subsection{Method of Analysis}

Results were summarised with text descriptions, tables, and waffle graphs. A metaanalysis with a random-effects model was performed, using quantitative data from studies on fatal diseases. The pooled risk ratio (RR) was calculated, along with the corresponding 95\% CI, to report the vaccine efficacy (VE). Studies with less than 10 animals per group were excluded. The analysis was done with the 'meta' and 'metafor' packages in R software version 4.1.1. [37]. The inverse variance index $\left(\mathrm{I}^{2}\right)$ was used to quantify heterogeneity, indicating the $\mathrm{I}^{2}$ values of $25 \%, 50 \%$, and $75 \%$ as low, moderate, and high heterogeneity, respectively [38]. Outliers were investigated using the Baujat and diagnostic plots [39,40]. The potential publication bias was assessed by the examination of the funnel plot. Considering that the asymmetry observed in a funnel plot may be also due to the correlation between the log of RR and its SE, the presence of a small study effect was tested with the Peters' test for binary outcomes [41]. Subgroup analyses, using mixed effect models, were performed to identify possible sources of heterogeneity related to the animal species and the type of agent. 


\section{Results}

\subsection{Study Selection}

The first literature search identified a total of 1,655 studies. After the duplicates $(n=758)$ were removed, the titles and abstracts of the remaining studies $(n=897)$ were screened for relevance, and 149 articles were further evaluated for eligibility based on the inclusion criteria. Out of them, 40 were included in the qualitative synthesis, along with three articles retrieved with the screening of the reference lists. Finally, 10 articles were included in the meta-analysis (Figure 1A). Considering the articles on DNA vaccines $(n=300), 31$ duplicates were removed, and the titles and abstracts of the remaining articles $(n=269)$ were screened for relevance. Seventy-six articles were assessed for eligibility. Out of them, 35 were included in the qualitative synthesis, and 18 were included in the meta-analysis (Figure 1B).

(A) Broad literature search on thermostable vaccines

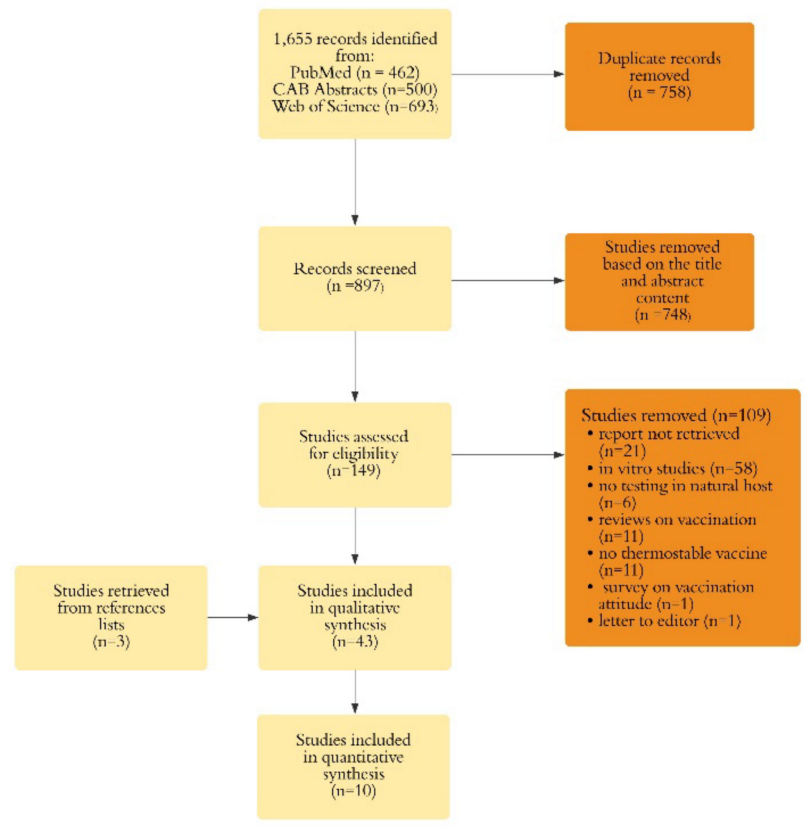

(B) Literature search on DNA vaccines

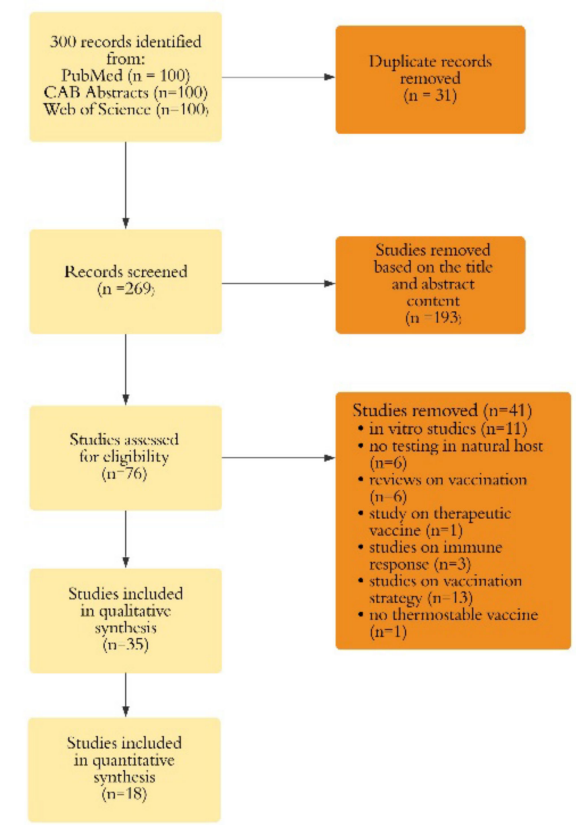

Figure 1. Diagram showing the stepwise process of study selection and pre-determined inclusion and reasons of exclusion for the broad search on thermostable vaccines (A), and the literature search on DNA vaccines (B).

\subsection{Study Characteristics}

A total of 78 studies, published between 1990 and 2021, were included in this systematic review (Tables 2 and 3). 
Table 2. Overview of the studies included in the qualitative synthesis retrieved from the broad search on thermostable vaccines.

\begin{tabular}{|c|c|c|c|c|c|c|c|c|c|c|c|c|}
\hline Study & $\begin{array}{l}\text { Target } \\
\text { Agent }\end{array}$ & $\begin{array}{l}\text { Type of } \\
\text { Agent }\end{array}$ & $\begin{array}{l}\text { Animal } \\
\text { Species }\end{array}$ & Country & $\begin{array}{l}\text { Product } \\
\text { Name }\end{array}$ & $\begin{array}{l}\text { Vaccine } \\
\text { Type }\end{array}$ & Strain/Gene & $\begin{array}{c}\text { Market } \\
\text { Availability }\end{array}$ & $\begin{array}{l}\text { Thermostability } \\
\text { Characteristics }\end{array}$ & $\begin{array}{l}\text { Route of Ad- } \\
\text { ministration }\end{array}$ & $\begin{array}{l}\text { Type of } \\
\text { Study }\end{array}$ & Assessment \\
\hline $\begin{array}{c}\text { Abah et al. } \\
\text { [42] }\end{array}$ & $\begin{array}{l}\text { Newcastle } \\
\text { disease } \\
\text { virus }\end{array}$ & Virus & Chicken & Nigeria & N.A. & $\begin{array}{l}\text { Live- } \\
\text { attenuated }\end{array}$ & $\mathrm{I}-2$ & $\begin{array}{l}\text { Locally } \\
\text { produced }\end{array}$ & N.A. & Oral (feed) & $\begin{array}{c}\text { Clinical } \\
\text { trial } \\
\text { (vaccinated } \\
\text { vs. control) }\end{array}$ & $\begin{array}{l}\text { Assessment } \\
\text { of humoral } \\
\text { immunity }\end{array}$ \\
\hline $\begin{array}{l}\text { Abdi et al. } \\
\text { [43] }\end{array}$ & $\begin{array}{l}\text { Newcastle } \\
\text { disease } \\
\text { virus }\end{array}$ & Virus & Chicken & Ethiopia & $\begin{array}{c}\text { NDV } \\
\text { vaccine } \\
\text { (National } \\
\text { Veterinary } \\
\text { Institute of } \\
\text { Bishoftu, } \\
\text { Ethiopia) }\end{array}$ & $\begin{array}{l}\text { Live- } \\
\text { attenuated } \\
2\end{array}$ & $\mathrm{I}-2$ & $\begin{array}{l}\text { Commercially } \\
\text { available }\end{array}$ & N.A. & $\begin{array}{l}\text { Oral (feed } \\
\text { and water) }\end{array}$ & $\begin{array}{c}\text { Clinical } \\
\text { trial } \\
\text { (vaccinated } \\
\text { vs. control) }\end{array}$ & $\begin{array}{l}\text { Assessment } \\
\text { of humoral } \\
\text { immunity, } \\
\text { clinical signs, } \\
\text { and RPS post- } \\
\text { challenge }\end{array}$ \\
\hline $\begin{array}{l}\text { Acharya } \\
\text { et al. [44] }\end{array}$ & $\begin{array}{l}\text { Newcastle } \\
\text { disease } \\
\text { virus }\end{array}$ & Virus & Chicken & Nepal & N.A. & $\begin{array}{l}\text { Live- } \\
\text { attenuated }\end{array}$ & $\mathrm{I}-2$ & $\begin{array}{l}\text { Locally } \\
\text { produced }\end{array}$ & $30^{\circ} \mathrm{C}$ for 7 days & Intraocular & $\begin{array}{l}\text { Field trial } \\
\text { (all animals } \\
\text { vaccinated) }\end{array}$ & $\begin{array}{l}\text { Assessment } \\
\text { of humoral } \\
\text { immunity }\end{array}$ \\
\hline $\begin{array}{l}\text { Asl Najjari } \\
\text { et al. [45] }\end{array}$ & $\begin{array}{l}\text { Newcastle } \\
\text { disease } \\
\text { virus }\end{array}$ & Virus & Chicken & Iran & N.A. & $\begin{array}{c}\text { Live- } \\
\text { attenuated }\end{array}$ & $\mathrm{I}-2$ & $\begin{array}{l}\text { Locally } \\
\text { produced }\end{array}$ & N.A. & Intraocular & $\begin{array}{c}\text { Clinical } \\
\text { trial } \\
\text { (vaccinated } \\
\text { vs. control) }\end{array}$ & $\begin{array}{l}\text { Assessment } \\
\text { of humoral } \\
\text { immunity, } \\
\text { clinical signs, } \\
\text { and RPS post- } \\
\text { challenge }\end{array}$ \\
\hline $\begin{array}{c}\text { Awa et al. } \\
\text { [46] }\end{array}$ & $\begin{array}{l}\text { Newcastle } \\
\text { disease } \\
\text { virus }\end{array}$ & Virus & Chicken & Cameroon & $\begin{array}{c}\text { Multivax } \\
\text { (LANAVET } \\
\text { Garoua, } \\
\text { Cameroon) }\end{array}$ & $\begin{array}{c}\text { Live- } \\
\text { attenuated }\end{array}$ & $\begin{array}{c}\text { La Sota }+ \\
\text { Cholevax }+ \\
\text { Typhovax }\end{array}$ & $\begin{array}{l}\text { Commercially } \\
\text { available }\end{array}$ & $\begin{array}{c}34^{\circ} \mathrm{C} \text { for } 10 \\
\text { weeks }\end{array}$ & Intramuscolar & $\begin{array}{l}\text { Clinical and } \\
\text { field trials } \\
\text { (all animals } \\
\text { vaccinated) }\end{array}$ & $\begin{array}{l}\text { Assessment } \\
\text { of humoral } \\
\text { immunity }\end{array}$ \\
\hline $\begin{array}{c}\text { Balamurugan } \\
\text { et al. } 2014 \\
{[47]}\end{array}$ & $\begin{array}{l}\text { Peste des } \\
\text { petits } \\
\text { ruminants } \\
\text { virus }\end{array}$ & Virus & Goats & India & N.A. & $\begin{array}{l}\text { Live- } \\
\text { attenuated } \\
3\end{array}$ & Jhansi/2003 & $\begin{array}{c}\text { Experimentally } \\
\text { developed }\end{array}$ & $\begin{array}{c}24-26 \text { days at } \\
25^{\circ} \mathrm{C} \\
7-8 \text { days at } \\
37{ }^{\circ} \mathrm{C} \\
3-4 \text { days at } \\
40{ }^{\circ} \mathrm{C} \\
\text { (Riyesh et al. } \\
\text { [48]) }\end{array}$ & Subcutaneous & $\begin{array}{c}\text { Clinical } \\
\text { trial } \\
\text { (vaccinated } \\
\text { vs. control) }\end{array}$ & $\begin{array}{l}\text { Assessment } \\
\text { of humoral } \\
\text { immunity, } \\
\text { clinical signs, } \\
\text { and RPS post- } \\
\text { challenge }\end{array}$ \\
\hline
\end{tabular}


Table 2. Cont.

\begin{tabular}{|c|c|c|c|c|c|c|c|c|c|c|c|c|}
\hline Study & $\begin{array}{l}\text { Target } \\
\text { Agent }\end{array}$ & $\begin{array}{c}\text { Type of } \\
\text { Agent }\end{array}$ & $\begin{array}{l}\text { Animal } \\
\text { Species }\end{array}$ & Country & $\begin{array}{l}\text { Product } \\
\text { Name }\end{array}$ & $\begin{array}{l}\text { Vaccine } \\
\text { Type }\end{array}$ & Strain/Gene & $\begin{array}{c}\text { Market } \\
\text { Availability }\end{array}$ & $\begin{array}{l}\text { Thermostability } \\
\text { Characteristics }\end{array}$ & $\begin{array}{l}\text { Route of Ad- } \\
\text { ministration }\end{array}$ & $\begin{array}{l}\text { Type of } \\
\text { Study }\end{array}$ & Assessment \\
\hline $\begin{array}{l}\text { Daouam } \\
\text { et al. [49] }\end{array}$ & $\begin{array}{l}\text { Rift Valley } \\
\text { Fever virus }\end{array}$ & Virus & $\begin{array}{c}\text { Cattle, } \\
\text { sheep, } \\
\text { and goats }\end{array}$ & Morocco & N.A. & $\begin{array}{l}\text { Live- } \\
\text { attenuated } \\
\qquad 2\end{array}$ & $\begin{array}{l}\text { Clone of } \\
\text { CL13T }\end{array}$ & $\begin{array}{l}\text { Experimentally } \\
\text { developed }\end{array}$ & $\begin{array}{c}37^{\circ} \mathrm{C} \text { for } 4 \text { days } \\
20 \text { months at } \\
4^{\circ} \mathrm{C}\end{array}$ & Subcutaneous & $\begin{array}{c}\text { Clinical } \\
\text { trial } \\
\text { (vaccinated } \\
\text { vs. control) }\end{array}$ & $\begin{array}{c}\text { Assessment } \\
\text { of humoral } \\
\text { immunity }\end{array}$ \\
\hline $\begin{array}{l}\text { Daouam } \\
\text { et al. [50] }\end{array}$ & $\begin{array}{l}\text { Rift Valley } \\
\text { Fever virus }\end{array}$ & Virus & Camels & Morocco & N.A. & $\begin{array}{c}\text { Live- } \\
\text { attenuated } \\
2\end{array}$ & $\begin{array}{l}\text { Clone of } \\
\text { CL13T }\end{array}$ & $\begin{array}{l}\text { Experimentally } \\
\text { developed }\end{array}$ & $\begin{array}{l}\text { (see Daouam } \\
\text { et al. [49]) }\end{array}$ & Subcutaneous & $\begin{array}{c}\text { Clinical } \\
\text { trial (all } \\
\text { animals } \\
\text { vaccinated) }\end{array}$ & $\begin{array}{c}\text { Assessment } \\
\text { of humoral } \\
\text { immunity }\end{array}$ \\
\hline $\begin{array}{l}\text { Dulal et al. } \\
\text { [51] }\end{array}$ & $\begin{array}{l}\text { Rift Valley } \\
\text { Fever virus }\end{array}$ & Virus & Cattle & $\begin{array}{l}\text { United } \\
\text { King- } \\
\text { dom }\end{array}$ & $\begin{array}{l}\text { ChAdOx1- } \\
\text { GnGc }\end{array}$ & $\begin{array}{l}\text { Recombinant } \\
\text { vector }\end{array}$ & MP-12 & $\begin{array}{l}\text { Experimentally } \\
\text { developed }\end{array}$ & $\begin{array}{l}25^{\circ}, 37^{\circ} \text { or } \\
45^{\circ} \mathrm{C} \text { for } 6 \\
\text { months }\end{array}$ & Intramuscolar & $\begin{array}{c}\text { Clinical } \\
\text { trial (all } \\
\text { animals } \\
\text { vaccinated) }\end{array}$ & $\begin{array}{c}\text { Assessment } \\
\text { of humoral } \\
\text { immunity }\end{array}$ \\
\hline $\begin{array}{l}\text { Echeonwu } \\
\text { et al. [52] }\end{array}$ & $\begin{array}{l}\text { Newcastle } \\
\text { disease } \\
\text { virus }\end{array}$ & Virus & Chicken & Nigeria & N.A. & $\begin{array}{c}\text { Live- } \\
\text { attenuated } \\
2\end{array}$ & $\mathrm{I}-2$ & $\begin{array}{c}\text { Locally } \\
\text { produced }\end{array}$ & N.A. & Oral (feed) & $\begin{array}{c}\text { Clinical } \\
\text { trial } \\
\text { (vaccinated } \\
\text { vs. control) }\end{array}$ & $\begin{array}{l}\text { Assessment } \\
\text { of humoral } \\
\text { immunity, } \\
\text { clinical signs, } \\
\text { and RPS post- } \\
\text { challenge }\end{array}$ \\
\hline $\begin{array}{c}\text { Foster et al. } \\
\quad[53]\end{array}$ & $\begin{array}{c}\text { Newcastle } \\
\text { disease } \\
\text { virus }\end{array}$ & Virus & Chicken & Tanzania & $\begin{array}{l}\text { Websters } \\
\text { HR V4 }\end{array}$ & $\begin{array}{c}\text { Live- } \\
\text { attenuated }\end{array}$ & V-4 & $\begin{array}{l}\text { Locally } \\
\text { produced }\end{array}$ & N.A. & $\begin{array}{l}\text { Intraocular } \\
\text { and oral } \\
\text { (water) }\end{array}$ & $\begin{array}{l}\text { Field trial } \\
\text { (vaccinated } \\
\text { vs. control) }\end{array}$ & $\begin{array}{l}\text { Assessment } \\
\text { of humoral } \\
\text { immunity }\end{array}$ \\
\hline $\begin{array}{l}\text { Habibi et al. } \\
\text { [54] }\end{array}$ & $\begin{array}{l}\text { Newcastle } \\
\text { disease } \\
\text { virus }\end{array}$ & Virus & Chicken & Iran & N.A. & $\begin{array}{c}\text { Live- } \\
\text { attenuated }\end{array}$ & $\mathrm{I}-2$ & $\begin{array}{c}\text { Locally } \\
\text { produced }\end{array}$ & N.A. & $\begin{array}{l}\text { Oral (feed } \\
\text { and water) }\end{array}$ & $\begin{array}{c}\text { Clinical } \\
\text { trial } \\
\text { (vaccinated } \\
\text { vs. control) }\end{array}$ & $\begin{array}{l}\text { Assessment } \\
\text { of humoral } \\
\text { immunity, } \\
\text { clinical signs, } \\
\text { and RPS post- } \\
\text { challenge }\end{array}$ \\
\hline $\begin{array}{c}\text { Habibi et al. } \\
\text { [55] }\end{array}$ & $\begin{array}{l}\text { Newcastle } \\
\text { disease } \\
\text { virus }\end{array}$ & Virus & Chicken & Iran & N.A. & $\begin{array}{c}\text { Live- } \\
\text { attenuated }\end{array}$ & $\mathrm{I}-2$ & $\begin{array}{c}\text { Locally } \\
\text { produced }\end{array}$ & N.A. & Oral (feed) & $\begin{array}{c}\text { Clinical } \\
\text { trial } \\
\text { (vaccinated } \\
\text { vs. control) }\end{array}$ & $\begin{array}{l}\text { Assessment } \\
\text { of humoral } \\
\text { immunity, } \\
\text { clinical signs, } \\
\text { and RPS post- } \\
\text { challenge }\end{array}$ \\
\hline
\end{tabular}


Table 2. Cont.

\begin{tabular}{|c|c|c|c|c|c|c|c|c|c|c|c|c|}
\hline Study & $\begin{array}{l}\text { Target } \\
\text { Agent }\end{array}$ & $\begin{array}{l}\text { Type of } \\
\text { Agent }\end{array}$ & $\begin{array}{l}\text { Animal } \\
\text { Species }\end{array}$ & Country & $\begin{array}{l}\text { Product } \\
\text { Name }\end{array}$ & $\begin{array}{l}\text { Vaccine } \\
\text { Type }\end{array}$ & Strain/Gene & $\begin{array}{c}\text { Market } \\
\text { Availability }\end{array}$ & $\begin{array}{l}\text { Thermostability } \\
\text { Characteristics }\end{array}$ & $\begin{array}{l}\text { Route of Ad- } \\
\text { ministration }\end{array}$ & $\begin{array}{l}\text { Type of } \\
\text { Study }\end{array}$ & Assessmen \\
\hline $\begin{array}{l}\text { Henning } \\
\text { et al. [56] }\end{array}$ & $\begin{array}{c}\text { Newcastle } \\
\text { disease } \\
\text { virus }\end{array}$ & Virus & Chicken & Myanmar & N.A. & $\begin{array}{c}\text { Live- } \\
\text { attenuated }\end{array}$ & $\mathrm{I}-2$ & $\begin{array}{l}\text { Locally } \\
\text { produced }\end{array}$ & N.A. & $\begin{array}{l}\text { Intraocular } \\
\text { and } \\
\text { intranasal }\end{array}$ & $\begin{array}{l}\text { Field trial } \\
\text { (vaccinated } \\
\text { vs. control) }\end{array}$ & $\begin{array}{c}\text { Assessment } \\
\text { of humoral } \\
\text { immunity }\end{array}$ \\
\hline $\begin{array}{l}\text { Illango et al. } \\
\text { [57] }\end{array}$ & $\begin{array}{l}\text { Newcastle } \\
\text { disease } \\
\text { virus }\end{array}$ & Virus & Chicken & Uganda & N.A. & $\begin{array}{c}\text { Live- } \\
\text { attenuated }\end{array}$ & $\mathrm{I}-2$ & $\begin{array}{l}\text { Locally } \\
\text { produced }\end{array}$ & N.A. & Oral (water) & $\begin{array}{c}\text { Clinical } \\
\text { trial } \\
\text { (vaccinated } \\
\text { vs. control) }\end{array}$ & $\begin{array}{c}\text { Assessment } \\
\text { of humoral } \\
\text { immunity }\end{array}$ \\
\hline $\begin{array}{c}\text { Jeong et al. } \\
{[58]}\end{array}$ & $\begin{array}{l}\text { Newcastle } \\
\text { disease } \\
\text { virus }\end{array}$ & Virus & Chicken & Korea & N.A. & $\begin{array}{l}\text { Live- } \\
\text { attenuated }\end{array}$ & K148/08 & $\begin{array}{l}\text { Experimentally } \\
\text { developed }\end{array}$ & $\begin{array}{c}\text { Thermostability } \\
\text { test }^{13}\end{array}$ & $\begin{array}{c}\text { Cabinet } \\
\text { sprayer and } \\
\text { Intraocular }\end{array}$ & $\begin{array}{c}\text { Clinical } \\
\text { trial } \\
\text { (vaccinated } \\
\text { vs. control) }\end{array}$ & $\begin{array}{l}\text { Assessment } \\
\text { of Humoral } \\
\text { immunity, } \\
\text { histopatho- } \\
\text { logical } \\
\text { lesions, and } \\
\text { RPS post- } \\
\text { challenge }\end{array}$ \\
\hline $\begin{array}{c}\text { Jones et al. } \\
\text { [59] }\end{array}$ & $\begin{array}{l}\text { Peste des } \\
\text { petits } \\
\text { ruminants } \\
\text { virus }\end{array}$ & Virus & Goats & USA & vRVFH & $\begin{array}{l}\text { Recombinant } \\
\text { vector }^{5}\end{array}$ & $\begin{array}{c}\text { F and H } \\
\text { (Rinder- } \\
\text { pest) }\end{array}$ & $\begin{array}{l}\text { Experimentally } \\
\text { developed }\end{array}$ & N.A. & Intramuscolar & $\begin{array}{c}\text { Clinical } \\
\text { trial } \\
\text { (vaccinated } \\
\text { vs. control) }\end{array}$ & $\begin{array}{l}\text { Assessment } \\
\text { of humoral } \\
\text { immunity } \\
\text { and clinical } \\
\text { signs post- } \\
\text { challenge }\end{array}$ \\
\hline $\begin{array}{l}\text { Khandelwal } \\
\text { et al. [60] }\end{array}$ & $\begin{array}{l}\text { Peste des } \\
\text { petits } \\
\text { ruminants } \\
\text { virus }\end{array}$ & Virus & Sheep & India & N.A. & $\begin{array}{l}\text { Recombinant } \\
\text { subunit } 6\end{array}$ & $\mathrm{HN}$ & $\begin{array}{l}\text { Experimentally } \\
\text { developed }\end{array}$ & N.A. & Oral (feed) & $\begin{array}{l}\text { Field trial } \\
\text { (all animals } \\
\text { vaccinated) }\end{array}$ & $\begin{array}{c}\text { Assessment } \\
\text { of humoral } \\
\text { immunity }\end{array}$ \\
\hline $\begin{array}{l}\text { Lankester } \\
\text { et al. [61] }\end{array}$ & Rabies & Virus & Dogs & Tanzania & $\begin{array}{c}\text { Nobivac } \\
\text { (rabies, } \\
\text { MSD } \\
\text { Animal } \\
\text { Health, } \\
\text { Boxmeer, } \\
\text { The Nether- } \\
\text { lands) }\end{array}$ & $\begin{array}{c}\text { Live- } \\
\text { attenuated }\end{array}$ & Pasteur RIV & $\begin{array}{l}\text { Commercially } \\
\text { available }\end{array}$ & $\begin{array}{c}25^{\circ} \mathrm{C} \text { for } \\
6 \text { months and } \\
30^{\circ} \mathrm{C} \text { for } \\
3 \text { months }\end{array}$ & Subcutaneous & $\begin{array}{l}\text { Field trial } \\
\text { (all animals } \\
\text { vaccinated) }\end{array}$ & $\begin{array}{c}\text { Assessment } \\
\text { of humoral } \\
\text { immunity }\end{array}$ \\
\hline
\end{tabular}


Table 2. Cont.

\begin{tabular}{|c|c|c|c|c|c|c|c|c|c|c|c|c|}
\hline Study & $\begin{array}{l}\text { Target } \\
\text { Agent }\end{array}$ & $\begin{array}{l}\text { Type of } \\
\text { Agent }\end{array}$ & $\begin{array}{l}\text { Animal } \\
\text { Species }\end{array}$ & Country & $\begin{array}{l}\text { Product } \\
\text { Name }\end{array}$ & $\begin{array}{c}\text { Vaccine } \\
\text { Type }\end{array}$ & Strain/Gene & $\begin{array}{c}\text { Market } \\
\text { Availability }\end{array}$ & $\begin{array}{l}\text { Thermostability } \\
\text { Characteristics }\end{array}$ & $\begin{array}{l}\text { Route of Ad- } \\
\text { ministration }\end{array}$ & $\begin{array}{l}\text { Type of } \\
\text { Study }\end{array}$ & Assessment \\
\hline $\begin{array}{l}\text { Liu et al. } \\
\text { [62] }\end{array}$ & $\begin{array}{l}\text { Mycoplasma } \\
\text { gallisep- } \\
\text { ticum }\end{array}$ & Bacterium & Chicken & China & N.A. & $\begin{array}{l}\text { Recombinant } \\
\text { vector }{ }^{7}\end{array}$ & pmga1.2p & $\begin{array}{l}\text { Experimentally } \\
\text { developed }\end{array}$ & N.A. & $\begin{array}{c}\text { Intra-gastric } \\
\text { gavage }\end{array}$ & $\begin{array}{c}\text { Clinical } \\
\text { trial } \\
\text { (vaccinated } \\
\text { vs. control) }\end{array}$ & $\begin{array}{c}\text { Assessment } \\
\text { of humoral } \\
\text { immunity }\end{array}$ \\
\hline $\begin{array}{l}\text { Liu et al. } \\
\text { [63] }\end{array}$ & $\begin{array}{c}\text { Avian } \\
\text { influenza } \\
\text { virus }\end{array}$ & Virus & Chicken & China & N.A. & $\begin{array}{l}\text { Recombinant } \\
\text { vector }\end{array}$ & $\begin{array}{l}\mathrm{NP} \text { of } \\
\mathrm{H} 9 \mathrm{~N} 2\end{array}$ & $\begin{array}{l}\text { Experimentally } \\
\text { developed }\end{array}$ & N.A. & $\begin{array}{c}\text { Intra-gastric } \\
\text { gavage }\end{array}$ & $\begin{array}{c}\text { Clinical } \\
\text { trial } \\
\text { (vaccinated } \\
\text { vs. control) }\end{array}$ & $\begin{array}{l}\text { Assessment } \\
\text { of humoral } \\
\text { immunity }\end{array}$ \\
\hline $\begin{array}{l}\text { Lv et al. } \\
\text { [64] }\end{array}$ & $\begin{array}{l}\text { Porcine re- } \\
\text { productive } \\
\text { and } \\
\text { respiratory } \\
\text { syndrome } \\
\text { virus }\end{array}$ & Virus & Pigs & China & N.A. & $\begin{array}{c}\text { Live- } \\
\text { attenuated } \\
8\end{array}$ & JXA1-R & $\begin{array}{l}\text { Experimentally } \\
\text { developed }\end{array}$ & $\begin{array}{c}25^{\circ} \mathrm{C} \text { for } \\
12 \text { months and } \\
37^{\circ} \mathrm{C} \text { for } \\
4 \text { months }\end{array}$ & Not specified & $\begin{array}{c}\text { Clinical } \\
\text { trial } \\
\text { (vaccinated } \\
\text { vs. control) }\end{array}$ & $\begin{array}{c}\text { Assessment } \\
\text { of humoral } \\
\text { immunity }\end{array}$ \\
\hline $\begin{array}{l}\text { Mariner } \\
\text { et al. [65] }\end{array}$ & $\begin{array}{l}\text { Rinderpest } \\
\text { virus }\end{array}$ & Virus & Cattle & Nigeria & VRPV & $\begin{array}{c}\text { Live- } \\
\text { attenuated } \\
3\end{array}$ & RBOK & $\begin{array}{l}\text { Experimentally } \\
\text { developed }\end{array}$ & $\begin{array}{c}25.9^{\circ} \mathrm{C} \\
\left(17.1-37.8^{\circ} \mathrm{C}\right) \\
\text { for } 34 \text { days }\end{array}$ & Subcutaneous & $\begin{array}{c}\text { Field trial } \\
\text { (vaccinated } \\
\text { vs. control) }\end{array}$ & $\begin{array}{l}\text { Assessment } \\
\text { of humoral } \\
\text { immunity }\end{array}$ \\
\hline $\begin{array}{l}\text { Mariner } \\
\text { et al. [66] }\end{array}$ & $\begin{array}{l}\text { Peste des } \\
\text { petits } \\
\text { ruminants } \\
\text { virus }\end{array}$ & Virus & Goats & USA & TVRPV & $\begin{array}{l}\text { Live- } \\
\text { attenuated } \\
3\end{array}$ & RBOK & $\begin{array}{l}\text { Experimentally } \\
\text { developed }\end{array}$ & $\begin{array}{l}37^{\circ} \mathrm{C} \text { for up to } \\
245 \text { days }\end{array}$ & Subcutaneous & $\begin{array}{c}\text { Clinical } \\
\text { trial } \\
\text { (vaccinated } \\
\text { vs. control) }\end{array}$ & $\begin{array}{l}\text { Assessment } \\
\text { of humoral } \\
\text { immunity, } \\
\text { clinical signs, } \\
\text { and RPS post- } \\
\text { challenge }\end{array}$ \\
\hline $\begin{array}{l}\text { Mehrabadi } \\
\text { et al. [67] }\end{array}$ & $\begin{array}{l}\text { Newcastle } \\
\text { disease } \\
\text { virus }\end{array}$ & Virus & Chicken & Iran & $\begin{array}{l}\text { ND.TR.IR } \\
\text { (Razi } \\
\text { Institute, } \\
\text { Iran) }\end{array}$ & $\begin{array}{c}\text { Live- } \\
\text { attenuated } \\
2\end{array}$ & $\mathrm{I}-2$ & $\begin{array}{l}\text { Commercially } \\
\text { available }\end{array}$ & N.A. & Oral (water) & $\begin{array}{l}\text { Field trial } \\
\text { (vaccinated } \\
\text { vs. control) }\end{array}$ & $\begin{array}{l}\text { Assessment } \\
\text { of humoral } \\
\text { immunity }\end{array}$ \\
\hline $\begin{array}{c}\text { Murr et al. } \\
{[68]}\end{array}$ & $\begin{array}{l}\text { Peste des } \\
\text { petits } \\
\text { ruminants } \\
\text { virus }\end{array}$ & Virus & Goats & Germany & rNDV_HKur & $\begin{array}{l}\text { Recombinant } \\
\text { vector } 9\end{array}$ & Kurdistan/11 & 1/Hxperimentally & $\begin{array}{c}-80{ }^{\circ} \mathrm{C}, \\
-20^{\circ} \mathrm{C}, 4^{\circ} \mathrm{C}, \\
21^{\circ} \mathrm{C} \text {, and } \\
37^{\circ} \mathrm{C} \text { for } \\
7 \text { days }\end{array}$ & Subcutaneous & $\begin{array}{c}\text { Clinical } \\
\text { trial } \\
\text { (vaccinated } \\
\text { vs. control) }\end{array}$ & $\begin{array}{l}\text { Assessment } \\
\text { of humoral } \\
\text { immunity } \\
\text { and clinical } \\
\text { signs post- } \\
\text { challenge }\end{array}$ \\
\hline
\end{tabular}


Table 2. Cont.

\begin{tabular}{|c|c|c|c|c|c|c|c|c|c|c|c|c|}
\hline Study & $\begin{array}{l}\text { Target } \\
\text { Agent }\end{array}$ & $\begin{array}{l}\text { Type of } \\
\text { Agent }\end{array}$ & $\begin{array}{l}\text { Animal } \\
\text { Species }\end{array}$ & Country & $\begin{array}{l}\text { Product } \\
\text { Name }\end{array}$ & $\begin{array}{l}\text { Vaccine } \\
\text { Type }\end{array}$ & Strain/Gene & $\begin{array}{c}\text { Market } \\
\text { Availability }\end{array}$ & $\begin{array}{l}\text { Thermostability } \\
\text { Characteristics }\end{array}$ & $\begin{array}{l}\text { Route of Ad- } \\
\text { ministration }\end{array}$ & $\begin{array}{l}\text { Type of } \\
\text { Study }\end{array}$ & Assessment \\
\hline $\begin{array}{l}\text { Nega et al. } \\
\text { [69] }\end{array}$ & $\begin{array}{l}\text { Newcastle } \\
\text { disease } \\
\text { virus }\end{array}$ & Virus & Chicken & Ethiopia & N.A. & $\begin{array}{c}\text { Live- } \\
\text { attenuated }\end{array}$ & $\mathrm{I}-2$ & $\begin{array}{l}\text { Locally } \\
\text { produced }\end{array}$ & N.A. & Intraocular & $\begin{array}{l}\text { Field trial } \\
\text { (all animals } \\
\text { vaccinated) }\end{array}$ & $\begin{array}{l}\text { Assessment } \\
\text { of humoral } \\
\text { immunity, } \\
\text { clinical signs, } \\
\text { and RPS post- } \\
\text { challenge }\end{array}$ \\
\hline $\begin{array}{l}\text { Nwanta } \\
\text { et al. [70] }\end{array}$ & $\begin{array}{l}\text { Newcastle } \\
\text { disease } \\
\text { virus }\end{array}$ & Virus & Chicken & Nigeria & $\begin{array}{l}\text { NDV4HR } \\
\text { (Malaysian } \\
\text { Vaccines } \\
\text { and Phar- } \\
\text { maceutical } \\
\text { SNP BHD, } \\
\text { Malaysia) }\end{array}$ & $\begin{array}{l}\text { Live- } \\
\text { attenuated } \\
2\end{array}$ & $V-4$ & $\begin{array}{l}\text { Commercially } \\
\text { available }\end{array}$ & N.A. & Oral (feed) & $\begin{array}{l}\text { Field trial } \\
\text { (all animals } \\
\text { vaccinated) }\end{array}$ & $\begin{array}{l}\text { Assessment } \\
\text { of humoral } \\
\text { immunity }\end{array}$ \\
\hline $\begin{array}{l}\text { Omony } \\
\text { et al. [71] }\end{array}$ & $\begin{array}{l}\text { Newcastle } \\
\text { disease } \\
\text { virus }\end{array}$ & Virus & Chicken & Uganda & N.A. & $\begin{array}{c}\text { Live- } \\
\text { attenuated }\end{array}$ & $\begin{array}{c}\text { NDV- } \\
\text { 133/UG/MU/ } \\
\text { 2011, NDV- } \\
\text { 177/UG/MU/ } \\
\text { 2011NDV- } \\
\text { 178/UG/MU/ } \\
\text { 2011 and } \\
\text { NDV- } \\
\text { 173/UG/MU/ } \\
\text { 2011 }\end{array}$ & $\begin{array}{c}\text { Experimentally } \\
\text { developed }\end{array}$ & N.A. & $\begin{array}{l}\text { Intraocular } \\
\text { and } \\
\text { Intranasal }\end{array}$ & $\begin{array}{c}\text { Clinical } \\
\text { trial } \\
\text { (vaccinated } \\
\text { vs. control) }\end{array}$ & $\begin{array}{l}\text { Assessment } \\
\text { of humoral } \\
\text { immunity, } \\
\text { clinical signs, } \\
\text { and RPS post- } \\
\text { challenge }\end{array}$ \\
\hline $\begin{array}{l}\text { Rahman } \\
\text { et al. [72] }\end{array}$ & $\begin{array}{l}\text { Peste des } \\
\text { petits } \\
\text { ruminants } \\
\text { virus }\end{array}$ & Virus & Goats & Bangladesh & N.A. & $\begin{array}{c}\text { Live- } \\
\text { attenuated }\end{array}$ & N.A. & $\begin{array}{l}\text { Experimentally } \\
\text { developed }\end{array}$ & $\begin{array}{c}\text { Percent } \\
\text { inhibition } \\
\text { values } \\
\text { decreased by } \\
8-20 \% \text { at } \\
180 \mathrm{DPV} \text {, when } \\
\text { the vaccine is } \\
\text { kept } 25^{\circ}, 30^{\circ}, \\
35^{\circ} \text {, and } 40^{\circ} \mathrm{C} \\
\text { for } 7 \text { and } \\
14 \text { days }\end{array}$ & Subcutaneous & $\begin{array}{c}\text { Clinical } \\
\text { trial } \\
\text { (vaccinated } \\
\text { vs. control) }\end{array}$ & $\begin{array}{l}\text { Assessment } \\
\text { of humoral } \\
\text { immunity }\end{array}$ \\
\hline
\end{tabular}


Table 2. Cont.

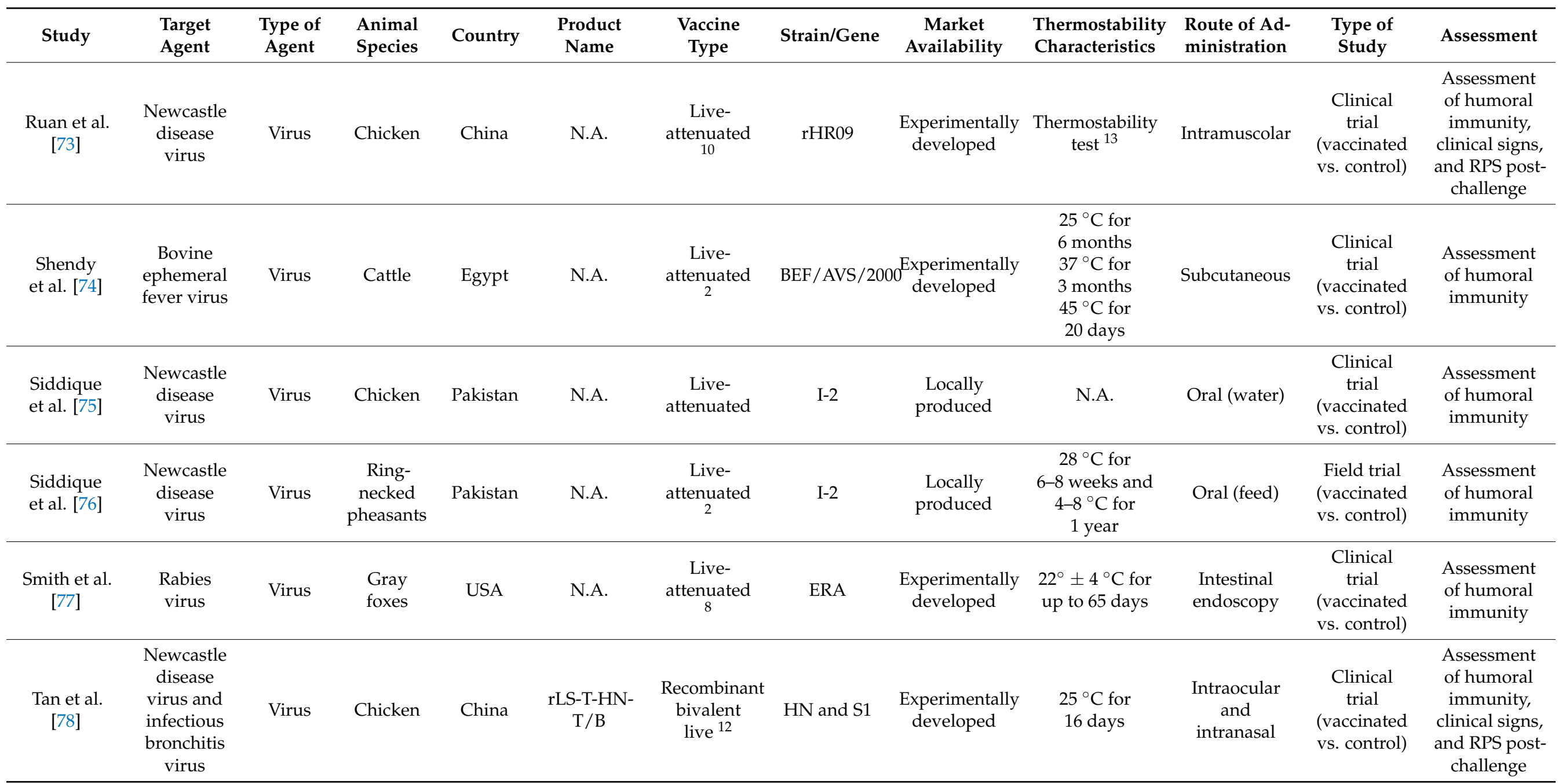


Table 2. Cont.

\begin{tabular}{|c|c|c|c|c|c|c|c|c|c|c|c|c|}
\hline Study & $\begin{array}{l}\text { Target } \\
\text { Agent }\end{array}$ & $\begin{array}{c}\text { Type of } \\
\text { Agent }\end{array}$ & $\begin{array}{l}\text { Animal } \\
\text { Species }\end{array}$ & Country & $\begin{array}{l}\text { Product } \\
\text { Name }\end{array}$ & $\begin{array}{l}\text { Vaccine } \\
\text { Type }\end{array}$ & Strain/Gene & $\begin{array}{c}\text { Market } \\
\text { Availability }\end{array}$ & $\begin{array}{l}\text { Thermostability } \\
\text { Characteristics }\end{array}$ & $\begin{array}{l}\text { Route of Ad- } \\
\text { ministration }\end{array}$ & $\begin{array}{l}\text { Type of } \\
\text { Study }\end{array}$ & Assessment \\
\hline $\begin{array}{l}\text { Tu et al. } \\
\text { [79] }\end{array}$ & $\begin{array}{l}\text { Newcastle } \\
\text { disease } \\
\text { virus }\end{array}$ & Virus & Chicken & Vietnam & N.A. & $\begin{array}{c}\text { Live- } \\
\text { attenuated } \\
2\end{array}$ & $\mathrm{I}-2$ & $\begin{array}{l}\text { Locally } \\
\text { produced }\end{array}$ & $\begin{array}{l}30{ }^{\circ} \mathrm{C} \text { for } \\
3 \text { weeks }\end{array}$ & $\begin{array}{l}\text { Intraocular } \\
\text { and oral } \\
\text { (water) }\end{array}$ & $\begin{array}{l}\text { Clinical and } \\
\text { field trials } \\
\text { (vaccinated } \\
\text { vs. control) }\end{array}$ & $\begin{array}{l}\text { Assessment } \\
\text { of humoral } \\
\text { immunity, } \\
\text { clinical signs, } \\
\text { and RPS post- } \\
\text { challenge }\end{array}$ \\
\hline $\begin{array}{l}\text { Verardi } \\
\text { et al. [80] }\end{array}$ & $\begin{array}{l}\text { Rinderpest } \\
\text { virus }\end{array}$ & Virus & Cattle & $\begin{array}{l}\text { Ethiopia } \\
\text { and } \\
\text { Kenya }\end{array}$ & N.A. & $\begin{array}{l}\text { Recombinant } \\
\text { vector }\end{array}$ & v2RVFH & $\begin{array}{c}\text { Experimentally } \\
\text { developed }\end{array}$ & N.A. & Intramuscolar & $\begin{array}{l}\text { Field trial } \\
\text { (vaccinated } \\
\text { vs. control) }\end{array}$ & $\begin{array}{l}\text { Assessment } \\
\text { of humoral } \\
\text { immunity, } \\
\text { clinical signs, } \\
\text { and RPS post- } \\
\text { challenge }\end{array}$ \\
\hline $\begin{array}{l}\text { Wambura } \\
\text { et al. [81] }\end{array}$ & $\begin{array}{l}\text { Flow pox } \\
\text { virus }\end{array}$ & Virus & Chicken & Tanzania & N.A. & $\begin{array}{c}\text { Live- } \\
\text { attenuated }\end{array}$ & TPV-1 & $\begin{array}{l}\text { Locally } \\
\text { produced }\end{array}$ & $\begin{array}{c}25-34{ }^{\circ} \mathrm{C} \text { for } \\
6 \text { months }\end{array}$ & $\begin{array}{l}\text { Wing web } \\
\text { stab }\end{array}$ & $\begin{array}{c}\text { Clinical } \\
\text { trial } \\
\text { (vaccinated } \\
\text { vs. control) }\end{array}$ & $\begin{array}{l}\text { Assessment } \\
\text { of humoral } \\
\text { immunity, } \\
\text { clinical signs, } \\
\text { and RPS post- } \\
\text { challenge }\end{array}$ \\
\hline $\begin{array}{l}\text { Wambura } \\
\text { et al. [82] }\end{array}$ & $\begin{array}{l}\text { Newcastle } \\
\text { disease } \\
\text { virus }\end{array}$ & Virus & Chicken & Tanzania & N.A. & $\begin{array}{c}\text { Live- } \\
\text { attenuated }\end{array}$ & $\mathrm{I}-2$ & $\begin{array}{c}\text { Locally } \\
\text { produced }\end{array}$ & N.A. & $\begin{array}{l}\text { Oral (feed } \\
\text { and water) } \\
\text { and ocular }\end{array}$ & $\begin{array}{c}\text { Clinical } \\
\text { trial } \\
\text { (vaccinated } \\
\text { vs. control) }\end{array}$ & $\begin{array}{l}\text { Assessment } \\
\text { of humoral } \\
\text { immunity, } \\
\text { clinical signs, } \\
\text { and RPS post- } \\
\text { challenge }\end{array}$ \\
\hline $\begin{array}{l}\text { Wambura } \\
\text { et al. [83] }\end{array}$ & $\begin{array}{l}\text { Newcastle } \\
\text { disease } \\
\text { virus }\end{array}$ & Virus & $\begin{array}{c}\text { Helmeted } \\
\text { guinea } \\
\text { fowls }\end{array}$ & Tanzania & N.A. & $\begin{array}{c}\text { Live- } \\
\text { attenuated }\end{array}$ & $\mathrm{I}-2$ & $\begin{array}{c}\text { Locally } \\
\text { produced }\end{array}$ & N.A. & Oral (feed) & $\begin{array}{l}\text { Field trial } \\
\text { (vaccinated } \\
\text { vs. control) }\end{array}$ & $\begin{array}{l}\text { Assessment } \\
\text { of humoral } \\
\text { immunity, } \\
\text { clinical signs, } \\
\text { and RPS post- } \\
\text { challenge }\end{array}$ \\
\hline
\end{tabular}


Table 2. Cont.

\begin{tabular}{|c|c|c|c|c|c|c|c|c|c|c|c|c|}
\hline Study & $\begin{array}{l}\text { Target } \\
\text { Agent }\end{array}$ & $\begin{array}{c}\text { Type of } \\
\text { Agent }\end{array}$ & $\begin{array}{l}\text { Animal } \\
\text { Species }\end{array}$ & Country & $\begin{array}{l}\text { Product } \\
\text { Name }\end{array}$ & $\begin{array}{c}\text { Vaccine } \\
\text { Type }\end{array}$ & Strain/Gene & $\begin{array}{c}\text { Market } \\
\text { Availability }\end{array}$ & $\begin{array}{l}\text { Thermostability } \\
\text { Characteristics }\end{array}$ & $\begin{array}{l}\text { Route of Ad- } \\
\text { ministration }\end{array}$ & $\begin{array}{l}\text { Type of } \\
\text { Study }\end{array}$ & Assessmen \\
\hline $\begin{array}{c}\text { Wen et al. } \\
\text { [84] }\end{array}$ & $\begin{array}{c}\text { Newcastle } \\
\text { disease } \\
\text { virus }\end{array}$ & Virus & Chicken ${ }^{1}$ & China & N.A. & $\begin{array}{c}\text { Live- } \\
\text { attenuated }\end{array}$ & TS09-C & $\begin{array}{c}\text { Experimentally } \\
\text { developed }\end{array}$ & N.A. & In ovo & $\begin{array}{c}\text { Clinical } \\
\text { trial } \\
\text { (vaccinated } \\
\text { vs. control) }\end{array}$ & $\begin{array}{l}\text { Assessment } \\
\text { of humoral } \\
\text { immunity, } \\
\text { histopatho- } \\
\text { logical } \\
\text { lesions, and } \\
\text { RPS post- } \\
\text { challenge }\end{array}$ \\
\hline $\begin{array}{l}\text { Zuo et al. } \\
\quad[85]\end{array}$ & $\begin{array}{l}\text { Classical } \\
\text { swine fever } \\
\text { virus }\end{array}$ & Virus & Pigs & China & ST16 & $\begin{array}{c}\text { Live- } \\
\text { attenuated } \\
2\end{array}$ & C & $\begin{array}{c}\text { Experimentally } \\
\text { developed }\end{array}$ & $\begin{array}{l}25^{\circ} \mathrm{C} \text { for } \\
6 \text { months }\end{array}$ & Intramuscolar & $\begin{array}{c}\text { Clinical } \\
\text { trial } \\
\text { (vaccinated } \\
\text { vs. control) }\end{array}$ & $\begin{array}{l}\text { Assessment } \\
\text { of humoral } \\
\text { immunity }\end{array}$ \\
\hline
\end{tabular}

${ }^{1}$ SPF chicken embryos, ${ }^{2}$ Freeze-dried, ${ }^{3}$ Freeze-dried Vero cell-adapted ${ }^{4}$ Chimpanzee adenovirus vector, ${ }^{5}$ Double recombinant Vaccina virus,${ }^{6}$ Transgenic peanut, ${ }^{7}$ Bacillus thurigensis vector, ${ }^{8}$ Foam-dried, ${ }^{9}$ NDV vector, ${ }^{10}$ Generated by reverse genetics system, ${ }^{11}$ Vaccina virus vector, ${ }^{12}$ NDV vector, ${ }^{13}$ Thermostability test according to Wen et al. [86]. 
Table 3. Overview of the studies included in the qualitative synthesis retrieved from the search on DNA vaccines.

\begin{tabular}{|c|c|c|c|c|c|c|c|c|c|c|}
\hline Study & Target Agent & $\begin{array}{c}\text { Type of } \\
\text { Agent }\end{array}$ & $\begin{array}{l}\text { Animal } \\
\text { Species }\end{array}$ & Country & $\begin{array}{l}\text { Product } \\
\text { Name }\end{array}$ & $\begin{array}{l}\text { Encoding } \\
\text { Gene }\end{array}$ & $\begin{array}{c}\text { Market } \\
\text { Availability }\end{array}$ & $\begin{array}{l}\text { Route of Ad- } \\
\text { ministration }\end{array}$ & Type of Study & Assessment \\
\hline $\begin{array}{c}\text { Ahmadivand } \\
\text { et al. [87] }\end{array}$ & $\begin{array}{c}\text { Infectious } \\
\text { pancreatic } \\
\text { necrosis virus }\end{array}$ & Virus & $\begin{array}{c}\text { Fish } \\
\text { (rainbow } \\
\text { trout) }\end{array}$ & Iran & $\begin{array}{l}\text { pcDNA3.1- } \\
\text { VP2 }\end{array}$ & VP2 & $\begin{array}{c}\text { Experimentally } \\
\text { developed }\end{array}$ & Intramuscular & $\begin{array}{l}\text { Clinical trial } \\
\text { (vaccinated vs. } \\
\text { control) }\end{array}$ & $\begin{array}{l}\text { Assessment of } \\
\text { humoral and } \\
\text { cell-mediated } \\
\text { immunity, clinical } \\
\text { signs, and survival } \\
\text { rate post-challenge }\end{array}$ \\
\hline $\begin{array}{c}\text { Bande et al. } \\
\text { [88] }\end{array}$ & $\begin{array}{c}\text { Avian } \\
\text { infectious } \\
\text { bronchitis } \\
\text { coronavirus }\end{array}$ & Virus & Chicken & Malaysia & $\begin{array}{l}\text { pBudCR88- } \\
\text { S1/M41-S1 }\end{array}$ & $\begin{array}{c}\text { S1 } \\
\text { glycoprotein }\end{array}$ & $\begin{array}{c}\text { Experimentally } \\
\text { developed }\end{array}$ & Intramuscular & $\begin{array}{l}\text { Clinical trial } \\
\text { (vaccinated vs. } \\
\text { control) }\end{array}$ & $\begin{array}{c}\text { Assessment of } \\
\text { humoral and } \\
\text { cell-mediated } \\
\text { immunity, and } \\
\text { histopathological } \\
\text { lesions post-challenge }\end{array}$ \\
\hline $\begin{array}{c}\text { Bunning et al. } \\
\text { [89] }\end{array}$ & $\begin{array}{l}\text { West Nile } \\
\text { virus }\end{array}$ & Virus & $\begin{array}{c}\text { American } \\
\text { crows }\end{array}$ & USA & N.A. & prM and $E$ & $\begin{array}{c}\text { Experimentally } \\
\text { developed }\end{array}$ & $\begin{array}{c}\text { Oral and } \\
\text { intramuscular }\end{array}$ & $\begin{array}{l}\text { Clinical trial } \\
\text { (vaccinated vs. } \\
\text { control) }\end{array}$ & $\begin{array}{l}\text { Assessment of } \\
\text { humoral immunity, } \\
\text { clinical signs, and } \\
\text { survival rate } \\
\text { post-challenge }\end{array}$ \\
\hline Cai et al. [90] & $\begin{array}{c}\text { Vibrio } \\
\text { alginolyticus }\end{array}$ & Bacterium & $\begin{array}{c}\text { Fish } \\
\text { (crimson } \\
\text { snapper) }\end{array}$ & China & $\begin{array}{l}\text { pcDNA- } \\
\text { ompW }\end{array}$ & ompW & $\begin{array}{c}\text { Experimentally } \\
\text { developed }\end{array}$ & Intramuscular & $\begin{array}{l}\text { Clinical trial } \\
\text { (vaccinated vs. } \\
\text { control) }\end{array}$ & $\begin{array}{l}\text { Assessment of } \\
\text { humoral immunity, } \\
\text { clinical signs, and } \\
\text { survival rate } \\
\text { post-challenge }\end{array}$ \\
\hline $\begin{array}{c}\text { Chen et al. } \\
\text { [91] }\end{array}$ & $\begin{array}{c}\text { Nocardia } \\
\text { seriolae }\end{array}$ & Bacterium & $\begin{array}{c}\text { Fish(hybrid } \\
\text { snake- } \\
\text { head) }\end{array}$ & China & $\begin{array}{l}\text { pcDNA-RplL } \\
\text { and } \\
\text { pcDNA-RpsA }\end{array}$ & $\begin{array}{l}\text { RpsA and } \\
\text { RplL }\end{array}$ & $\begin{array}{c}\text { Experimentally } \\
\text { developed }\end{array}$ & Intramuscular & $\begin{array}{l}\text { Clinical trial } \\
\text { (vaccinated vs. } \\
\text { control) }\end{array}$ & $\begin{array}{l}\text { Assessment of } \\
\text { humoral and } \\
\text { cell-mediated } \\
\text { immunity, clinical } \\
\text { signs, and survival } \\
\text { rate post-challenge }\end{array}$ \\
\hline $\begin{array}{c}\text { Citarasu et al. } \\
\text { [92] }\end{array}$ & $\begin{array}{l}\text { Macrobrachium } \\
\text { rosenbergii } \\
\text { nodavirus }\end{array}$ & Virus & $\begin{array}{l}\text { Fish(giant } \\
\text { freshwa- } \\
\text { ter) }\end{array}$ & India & $\begin{array}{l}\text { MrNV-CP- } \\
\text { RNA-2- } \\
\text { pVAX1 }\end{array}$ & $\begin{array}{l}\text { MrNV-CP- } \\
\text { RNA-2 }\end{array}$ & $\begin{array}{c}\text { Experimentally } \\
\text { developed }\end{array}$ & $\begin{array}{c}\text { Oral } \\
\text { (feed) }\end{array}$ & $\begin{array}{l}\text { Clinical trial } \\
\text { (vaccinated vs. } \\
\text { control) }\end{array}$ & $\begin{array}{l}\text { Assessment of } \\
\text { immunological and } \\
\text { hematological } \\
\text { parameters, and } \\
\text { survival rate } \\
\text { post-challenge }\end{array}$ \\
\hline
\end{tabular}


Table 3. Cont.

\begin{tabular}{|c|c|c|c|c|c|c|c|c|c|c|}
\hline Study & Target Agent & $\begin{array}{l}\text { Type of } \\
\text { Agent }\end{array}$ & $\begin{array}{l}\text { Animal } \\
\text { Species }\end{array}$ & Country & $\begin{array}{l}\text { Product } \\
\text { Name }\end{array}$ & $\begin{array}{l}\text { Encoding } \\
\text { Gene }\end{array}$ & $\begin{array}{c}\text { Market } \\
\text { Availability }\end{array}$ & $\begin{array}{l}\text { Route of Ad- } \\
\text { ministration }\end{array}$ & Type of Study & Assessment \\
\hline $\begin{array}{l}\text { Clapp et al. } \\
\text { [93] }\end{array}$ & Brucella abortus & Bacterium & Bison & USA & $\begin{array}{l}\text { pCMVbp26 + } \\
\text { pCMVTF }\end{array}$ & $\mathrm{bp} 26+\mathrm{TF}$ & $\begin{array}{l}\text { Experimentally } \\
\text { developed }\end{array}$ & N.A. & $\begin{array}{l}\text { Clinical trial } \\
\text { (vaccinated vs. } \\
\text { control) }\end{array}$ & $\begin{array}{l}\text { Assessment of } \\
\text { humoral and } \\
\text { cell-mediated } \\
\text { immunity }\end{array}$ \\
\hline Cui et al. [94] & $\begin{array}{l}\text { Porcine } \\
\text { reproductive } \\
\text { and } \\
\text { respiratory } \\
\text { syndrome } \\
\text { virus }\end{array}$ & Virus & Pigs & USA & $\begin{array}{c}\text { DNA GP5- } \\
\text { Mosaic/VACV } \\
\text { GP5-Mosaic }\end{array}$ & $\begin{array}{c}\text { ATCC } \\
\text { VR-2332 and } \\
\text { MN184C }\end{array}$ & $\begin{array}{l}\text { Experimentally } \\
\text { developed }\end{array}$ & $\begin{array}{l}\text { Intradermal } \\
\text { and } \\
\text { intramuscular }\end{array}$ & $\begin{array}{l}\text { Clinical trial } \\
\text { (vaccinated vs. } \\
\text { control) }\end{array}$ & $\begin{array}{l}\text { Assessment of } \\
\text { humoral and } \\
\text { cell-mediated } \\
\text { immunity, clinical } \\
\text { signs, and survival } \\
\text { rate post-challenge }\end{array}$ \\
\hline $\begin{array}{c}\text { Dahiya et al. } \\
\text { [95] }\end{array}$ & $\begin{array}{c}\text { Canine } \\
\text { parvovirus }\end{array}$ & Virus & Dogs & India & $\begin{array}{l}\text { pAlpha-CPV- } \\
\text { VP2 }\end{array}$ & VP2 & $\begin{array}{l}\text { Experimentally } \\
\text { developed }\end{array}$ & Intradermal & $\begin{array}{l}\text { Clinical trial } \\
\text { (vaccinated vs. } \\
\text { control) }\end{array}$ & $\begin{array}{l}\text { Assessment of } \\
\text { humoral and } \\
\text { cell-mediated } \\
\text { immunity }\end{array}$ \\
\hline $\begin{array}{c}\text { Davis et al. } \\
\text { [96] }\end{array}$ & $\begin{array}{l}\text { West Nile } \\
\text { virus }\end{array}$ & Virus & Penguins & USA & $\begin{array}{c}\text { WNDV } \\
\text { Vaccine } \\
\text { (Aldevron Llc, } \\
\text { Fargo, North } \\
\text { Dakota, USA). }\end{array}$ & $\mathrm{prM} / \mathrm{M}$ and $\mathrm{E}$ & $\begin{array}{l}\text { Commercially } \\
\text { available }\end{array}$ & Intramuscular & $\begin{array}{l}\text { Clinical trial } \\
\text { (vaccinated vs. } \\
\text { control) }\end{array}$ & $\begin{array}{c}\text { Assessment of } \\
\text { humoral immunity }\end{array}$ \\
\hline $\begin{array}{c}\text { Eman et al. } \\
{[97]}\end{array}$ & $\begin{array}{c}\text { Avian in- } \\
\text { fluenza(H5N1) }\end{array}$ & Virus & Chicken & India & $\begin{array}{c}\text { pDEST 40/H5 } \\
\text { and pDEST } \\
40 / \mathrm{N} 1\end{array}$ & $\mathrm{H} 5$ and N1 & $\begin{array}{l}\text { Experimentally } \\
\text { developed }\end{array}$ & Ocular & $\begin{array}{c}\text { Clinical trial } \\
\text { (vaccinated vs. } \\
\text { control) }\end{array}$ & $\begin{array}{c}\text { Assessment of } \\
\text { humoral immunity }\end{array}$ \\
\hline Fu et al. [98] & $\begin{array}{l}\text { Duck hepatitis } \\
\text { virus type } 1\end{array}$ & Virus & Ducks & China & pSCA/VP1 & VP1 & $\begin{array}{l}\text { Experimentally } \\
\text { developed }\end{array}$ & Intramuscular & $\begin{array}{l}\text { Clinical trial } \\
\text { (vaccinated vs. } \\
\text { control) }\end{array}$ & $\begin{array}{l}\text { Assessment of } \\
\text { humoral and } \\
\text { cell-mediated } \\
\text { immunity, clinical } \\
\text { signs, and survival } \\
\text { rate post-challenge }\end{array}$ \\
\hline $\begin{array}{c}\text { Garver et al. } \\
\text { [99] }\end{array}$ & $\begin{array}{c}\text { Infectious } \\
\text { hematopoietic } \\
\text { necrosis virus }\end{array}$ & Virus & $\begin{array}{l}\text { Fish(spring } \\
\text { chinook, } \\
\text { sockeye and } \\
\text { kokanee } \\
\text { salmon fry) }\end{array}$ & USA & pIHNw-G & G & $\begin{array}{l}\text { Experimentally } \\
\text { developed }\end{array}$ & Intramuscular & $\begin{array}{l}\text { Clinical trial } \\
\text { (vaccinated vs. } \\
\text { control) }\end{array}$ & $\begin{array}{c}\text { Assessment of } \\
\text { humoral immunity }\end{array}$ \\
\hline
\end{tabular}


Table 3. Cont.

\begin{tabular}{|c|c|c|c|c|c|c|c|c|c|c|}
\hline Study & Target Agent & $\begin{array}{c}\text { Type of } \\
\text { Agent }\end{array}$ & $\begin{array}{l}\text { Animal } \\
\text { Species }\end{array}$ & Country & $\begin{array}{l}\text { Product } \\
\text { Name }\end{array}$ & $\begin{array}{l}\text { Encoding } \\
\text { Gene }\end{array}$ & $\begin{array}{c}\text { Market } \\
\text { Availability }\end{array}$ & $\begin{array}{l}\text { Route of Ad- } \\
\text { ministration }\end{array}$ & Type of Study & Assessment \\
\hline $\begin{array}{c}\text { Gong et al. } \\
\text { [100] }\end{array}$ & $\begin{array}{c}\text { Pasteurella } \\
\text { multocida }\end{array}$ & Bacterium & Chicken & China & N.A. & ptfA & $\begin{array}{c}\text { Experimentally } \\
\text { developed }\end{array}$ & Intramuscular & $\begin{array}{l}\text { Clinical trial } \\
\text { (vaccinated vs. } \\
\text { control) }\end{array}$ & $\begin{array}{l}\text { Assessment of } \\
\text { humoral and } \\
\text { cell-mediated } \\
\text { immunity, clinical } \\
\text { signs, and survival } \\
\text { rate post-challenge }\end{array}$ \\
\hline $\begin{array}{c}\text { Huang et al. } \\
\text { [101] }\end{array}$ & $\begin{array}{c}\text { Duck } \\
\text { Tembusu } \\
\text { Virus }\end{array}$ & Virus & Ducks & China & pVAX1-C & $\begin{array}{l}\text { Capsid gene } \\
\text { (GenBank: } \\
\text { JX196334.1) }\end{array}$ & $\begin{array}{c}\text { Experimentally } \\
\text { developed }\end{array}$ & Oral & $\begin{array}{l}\text { Clinical trial } \\
\text { (vaccinated vs. } \\
\text { control) }\end{array}$ & $\begin{array}{l}\text { Assessment of } \\
\text { humoral immunity, } \\
\text { clinical signs, and } \\
\text { survival rate } \\
\text { post-challenge }\end{array}$ \\
\hline $\begin{array}{c}\text { Kotla et al. } \\
\text { [102] }\end{array}$ & $\begin{array}{l}\text { Foot-and- } \\
\text { mouth disease } \\
\text { virus }\end{array}$ & Virus & Cattle & India & $\begin{array}{c}\text { P1-2A- } \\
\text { 3CpCDNA + } \\
\text { bIL- } \\
\text { 18pCDNA }\end{array}$ & $\begin{array}{c}\text { P1-2A-3C + } \\
\text { bovine IL-18 }\end{array}$ & $\begin{array}{c}\text { Experimentally } \\
\text { developed }\end{array}$ & Intramuscular & $\begin{array}{l}\text { Clinical trial } \\
\text { (vaccinated vs. } \\
\text { control) }\end{array}$ & $\begin{array}{l}\text { Assessment of } \\
\text { humoral and } \\
\text { cell-mediated } \\
\text { immunity }\end{array}$ \\
\hline Liu et al. [103] & $\begin{array}{c}\text { Edwardsiella } \\
\text { tarda }\end{array}$ & Bacterium & $\begin{array}{l}\text { Fish (olive } \\
\text { flounder) }\end{array}$ & China & pCG-OmpC & OmpC & $\begin{array}{c}\text { Experimentally } \\
\text { developed }\end{array}$ & Intramuscular & $\begin{array}{l}\text { Clinical trial } \\
\text { (vaccinated vs. } \\
\text { control) }\end{array}$ & $\begin{array}{l}\text { Assessment of } \\
\text { humoral and } \\
\text { cell-mediated } \\
\text { immunity, clinical } \\
\text { signs, and survival } \\
\text { rate post-challenge }\end{array}$ \\
\hline Liu et al. [104] & $\begin{array}{c}\text { Campylobacter } \\
\text { spp. }\end{array}$ & Bacterium & Chicken & USA & $\begin{array}{l}\text { pCAGGS_CfrA } \\
\text { and } \\
\text { pCAGGS_CmeC }\end{array}$ & $\begin{array}{l}\text { cfrA and } \\
\text { cmeC }\end{array}$ & $\begin{array}{c}\text { Experimentally } \\
\text { developed }\end{array}$ & In ovo & $\begin{array}{l}\text { Clinical trial } \\
\text { (all animals } \\
\text { vaccinated) }\end{array}$ & $\begin{array}{l}\text { Assessment of } \\
\text { humoral and } \\
\text { intestinal colonization } \\
\text { post-challenge }\end{array}$ \\
\hline $\begin{array}{l}\text { Pasnik and } \\
\text { Smith [105] }\end{array}$ & $\begin{array}{l}\text { Mycobacterium } \\
\text { marinum }\end{array}$ & Bacterium & $\begin{array}{l}\text { Fish(hybrid } \\
\text { striped } \\
\text { bass) }\end{array}$ & USA & pCMV-85A & Ag85A & $\begin{array}{c}\text { Experimentally } \\
\text { developed }\end{array}$ & Intramuscular & $\begin{array}{l}\text { Clinical trial } \\
\text { (vaccinated vs. } \\
\text { control) }\end{array}$ & $\begin{array}{l}\text { Assessment of } \\
\text { humoral and } \\
\text { cell-mediated } \\
\text { immunity, clinical } \\
\text { signs, and survival } \\
\text { rate post-challenge }\end{array}$ \\
\hline
\end{tabular}


Table 3. Cont.

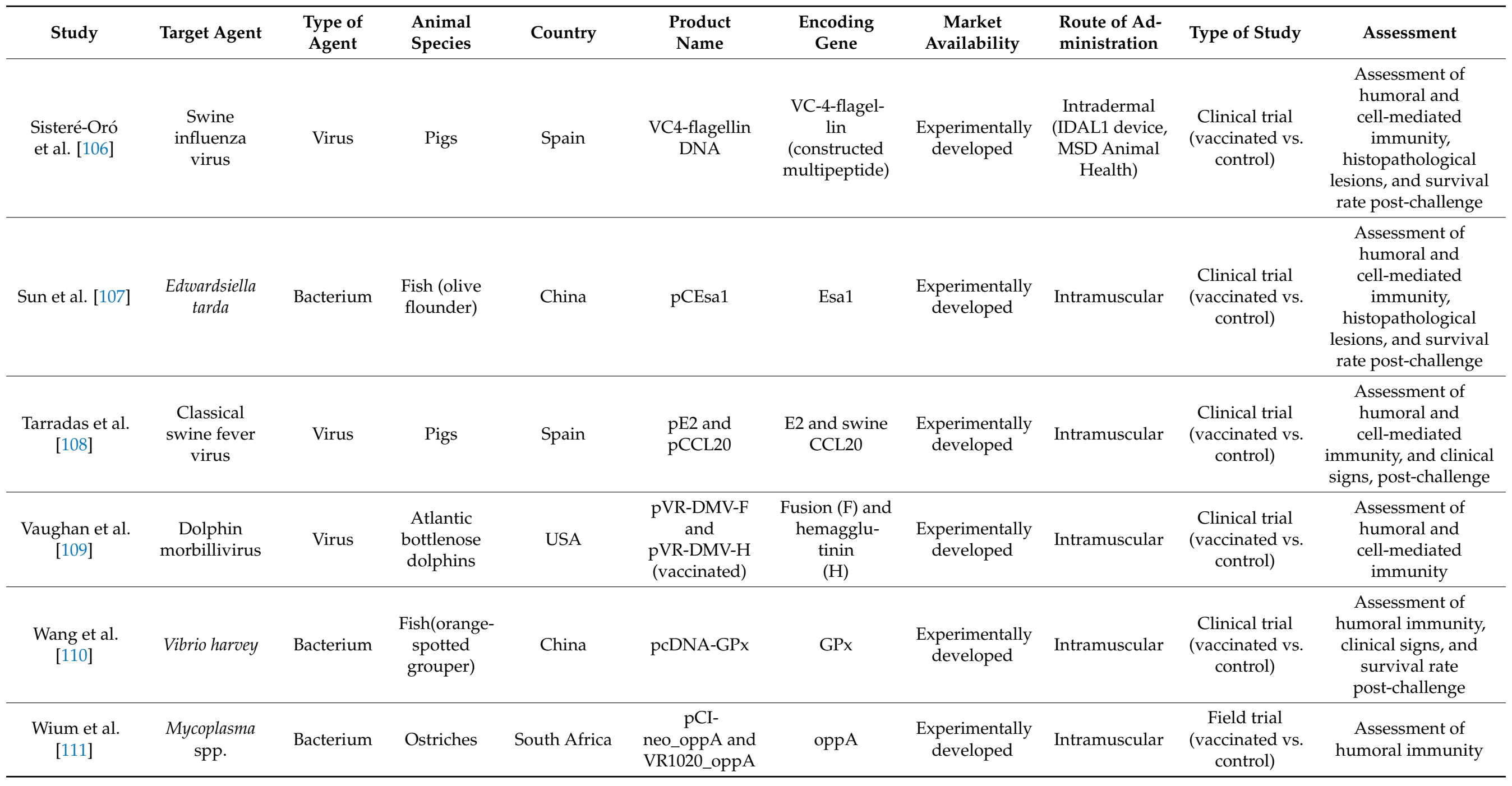


Table 3. Cont.

\begin{tabular}{|c|c|c|c|c|c|c|c|c|c|c|}
\hline Study & Target Agent & $\begin{array}{c}\text { Type of } \\
\text { Agent }\end{array}$ & $\begin{array}{l}\text { Animal } \\
\text { Species }\end{array}$ & Country & $\begin{array}{l}\text { Product } \\
\text { Name }\end{array}$ & $\begin{array}{l}\text { Encoding } \\
\text { Gene }\end{array}$ & $\begin{array}{c}\text { Market } \\
\text { Availability }\end{array}$ & $\begin{array}{l}\text { Route of Ad- } \\
\text { ministration }\end{array}$ & Type of Study & Assessment \\
\hline $\begin{array}{l}\text { Xing et al. } \\
\text { [112] }\end{array}$ & $\begin{array}{c}\text { Vibrio } \\
\text { anguillarum }\end{array}$ & Bacterium & $\begin{array}{c}\text { Fish (olive } \\
\text { flounder) }\end{array}$ & China & $\begin{array}{c}\text { pcDNA3.1- } \\
\text { VAA } \\
\text { (pVAA) }\end{array}$ & VAA & $\begin{array}{c}\text { Experimentally } \\
\text { developed }\end{array}$ & Intramuscular & $\begin{array}{l}\text { Clinical trial } \\
\text { (vaccinated vs. } \\
\text { control) }\end{array}$ & $\begin{array}{l}\text { Assessment of } \\
\text { humoral and } \\
\text { cell-mediated } \\
\text { immunity, } \\
\text { histopathological } \\
\text { lesions, and survival } \\
\text { rate post-challenge }\end{array}$ \\
\hline Xu et al. [114] & $\begin{array}{c}\text { Vibrio } \\
\text { anguillarum }\end{array}$ & Bacterium & $\begin{array}{l}\text { Fish (olive } \\
\text { flounder) }\end{array}$ & China & $\begin{array}{l}\text { pcDNA3.1- } \\
\text { OmpK } \\
\text { (pOmpK) }\end{array}$ & OmpK & $\begin{array}{c}\text { Experimentally } \\
\text { developed }\end{array}$ & Intramuscular & $\begin{array}{l}\text { Clinical trial } \\
\text { (vaccinated vs. } \\
\text { control) }\end{array}$ & $\begin{array}{l}\text { Assessment of } \\
\text { humoral and } \\
\text { cell-mediated } \\
\text { immunity, clinical } \\
\text { signs, and survival } \\
\text { rate post-challenge }\end{array}$ \\
\hline $\begin{array}{l}\text { Yang et al. } \\
\text { [115] }\end{array}$ & $\begin{array}{l}\text { Infectious } \\
\text { bronchitis } \\
\text { virus }\end{array}$ & Virus & Chicken & China & $\begin{array}{c}\text { pVAX1- } \\
\text { S1/M/N }\end{array}$ & $\mathrm{S} 1, \mathrm{~N}, \mathrm{M}$ & $\begin{array}{c}\text { Experimentally } \\
\text { developed }\end{array}$ & Intramuscular & $\begin{array}{l}\text { Clinical trial } \\
\text { (vaccinated vs. } \\
\text { control) }\end{array}$ & $\begin{array}{c}\text { Assessment of } \\
\text { humoral and } \\
\text { cell-mediated } \\
\text { immunity, and clinical } \\
\text { signs, post-challenge }\end{array}$ \\
\hline Yi et al. [116] & $\begin{array}{c}\text { Largemouth } \\
\text { bass virus }\end{array}$ & Virus & $\begin{array}{l}\text { Fish (large- } \\
\text { mouth } \\
\text { bass) }\end{array}$ & China & $\begin{array}{l}\text { pCDNA3.1(+)- } \\
\text { MCP-Flag }\end{array}$ & MCP & $\begin{array}{c}\text { Experimentally } \\
\text { developed }\end{array}$ & Intramuscular & $\begin{array}{l}\text { Clinical trial } \\
\text { (vaccinated vs. } \\
\text { control) }\end{array}$ & $\begin{array}{l}\text { Assessment of } \\
\text { humoral and } \\
\text { cell-mediated } \\
\text { immunity, clinical } \\
\text { signs, and survival } \\
\text { rate post-challenge }\end{array}$ \\
\hline
\end{tabular}


Table 3. Cont.

\begin{tabular}{|c|c|c|c|c|c|c|c|c|c|c|}
\hline Study & Target Agent & $\begin{array}{c}\text { Type of } \\
\text { Agent }\end{array}$ & $\begin{array}{l}\text { Animal } \\
\text { Species }\end{array}$ & Country & $\begin{array}{l}\text { Product } \\
\text { Name }\end{array}$ & $\begin{array}{l}\text { Encoding } \\
\text { Gene }\end{array}$ & $\begin{array}{c}\text { Market } \\
\text { Availability }\end{array}$ & $\begin{array}{l}\text { Route of Ad- } \\
\text { ministration }\end{array}$ & Type of Study & Assessment \\
\hline Yu et al. [117] & $\begin{array}{c}\text { Singapore } \\
\text { grouper } \\
\text { iridovirus }\end{array}$ & Virus & Fish(grouper) & China & $\begin{array}{c}\text { pcDNA3.1- } \\
\text { 19R }\end{array}$ & SGIV-19R & $\begin{array}{c}\text { Experimentally } \\
\text { developed }\end{array}$ & Intramuscular & $\begin{array}{l}\text { Clinical trial } \\
\text { (vaccinated vs. } \\
\text { control) }\end{array}$ & $\begin{array}{l}\text { Assessment of } \\
\text { humoral and } \\
\text { cell-mediated } \\
\text { immunity, clinical } \\
\text { signs, and survival } \\
\text { rate post-challenge }\end{array}$ \\
\hline $\begin{array}{l}\text { Yuan et al. } \\
\text { [118] }\end{array}$ & $\begin{array}{c}\text { Rabbit } \\
\text { hemorrhagic } \\
\text { disease virus }\end{array}$ & Virus & Rabbits & China & pcDNA-VP60 & VP60 & $\begin{array}{c}\text { Experimentally } \\
\text { developed }\end{array}$ & Intramuscular & $\begin{array}{l}\text { Clinical trial } \\
\text { (vaccinated vs. } \\
\text { control) }\end{array}$ & $\begin{array}{l}\text { Assessment of } \\
\text { humoral and } \\
\text { cell-mediated } \\
\text { immunity }\end{array}$ \\
\hline $\begin{array}{c}\text { Zhang et al. } \\
\text { [119] }\end{array}$ & $\begin{array}{l}\text { Spring viremia } \\
\text { of carp virus }\end{array}$ & Virus & $\begin{array}{l}\text { Fish(common } \\
\text { carp) }\end{array}$ & China & $\begin{array}{l}\text { pcDNA-M } \\
\text { and SWCNTs- } \\
\text { pcDNA-M }\end{array}$ & M & $\begin{array}{c}\text { Experimentally } \\
\text { developed }\end{array}$ & Intramuscular & $\begin{array}{l}\text { Clinical trial } \\
\text { (vaccinated vs. } \\
\text { control) }\end{array}$ & $\begin{array}{l}\text { Assessment of } \\
\text { humoral and } \\
\text { cell-mediated } \\
\text { immunity, clinical } \\
\text { signs, and survival } \\
\text { rate post-challenge }\end{array}$ \\
\hline $\begin{array}{l}\text { Zhu et al. } \\
\text { [121] }\end{array}$ & $\begin{array}{l}\text { Streptococcus } \\
\text { agalactiae }\end{array}$ & Bacterium & $\begin{array}{l}\text { Fish (Nile } \\
\text { tilapia) }\end{array}$ & China & $\begin{array}{l}\text { SL7207- } \\
\text { pVAX1-sip }\end{array}$ & Sip & $\begin{array}{c}\text { Experimentally } \\
\text { developed }\end{array}$ & $\begin{array}{c}\text { Oral } \\
\text { (gavage and } \\
\text { mixed fodder) }\end{array}$ & $\begin{array}{l}\text { Clinical trial } \\
\text { (vaccinated vs. } \\
\text { control) }\end{array}$ & $\begin{array}{l}\text { Assessment of } \\
\text { humoral and } \\
\text { cell-mediated } \\
\text { immunity, clinical } \\
\text { signs, and survival } \\
\text { rate post-challenge }\end{array}$ \\
\hline
\end{tabular}


These include:

- Two studies performing both clinical and field trials (one using vaccinated and control groups, and one with all animals vaccinated);

- Thirteen studies performing field trials (eight using vaccinated and control groups, and five with all animals vaccinated);

- Sixty-three studies performing clinical trials (60 using vaccinated and control groups, and three with all animals vaccinated).

Most of the studies were carried out in chickens $(n=30)$, followed by fish $(n=16)$. Further details on the animal species are provided in the waffle chart (Figure 2A).

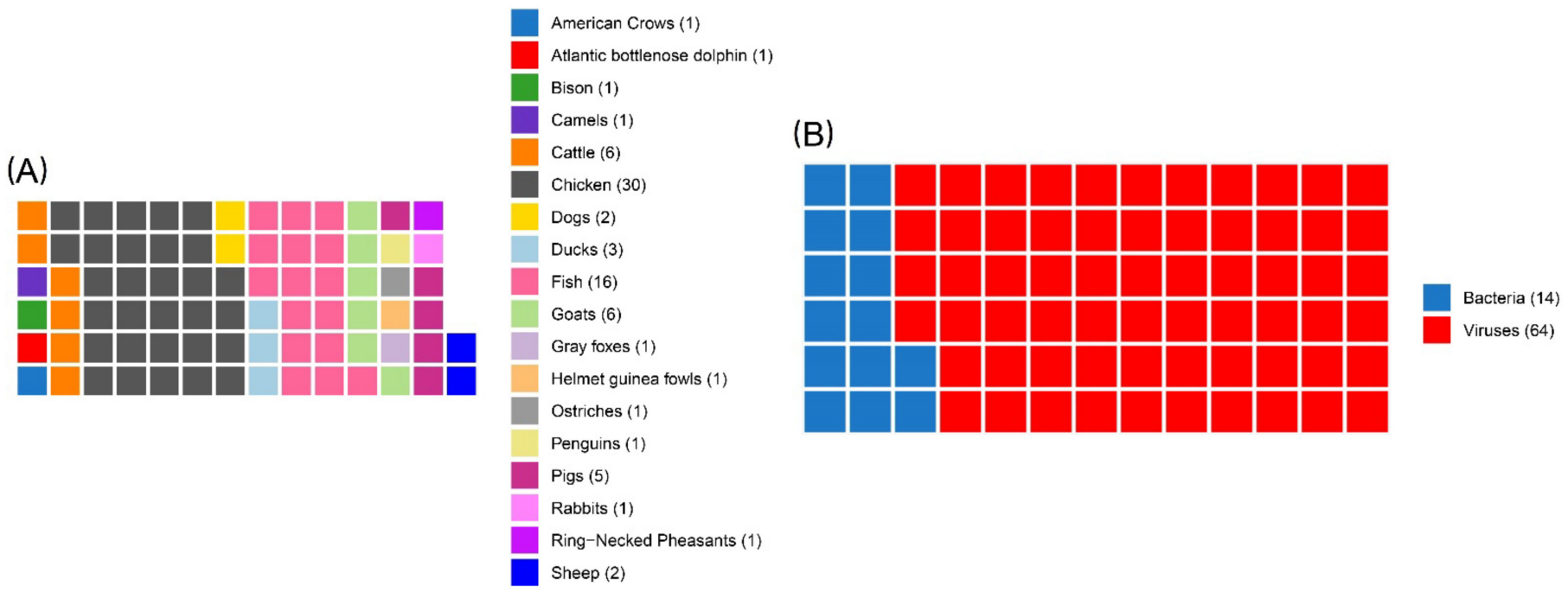

(C)

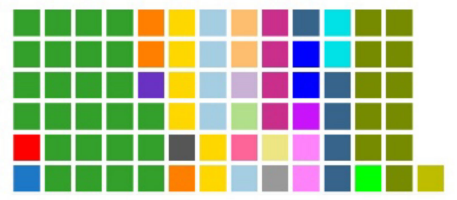

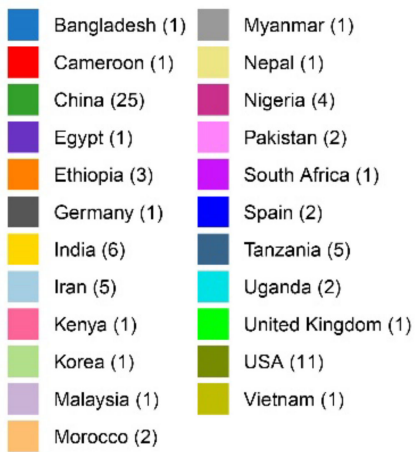

(D)

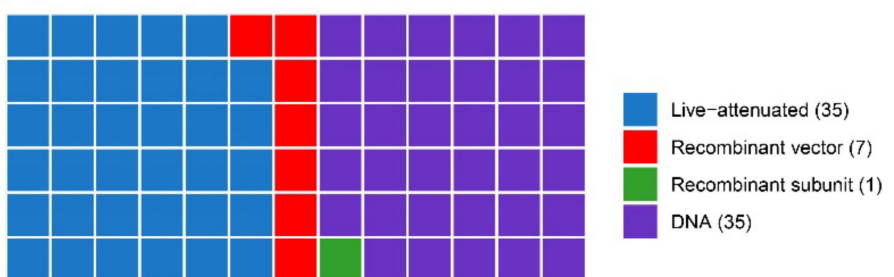

Figure 2. Waffle graphs highlighting the attributes of the studies included: animal species (A), type of agent (B), country (C), and type of vaccine (D).

With regards to the type of agent, 64 studies were on diseases caused by viruses and 14 by bacteria (Figure 2B). The majority of the articles were on vaccines against the Newcastle disease virus (NDV) $(n=23)$, followed by the Peste des petits ruminants virus (PPRV) $(n=6)$. The rank order of countries, based on the number of studies retrieved, was China $(n=25)$, USA $(n=11)$, India $(n=6)$, Iran $(n=5)$, Tanzania $(n=5)$, Nigeria $(n=4)$, Ethiopia $(n=3)$ (one study was carried out on cattle in both Ethiopia and Kenya), Morocco $(n=2)$, Pakistan $(n=2)$, Spain $(n=2)$, Uganda $(n=2)$, Bangladesh $(n=1)$, Cameroon $(n=1)$, Egypt $(n=1)$, Germany $(n=1)$, Kenya $(n=1)^{2}$, Korea $(n=1)$, Malaysia $(n=1)$, Myanmar $(n=1)$, Nepal $(n=1)$, South Africa $(n=1)$, United Kingdom $(n=1)$, and Vietnam $(n=1)$ (Figure 2C). In addition to the articles retrieved through searching DNA vaccines $(n=35), 35$ studies were on live-attenuated vaccines, seven were on recombinant vector vaccines, and one was on a recombinant subunit vaccine (Figure 2D). Most of the vaccines were experimentally 
developed ( $n=56$ ), while a few studies used vaccines that were locally produced ( $n=16$ ) or were available on the market $(n=6)$.

Out of the 43 articles retrieved with the broad literature search, 13 studies (these include only the studies that explicitly state that the freeze-drying process was used for the vaccine development) implemented a lyophilization (freeze-drying process) to obtain thermostability $[47,49,50,52,65-67,70,74,76,79,85]$. An alternative drying process was applied by Lv et al. [64] and Smith et al. [77], who used the vaporization method (foam-drying) to preserve the live attenuated vaccines against the porcine reproductive and respiratory syndrome virus (PRRSV) and the rabies virus (RABV), respectively, while Dulal et al. [51] successfully used the sugar-membrane technology to thermostabilize an adenovirus-vectored vaccine against the Rift Valley fever virus.

Thermostability characteristics were not reported in 23 studies (Table 2).

These include:

- Studies on vaccines against NDV $(n=17)$, specifying the use of thermostable strains $[42,43,45,52-57,67,69-71,75,82-84]$;

- $\quad$ Studies on vaccines against PPRV $(n=2)$, comprising of one work testing a Rinderpest heterologous vaccine [59], and one developing a heat-stable recombinant subunit vaccine expressed in the peanut plant [60];

- Studies $(n=2)$ using Bacillus thuringiensis and the surface layer protein CTC as a vaccine delivery system to develop heat-stable vaccines against avian influenza [63] and Mycoplasma gallisepticum [62];

- Study on a vaccine against Rinderpest virus $(n=1)$, describing a recombinant heat stable vaccinia virus [80].

The remaining studies assessed the heat stability under different temperature conditions and over different time periods, from 3-4 days at $40^{\circ} \mathrm{C}$ [47] to $25^{\circ} \mathrm{C}$ for 12 months [64]. Details on each study are provided in Table 2 . All the articles on DNA vaccines did not provide information on thermal stability. Nevertheless, some of them mentioned, in the introduction section, that DNA vaccines do not require the maintenance of a cold-chain as they are thermostable (e.g., Bande et al. [88]). Interestingly, only one retrieved study assessed the exposure of the vaccine to freezing temperatures [68].

Considering the objective of the study, 27 works aimed to assess humoral immunity, estimating the antibody titres after vaccine administration, and five articles evaluated both humoral and cell-mediated immunities. In the remaining studies $(n=46)$, animals were challenged with an infectious disease organism, evaluating the humoral immunity, cell-mediated immunity, clinical signs, histopathological changes, or survival rates post-challenge.

Only a few authors reported an insufficient immune response after vaccination. In particular, Rahman et al. [72] described a partial seroconversion in goats after the vaccination against PPRV, and Bunning et al. [89] reported a failure of the oral vaccination with a DNA vaccine against the West Nile virus (WNV) in the American crow.

\subsection{Risk of Bias (Quality) Assessment}

Overall, no relevant comments that could have affected the outcomes of the studies included were identified.

\subsection{Synthesis of Results}

Twenty-eight studies, comprising of 60 vaccinated groups, were included in the metaanalysis (Table 4). 
Table 4. Overview of the studies included in the quantitative synthesis to assess the pooled vaccine efficacies.

\begin{tabular}{|c|c|c|c|c|c|c|}
\hline Study & $\begin{array}{l}\text { Vaccinated } \\
\text { Group } \\
\text { Deaths }\end{array}$ & $\begin{array}{l}\text { Vaccinated } \\
\text { Group } \\
\text { Survivals }\end{array}$ & $\begin{array}{l}\text { Control } \\
\text { Group } \\
\text { Deaths }\end{array}$ & $\begin{array}{l}\text { Control } \\
\text { Group } \\
\text { Survivals }\end{array}$ & $\begin{array}{l}\text { Challenge } \\
\text { Time (dpv) }\end{array}$ & $\begin{array}{c}\text { Relative Percent of } \\
\text { Survival (RPS)-Days } \\
\text { Post-Challenge }\end{array}$ \\
\hline $\begin{array}{c}\text { Abdi et al. [43] (cracked millet, } \\
\text { untreated barley, and } \\
\text { cracked barley) }\end{array}$ & 6 & 9 & 12 & 3 & 21 & $50 \%-28$ days \\
\hline Abdi et al. [43] (cracked sorghum) & 9 & 5 & 12 & 3 & 21 & $20 \%-28$ days \\
\hline $\begin{array}{l}\text { Abdi et al. [43] (cracked wheat } \\
\text { and parboiled millet) }\end{array}$ & 4 & 10 & 12 & 3 & 21 & $64 \%-28$ days \\
\hline Abdi et al. [43] (parboiled wheat) & 2 & 12 & 12 & 3 & 21 & $82 \%-28$ days \\
\hline Abdi et al. [43] (untreated millet) & 6 & 6 & 12 & 3 & 21 & $38 \%-28$ days \\
\hline $\begin{array}{l}\text { Abdi et al. [43] (untreated } \\
\text { sorghum) }\end{array}$ & 7 & 8 & 12 & 3 & 21 & $42 \%-28$ days \\
\hline $\begin{array}{l}\text { Abdi et al. [43] (untreated wheat } \\
\text { and parboiled sorghum) }\end{array}$ & 3 & 12 & 12 & 3 & 21 & $75 \%-28$ days \\
\hline $\begin{array}{l}\text { Abdi et al. [43] (water, cracked } \\
\text { maize, and parboiled barley) }\end{array}$ & 0 & 15 & 12 & 3 & 21 & $100 \%-28$ days \\
\hline Ahmadivand et al. [87] (10 ng) & 6 & 84 & 51 & 39 & 30 & $88 \%-30$ days \\
\hline Ahmadivand et al. [87] (2 ng) & 12 & 78 & 51 & 39 & 30 & $76 \%-30$ days \\
\hline Ahmadivand et al. [87] (5 ng) & 6 & 84 & 51 & 39 & 30 & $88 \%-30$ days \\
\hline $\begin{array}{l}\text { Bunning et al. [89] (i.m. DNA } \\
\text { vaccine with adjuvant) }\end{array}$ & 4 & 6 & 10 & 0 & 70 & $60 \%-14$ days \\
\hline $\begin{array}{l}\text { Bunning et al. [89] } \\
\text { (i.m. DNA vaccine) }\end{array}$ & 5 & 4 & 10 & 0 & 70 & $44 \%-14$ days \\
\hline $\begin{array}{l}\text { Bunning et al. [89] (oral } \\
\text { microencapsulated DNA vaccine) }\end{array}$ & 10 & 0 & 10 & 0 & 70 & $0 \%-14$ days \\
\hline Cai et al. [90] & 7 & 93 & 94 & 6 & 49 & $92 \%-14$ days \\
\hline Chen et al. [91] (pcDNA-RpsA) & 8 & 22 & 29 & 1 & 35 & $71 \%-14$ days \\
\hline Chen et al. [91] (pcDNA-RplL) & 6 & 24 & 29 & 1 & 35 & $78 \%-14$ days \\
\hline Citarasu et al. [92] & 18 & 72 & 90 & 0 & 40 & $80 \%-10$ days \\
\hline Echeonwu et al. [52] & 0 & 50 & 20 & 0 & 14 & $100 \%-10$ days \\
\hline Gong et al. [100] & 8 & 17 & 25 & 0 & 14 & $68 \%-15$ days \\
\hline Habibi et al. [54] (feed) & 7 & 8 & 15 & 0 & 14 & $53 \%-10$ days \\
\hline Habibi et al. [54] (water) & 0 & 15 & 15 & 0 & 14 & $100 \%-10$ days \\
\hline $\begin{array}{c}\text { Habibi et al. [55] } \\
\text { (coated on the oiled wheat) }\end{array}$ & 0 & 15 & 15 & 0 & 14 & $100 \%-17$ days \\
\hline Habibi et al. [55] (water) & 0 & 15 & 15 & 0 & 14 & $100 \%-17$ days \\
\hline Huang et al. [101] & 0 & 10 & 3 & 7 & 16 & $100 \%-10$ days \\
\hline Jeong et al. [58] & 0 & 20 & 20 & 0 & 14 & $100 \%-7$ days \\
\hline Liu et al. [103] & 18 & 22 & 40 & 0 & 42 & $55 \%-15$ days \\
\hline $\begin{array}{c}\text { Omony et al. [71] } \\
\text { NDV-173/UG/MU/2011 }\end{array}$ & 10 & 0 & 10 & 0 & 21 & $0 \%-14$ days \\
\hline $\begin{array}{c}\text { Omony et al. [71] } \\
\text { NDV-133/UG/MU/2011 }\end{array}$ & 4 & 6 & 10 & 0 & 21 & $60 \%-14$ days \\
\hline
\end{tabular}


Table 4. Cont.

\begin{tabular}{|c|c|c|c|c|c|c|}
\hline Study & $\begin{array}{l}\text { Vaccinated } \\
\text { Group } \\
\text { Deaths }\end{array}$ & $\begin{array}{l}\text { Vaccinated } \\
\text { Group } \\
\text { Survivals }\end{array}$ & $\begin{array}{l}\text { Control } \\
\text { Group } \\
\text { Deaths }\end{array}$ & $\begin{array}{l}\text { Control } \\
\text { Group } \\
\text { Survivals }\end{array}$ & $\begin{array}{l}\text { Challenge } \\
\text { Time (dpv) }\end{array}$ & $\begin{array}{c}\text { Relative Percent of } \\
\text { Survival (RPS)-Days } \\
\text { Post-Challenge }\end{array}$ \\
\hline $\begin{array}{l}\text { Omony et al. [71] } 2014 \\
\text { NDV-177/UG/MU/2011 }\end{array}$ & 5 & 5 & 10 & 0 & 21 & $50 \%-14$ days \\
\hline $\begin{array}{c}\text { Omony et al. [71] } \\
\text { NDV-178/UG/MU/2011 }\end{array}$ & 8 & 2 & 10 & 0 & 21 & $20 \%-14$ days \\
\hline Pasnik and Smith [105] (25 ng-i.p) & 88 & 22 & 110 & 0 & 90 & $20 \%-36$ days \\
\hline Pasnik and Smith [105] (25 ng-i.m) & 22 & 88 & 110 & 0 & 90 & $80 \%-36$ days \\
\hline Pasnik and Smith [105] (5 ng-i.m) & 110 & 0 & 110 & 0 & 90 & 0\%-36 days \\
\hline Pasnik and Smith [105] (50 ng-i.m) & 11 & 99 & 110 & 0 & 90 & $90 \%-36$ days \\
\hline Ruan et al. 2020 [73] & 0 & 12 & 12 & 0 & 21 & $100 \%-14$ days \\
\hline Sun et al. 2011 [107] & 13 & 40 & 45 & 8 & 60 & $71 \%-20$ days \\
\hline Tan et al. [78] (IBV) & 1 & 9 & 10 & 0 & 21 & $90 \%-14$ days \\
\hline Tan et al. [78] (NDV) & 0 & 10 & 10 & 0 & 21 & $100 \%-14$ days \\
\hline Tu et al. [79] (0 days at $\left.30-35^{\circ} \mathrm{C}\right)$ & 2 & 12 & 15 & 0 & 12 & $86 \%-14$ days \\
\hline Tu et al. [79] (10 days at $\left.30-35^{\circ} \mathrm{C}\right)$ & 0 & 14 & 15 & 0 & 12 & $100 \%-14$ days \\
\hline Tu et al. [79] (17 days at $\left.30-35^{\circ} \mathrm{C}\right)$ & 0 & 15 & 15 & 0 & 12 & $100 \%-14$ days \\
\hline Tu et al. [79] ( 24 days at $\left.30-35^{\circ} \mathrm{C}\right)$ & 2 & 13 & 15 & 0 & 12 & $87 \%-14$ days \\
\hline Tu et al. [79] (3 days at $\left.30-35^{\circ} \mathrm{C}\right)$ & 0 & 15 & 15 & 0 & 12 & $100 \%-14$ days \\
\hline Tu et al. [79] (eye drop) & 1 & 9 & 10 & 0 & 14 & $90 \%-14$ days \\
\hline Tu et al. [79] (water) & 1 & 9 & 10 & 0 & 14 & $90 \%-14$ days \\
\hline Wambura et al. [81] (feed) & 0 & 15 & 15 & 0 & 35 & $100 \%-7$ days \\
\hline $\begin{array}{l}\text { Wambura et al. [81] } \\
\text { (wing web stab) }\end{array}$ & 0 & 15 & 15 & 0 & 35 & $100 \%-7$ days \\
\hline Wang et al. [110] & 9 & 31 & 40 & 0 & 35 & $77 \%-14$ days \\
\hline Xing et al. [112] & 13 & 17 & 26 & 4 & 42 & $50 \%-15$ days \\
\hline Xu et al. [113] & 1 & 29 & 13 & 17 & 60 & $92 \%-21$ days \\
\hline Xu et al. [114] & 14 & 16 & 28 & 2 & 42 & $50 \%-15$ days \\
\hline Yi et al. [116] & 11 & 19 & 30 & 0 & 30 & $63 \%-20$ days \\
\hline Yu et al. [117] (45 ng) & 8 & 22 & 16 & 14 & 15 & $50 \%-21$ days \\
\hline Yu et al. [117] (90 ng) & 4 & 26 & 16 & 14 & 15 & $75 \%-21$ days \\
\hline Zhang et al. [119] (pcDNA-M) & 66 & 34 & 100 & 0 & 28 & $34 \%-20$ days \\
\hline $\begin{array}{c}\text { Zhang et al. [119] } \\
\text { (SWCNTs-pcDNA-M) }\end{array}$ & 49 & 51 & 100 & 0 & 28 & $51 \%-20$ days \\
\hline Zhu et al. [120] & 0 & 10 & 1 & 9 & 14 & $100 \%-10$ days \\
\hline Zhu et al. [121] (gavage) & 13 & 17 & 30 & 0 & 21 & 57\%-30 days \\
\hline Zhu et al. [121] (mixed fodder) & 11 & 19 & 30 & 0 & 21 & $63 \%-30$ days \\
\hline
\end{tabular}

The animals in the trials included avian species $(n=12)$ and fish $(n=16)$, while the target agents were the virus $(n=18)$ and the bacteria $(n=10)$. As shown in Table 4 , the RPS was lower than $50 \%$ in 10/60 vaccinated groups. These include vaccinated groups from studies investigating the suitability and efficacy of different administration routes $[43,89,119]$, strains [71], or doses [105]. It is important to consider that all these studies have at least one vaccinated group with the RPS $>50 \%$. 
The pooled RR was 0.31 (95\% CI: $0.25-0.38$ ), resulting in a vaccine efficacy (VE) of $69 \%$. A vaccine efficacy of $69 \%$ indicates a $69 \%$ reduction in the death rate among the vaccinated groups. Effect estimates and confidence intervals are presented in the forest plot (Figure 3).

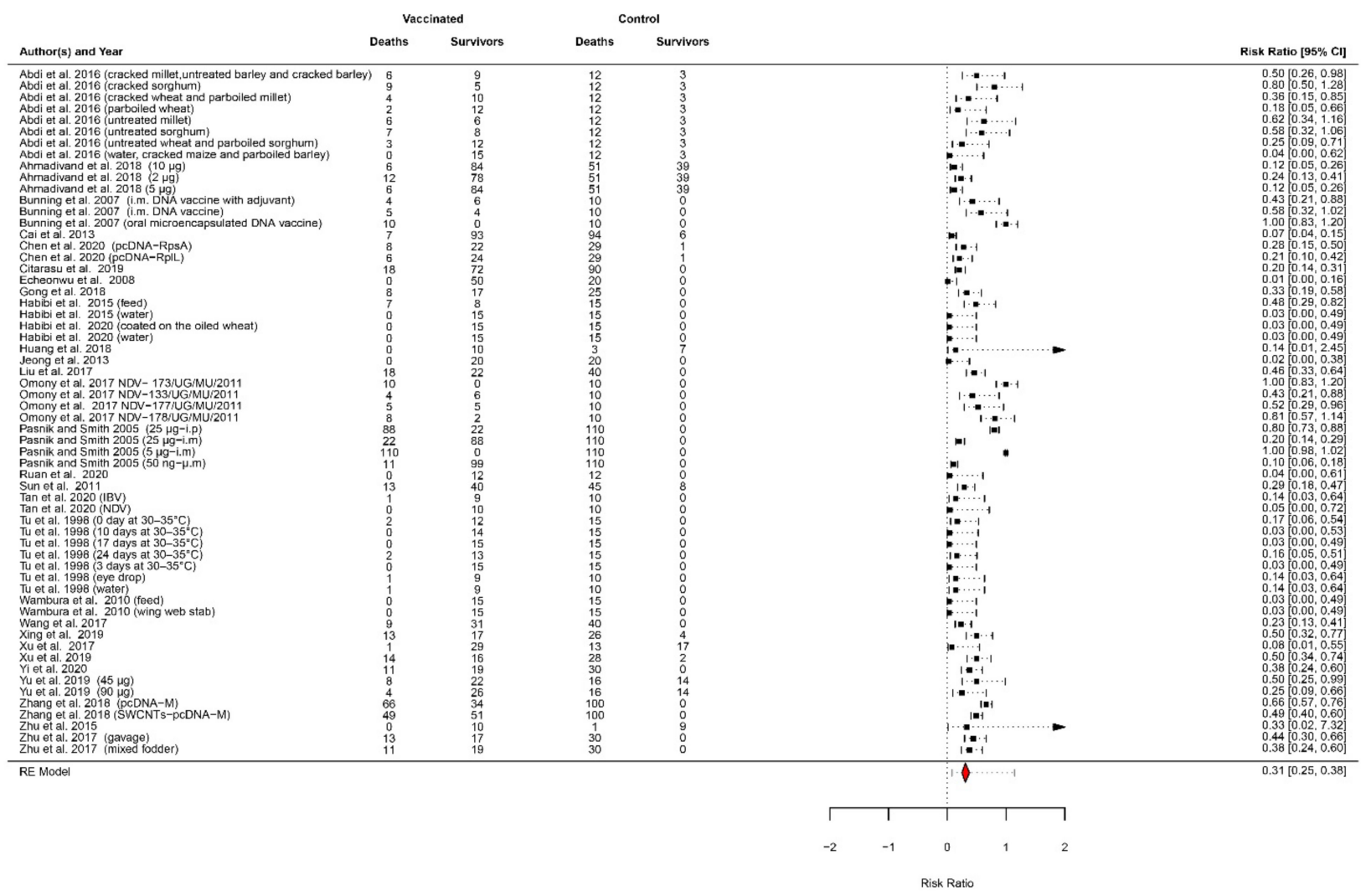

Figure 3. Forest plot of the risk ratio as a measure of vaccine efficacy (1-RR). Heterogeneity: $\mathrm{I}^{2}=95$ (95\% CI: 93-98), tau $^{2}=0.44$ (0.31-1.09), $\mathrm{Q}=781.99, p$-value $<0.0001$.

The heterogeneity was significantly high, being $I^{2}=95$ (95\% CI: 93-98), with a $p$-value $<0.0001$. One study was detected as influential, with an individual RR of 0.07 (93\% of VE) (Appendix A: Figures A1 and A2) [90]. Although the removal of this study would reduce the amount of heterogeneity and increase the precision of the estimated average outcome, we decided to keep it in the quantitative synthesis as it has one of the largest sample sizes (100 vaccinated animals and 100 control animals) and a high-quality study design. The inspection of the funnel plot shows some asymmetry (Appendix A: Figure A3). Nevertheless, the Peters' test $p$-value was 0.27 ; therefore, the hypothesis of the symmetry of the funnel plot was accepted. A meta-analysis was not performed to evaluate the vaccine effectiveness due to the small number of field trials retrieved.

The subgroup analysis performed, according to the animal species, showed that the RRs were similar in fish ( $R R=0.30$ (95\% CI: $0.22-0.40)$ ) and avian species $(R R=0.31$ (95\% CI: 0.23-0.43)). Similar values were obtained for bacteria diseases ( $R R=0.31$ (95\% CI: $0.21-0.44)$ ) and virus diseases ( $\mathrm{RR}=0.30(95 \% \mathrm{CI}: 0.23-0.39)$ ). For both moderators, the moderator test suggests that these variables do not influence the average VE (animal species: $\mathrm{QM}(\mathrm{df}=1)=0.0585, p$-value $=0.81$; type of agent: $\mathrm{QM}(\mathrm{df}=1)=0.0031, p$-value $=0.95)$. Moreover, the test for residual heterogeneity significantly indicated that the other moderators not considered in the model were influencing the VE (animal species: $\mathrm{I}^{2}=94$ (95\% CI: 92-98), $p$-value < 0.0001; type of agent: $\mathrm{I}^{2}=94$ (95\% CI: 91-97) $p$-value < 0.0001$)$. 


\section{Discussion}

\subsection{Summary of Evidence}

This study represents the first systematic review and meta-analysis on the current state of thermostable vaccines against a selection of animal infectious diseases, providing a quantitative measure of their efficacy against death $(\mathrm{VE}=69 \%)$.

Most of the studies included are on vaccines against avian diseases, and, in particular, against NDV [42-46,52-58,67,69-71,73,75,76,78,79,82-84]. Developing a thermostable vaccine for Newcastle disease (ND) was considered a priority for non-governmental organisations (NGOs) and studies were funded to evaluate the effectiveness and economic viabilities of the vaccination in developing countries. Strong encouragement and support were provided by the FAO and the International Atomic Energy Agency (IAEA) to reduce the burden of the disease and improve the welfare of rural households [122,123]. In this context, the key success of the vaccination against NDV was the development of thermostable vaccines by the Australian Centre for International Agriculture Research (ACIAR) [124].

A similar situation can be observed for the vaccines developed against PPRV, for which progress has been driven by the PPR Global Control and Eradication Strategy (GCES) launched by the FAO and OIE [125]. The first thermostable vaccine (Nigeria 75/1 PPR strain) against this highly contagious disease has recently received the regulatory approvals required to be produced and commercially distributed in Nepal [126]. Along with Rinderpest, ND and PPR represent perfect examples of high-impact diseases which have benefitted from the support and incentives of NGOs by implementing a vaccination campaign with thermostable products.

Interestingly, and as a first step towards addressing the issue, some field studies provided robust evidence on the immunogenicity of commercial vaccines stored at temperatures far in excess of the manufacturer's recommended cold-chain conditions $[46,61]$. Their results raise several questions, such as: (i) why manufacturers do not test for thermostability during vaccine development; (ii) why they do not include such information on the products labels; and (iii) how many other vaccines currently on the market could be stored outside the cold-chain, and for how long, whilst retaining equivalent potency? These studies provide preliminary evidence that some commercial vaccines might be used successfully, following a period of non-optimal storage in remote areas, regardless of the manufacturer's recommendations.

If we look back at recent and past history, our literature search highlights that the freeze-drying process is a valuable method to obtain vaccine thermostability $[47,49,50,52,65-$ $67,70,74,76,79,85]$. An improved freeze-drying process was used to develop a thermostable Rinderpest vaccine (Thermovax), which was an essential tool for eradicating the disease in remote pastoral areas [127]. In this study we identified dried formulations (freeze- or foam-dried) for vaccines against NDV (e.g., [52]), bovine ephemeral fever virus (BEFV) [74], classical swine fever virus (CSFV) [85], rabies [77], and PPR [47], highlighting that the drying process is a useful technique to improve the thermostability of vaccines against diverse diseases in several species. However, it is worth mentioning that the drying process alone is not able to confer a long-term stability in the formulations. There are other ways that have been used to enhance the shelf life of the products at ambient temperatures. For instance, the freeze-dried vaccine against CSFV was stabilized with a buffer composed by trehalose, glycine, thiourea, and phosphate [85]. Other examples of stabilizers retrieved from this review include: (i) lactalbumin, hydrolysate, and sucrose for the Rinderpest vaccine [65] (ii) the methylglucoside for the vaccine against bovine ephemeral fever (BEF), (iii) and a formulation composed of trehalose, tryptone, and other protectants for the vaccine against the porcine reproductive and respiratory syndrome virus (PRRSV) [64].

Lyophilized vaccines are more stable prior to their reconstitution in the liquid form, while their potency is known to decline once reconstituted. In addition, not all vaccines can be lyophilized and, thus, there have been efforts to increase the stability of vaccines in liquid form. For instance, the stability of liquid vaccines can be achieved by optimizing the properties of the solvent (e.g., buffer, $\mathrm{pH}$, and salt concentrations), and low-cost and 
safe excipients (e.g., glycerol) could provide freeze protection to vaccines with aluminum hydroxide, as an adjuvant to freeze damage [9]. Modern technologies have also become a key strategy to develop thermostable products. In this sense, Tan et al. [78] designed a thermostable recombinant NDV candidate vaccine against NDV and the infectious bronchitis virus (IBV), which was stable in the liquid form at $25{ }^{\circ} \mathrm{C}$ for 16 days. Similarly, Murr et al. [68] developed a recombinant NDV vector vaccine against PPR which was stable in the liquid form at $-80^{\circ} \mathrm{C},-20^{\circ} \mathrm{C}, 4^{\circ} \mathrm{C}, 21^{\circ} \mathrm{C}$, and $37^{\circ} \mathrm{C}$ for seven days.

Oral vaccinations are easy to implement and avoids stress in animals. Some thermostable vaccines have been developed with this route of administration in mind. The vaccine is incorporated into the feed during production, or it may be coated with pellets or encapsulated. Oral vaccines are particularly suitable for use in wild animals. In this sense, Smith et al. [77] developed a promising thermostable RABV vaccine using a foam drying process, highlighting the potential of this technique to produce a vaccine for oral use. The failure of the oral vaccination in the research by Bunning et al. [89] could have been due to the inactivation of the vaccines within the avian gastrointestinal tract. Oral vaccination was implemented in 16 other studies. These include articles on ND, using water and feed as vaccine carriers (e.g., $[42,43,76,83])$. The disadvantages of this route of administration are related to the large dose required to induce a uniform and long-lasting protection. For this reason, ND vaccines administered by eye-drops or treated feed have better performance than using water or untreated feed [42,43,57]. Additionally, oral vaccines may have an additional cost for the encapsulation, which may be necessary to avoid their degradation in the gastrointestinal environment prior to absorption [33].

Although a large number of trials using heat-stable vaccines was retrieved, very few peer-reviewed analyses exist on freeze-stable formulations. This finding shows how most efforts were directed to prevent vaccine deterioration and overcome the difficulty of maintaining the cold-chain in developing countries, which generally have high ambient temperatures. It is important to consider that although heat stability is perceived as a greater concern [128], conditions leading to freeze exposure occur, and may have an impact on the long-term stability of the vaccines, especially of those with aluminum adjuvants [9]. Damage due to freezing is likely in low- and middle-income countries, where cheap domestic refrigerators and cold boxes are used for storing and transporting vaccines. In particular, the poor performance of these refrigerators may lead to regular negative excursions, with potential damages to the vaccines during their storage [129]. Likewise, placing the vaccines with ice or gel packs inside portable containers may cause freeze damage to the vials too close to the ice and gel packs during their transportation [21]. With the exception of one article [68], this systematic review failed to identify studies in which the evaluation of the effect of freezing on vaccine potencies were assessed and, therefore, precluded identifying products fitting the definition of thermostable vaccines provided by the WHO [29]. Unsurprisingly, the information on heat stability and environmental temperatures, as provided by the authors, was reported heterogeneously in terms of different temperatures and periods of time (in ranges of days (e.g., Murr et al. [68]), weeks (e.g., Tu et al. [79]), or months (e.g., Dulal et al. [51]). Additionally, some authors defined the vaccines as thermostable only by performing a heat-treatment test in the lab (e.g., $56^{\circ} \mathrm{C}$ for $60 \mathrm{~min}[58,73])$. This diversity among benchmarks between the studies highlights the urgency to define standards when it comes to environmental or the freeze stability of vaccines.

With regards to the search on DNA vaccines, most of the articles retrieved were on vaccines that were experimentally developed. Although many DNA vaccine candidates have been evaluated with promising results in various animal species, it has been estimated, by a recent review, that only five DNA vaccines have been approved and licensed for veterinary use [130]. These include:

- $\quad$ Three against viral diseases;

- Two for fish (one against infectious hematopoietic necrosis virus (IHNV), and one against salmon alphavirus subtype 3); 
- One for horses against WNV, but used also in several avian species;

- One to treat cancer melanoma in dogs;

- $\quad$ One growth hormone-releasing hormone (GHRH) gene therapy for swine.

Conversely, no DNA vaccines have been licensed for human use to date [33,130]. DNA vaccination involves immunization with a plasmid encoding a gene of the pathogen. The production of DNA vaccines is cheaper than other types of vaccines. They are able to act in the presence of maternal antibodies, are temperature stable, and are safe to transport, which is especially important for remote areas [33]. Despite these advantages, some concerns have been raised, as DNA vaccines have failed to produce measurable antibodies, even if the host got protected, suggesting a major role of cellular immune responses. Another important concern is related to the potential deleterious effects following the integration into the host chromosome [131]. These issues, along with the cost of GMP (good manufacturing practices) grades, large-scale manufacturing restrains the commercial availability of DNA vaccines.

In the majority of the articles on DNA vaccines, both humoral and cellular immune responses were assessed, obtaining promising results on the production of a variety of immune modulators, cytokines, and co-stimulatory molecules (e.g., [102]). DNA vaccines have received particular attention in the field of aquaculture. They are safe for fish since they do not contain an oil adjuvant that can cause peritonitis, but also for the consumer, as the fish are consumed months after vaccination and the quantity of DNA used is very small [33]. In this work, 16 out of 35 studies on DNA vaccines were carried out on fish species in China. Since China is a major player in global aquaculture, contributing to roughly $61 \%$ of the total production [132], it is not surprising that researchers from China conducted extensive research on DNA vaccines against different diseases impacting aquaculture. In fish, the RPS, post-challenge, in the groups vaccinated ranged from $20 \%$ for the vaccine against Mycobacterium marinum developed by Pasnik and Smith [105], to 92\% for the vaccine against Vibrio alginolyticus developed by Cai et al. [90] and the vaccine against IHNV and the infectious pancreatic necrosis virus (IPNV) developed by $\mathrm{Xu}$ et al. [113]. It should also be considered that the immune efficiency varies based on the immunization routes, doses, and times of DNA immunization. In fact, Pasnik and Smith [105] reported a higher protection (RPS: 80-90\%) for the same vaccine administered at a higher dose, and a lower RPS at lower vaccine dose (RPS: $0 \%$ ). Our search also retrieved a great number of studies on DNA vaccines against avian diseases. Promising results have been obtained in avian species, with an RPS, post-challenge, ranging from $44 \%$ for the vaccine against WNV in the American crow [89] to $100 \%$ for the vaccine against novel duck reovirus (NDR) in ducks [120]. However, Bunning et al. [89] showed that the response to the DNA vaccines depended on the inclusion of an adjuvant (RPS: 60\%) and the route of administration, as none of the birds receiving the oral microencapsulated DNA vaccine against WNV developed antibodies, and none of them survived post-challenge (RPS: 0\%).

The VE, in terms of protection against death, is an objective measure to aggregate data on different vaccines. Indeed, numbers or rates of death are the most used measure for comparing the impact of different diseases in epidemiology [133]. In vaccine trials, challenging humans with dangerous pathogens is ethically unacceptable. Conversely, the evaluation of veterinary vaccines mainly relies on challenge studies. This is important to consider as serological studies may not always provide a good measure of efficacy [134]. For all these reasons, the pooled estimate of the VE was provided in terms of the reduced risk of death. The protection of thermostable vaccines against fatal diseases was estimated to be high $(\mathrm{VE}=69 \%)$, highlighting the benefits of vaccination to reduce the economic losses (direct deaths) due to the disease impact. The heterogeneity between studies was high.

Developing a portfolio of thermostable vaccines would not only help with improving access to vaccines in parts of the world where cold-chain capacity is lacking, overcoming a major supply-chain hurdle to the rollout of successful vaccination campaigns for humans and animals, but it would also greatly benefit the environment by reducing the great consumption of energy required to sustain the cold-chain. On top of the overall energy consumption of an increased number of refrigeration units, maintaining ultracold 
temperatures requires the use of hydrofluorocarbon gases, which are known to have a very heavy carbon footprint [135]. An additional benefit can be obtained by investing in thermostable products that can aid eradication programs, such as "differentiating infected from vaccinated animals" DIVA-vaccines, such as the ones presented in this review, developed by Verardi et al. [80], Daouam et al. [49], Dulal et al. [51], and Murr et al. [68]. These types of vaccines are promising for the effective disease control during outbreaks, and eradication programs in disease-endemic regions [136].

\subsection{Limitations}

The current study should be interpreted within the context of its limitations. Firstly, it does not provide a complete overview of the licensed thermostable vaccines for veterinary medicine. Instead, it aims to synthetize the peer-reviewed articles on thermostable vaccines developed against a selection of animal diseases. The target is not only to include the commercial vaccines, but also the vaccines experimentally developed, which are promising candidates. Additionally, only studies testing for VE, and the protection of the target hosts, were included, while in vitro studies, or studies testing the vaccines on non-natural hosts, were excluded. The intent was to retrieve an adequate number of studies to summarize the evidence on the efficacy of thermostable vaccines, rather than describe the progress made in vaccine technology. Some successful technologies that produce vaccine thermostability may not have been included in this study because the peer-reviewed articles were on vaccines tested under laboratory conditions.

Secondly, the search on DNA vaccines was intentionally limited by sorting for relevance and extracting the first 100 records from each bibliographic database. The screening of all the papers would have allowed us to retrieve a higher number of articles, which would have compromised the time efficiency of our search. Indeed, such an approach would have been unfeasible, given the growing number of peer-reviewed articles on DNA vaccine candidates for animal species [137]. Moreover, in this case, the aim was not to provide a comprehensive overview on DNA vaccines for veterinary use, which has been reviewed by several narrative reviews (e.g., Fomsgaard and Liu [130]). Instead, this study aims to highlight some applications of these vaccines, which have intrinsic thermostability characteristics.

Thirdly, considering that the methodology to assess the immunogenicity, durability of immunity, and the safety profile is specific to each disease, comparisons on the humoral and cell-mediated immunities elicited by the vaccines were not made. The outcomes of interest for veterinary vaccines consider the livestock profitability and vary according to the disease. In the articles extracted, the outcomes ranged from the evaluation of specific disease symptoms (in cases of non-acute diseases) (e.g., Murr et al. [68]) to mortality. These different conditions could not have been compared or pooled.

Fourthly, the heterogeneity of the included studies is likely to be due to the different diseases against which the vaccines have been developed. Because of the small number of articles for each disease, the heterogeneity was not investigated using a subgroup analysis according to the disease. Additionally, other factors influencing the performance of vaccines were not assessed. These include the age and sex of the animals, the level and time of the challenge (pathogen factors), the dose, and the route of vaccine administration. Despite these limitations, it is important to consider that most of the individual estimates show the same direction of effect $(R R<1)$, highlighting the significant protection conferred by the vaccination.

\section{Conclusions}

This study presents the first condensed evidence from peer-reviewed literature on the current availability of thermostable vaccines for veterinary use. Over the years diverse methods have been implemented to develop and improve vaccine thermostability. Moreover, the efficacy of these formulations has been proved for several animal diseases, with an overall risk of death, in vaccinated animals, that is reduced by nearly $70 \%$ compared 
with unvaccinated controls. Although we were not able to identify the exact percentage of thermostable formulations, many articles cited in this review stated that most of vaccines on the market are still dependent on cold-chain systems, stressing the importance of enhancing their stability (e.g., $[9,18,127])$. The recent COVID-19 pandemic has highlighted the difficulties in transporting and storing non-thermostable vaccine formulations, especially for low-income countries, highlighting the necessity to improve the distribution and storage of vaccines to adequately respond to the current and future pandemics. In this regard, the reevaluation of vaccine research and development, manufacturing, and supply-chain management strategies are essential to produce vaccines that are heat- and freeze-stable to make vaccinations widely available to anyone globally, regardless of cold-chain capacity. We suggest that each novel vaccine candidate should be evaluated for its thermostability along with its safety, immunogenicity, and protective efficacy before it is licensed for use. The shelf life of existing products should be investigated, by default, under non-cold-chain conditions, coupled with efforts to boost their thermostability. We also strongly encourage regulatory agencies to adopt a standard definition of vaccine heat- and freeze-stability requirements to be used for the development of new generation vaccines both for human and for veterinary use.

As a final point, we would like to invite funding agencies and donors who support vaccine research to reflect and consider on the added value that having more stable products would bring to their philanthropic efforts both in human and veterinary medicine.

Author Contributions: Conceptualization, I.C., methodology, I.C.; software, A.F.; validation, L.M.; formal analysis, A.F.; investigation, A.F.; resources, L.M.; data curation, A.F.; writing-original draft preparation, A.F.; writing - review and editing, A.F., L.M., S.H. and I.C.; review and contextualization, I.C. All authors have read and agreed to the published version of the manuscript.

Funding: This research received no external funding.

Institutional Review Board Statement: Not applicable.

Informed Consent Statement: Not applicable.

Acknowledgments: This research was supported by One Health Center of Excellence at the University of Florida and by the Circular Health Fellowship program of the One Health Center of Excellence of UF.

Conflicts of Interest: The authors declare no conflict of interest.

\section{Appendix A}

Table A1. OIE listed diseases for which vaccines have been developed $[13,14]$.

\begin{tabular}{ccc}
\hline Name & Causative Agent & Disease Group \\
\hline Anthrax & Bacillus anthracis & Multiple species diseases \\
\hline Aujeszky's disease & Suid herpesvirus 1 (SuHV-1) & Multiple species diseases \\
\hline Brucellosis & Brucella abortus/B. melitensis & Multiple species diseases \\
\hline Bluetongue & Bluetongue virus (BTV) & Multiple species diseases \\
\hline Echinococcosis/hydatidosis & $\begin{array}{c}\text { Echinococcus granulosus / } \\
\text { E. multilocularis }\end{array}$ & Multiple species diseases \\
\hline Epizootic haemorrhagic & $\begin{array}{c}\text { Epizootic haemorrhagic disease } \\
\text { virus (EHDV) }\end{array}$ & Multiple species diseases \\
\hline Foot and mouth disease & $\begin{array}{c}\text { Foot and mouth disease virus } \\
\text { (FMDV) }\end{array}$ & Multiple species diseases \\
\hline Heartwater (cowdriosis) & $\begin{array}{c}\text { Ehrlichia ruminantium (formerly } \\
\text { Cowdria ruminantium) }\end{array}$ & Multiple species diseases \\
\hline Tuberculosis & Mycobacterium tuberculosis complex & Multiple species diseases \\
\hline
\end{tabular}


Table A1. Cont.

\begin{tabular}{|c|c|c|}
\hline Name & Causative Agent & Disease Group \\
\hline Japanese encephalitis & Japanese encephalitis virus (JEV) & Multiple species diseases \\
\hline Paratuberculosis & $\begin{array}{l}\text { Mycobacterium avium subsp. } \\
\text { paratuberculosis (MAP) }\end{array}$ & Multiple species diseases \\
\hline Q fever (or Coxiellosis) & Coxiella burnetii & Multiple species diseases \\
\hline Rabies & $\begin{array}{c}\text { Rabies virus (RABV) and other } \\
\text { lyssaviruses }\end{array}$ & Multiple species diseases \\
\hline Rift Valley fever & Rift Valley fever virus (RVF) & Multiple species diseases \\
\hline Rinderpest & Rinderpest virus (RPV) & Multiple species diseases \\
\hline Tularemia & Francisella tularensis & Multiple species diseases \\
\hline West Nile Fever & West Nile virus (WNV) & Multiple species diseases \\
\hline Bovine anaplasmosis & Anaplasma marginale/A. centrale & Bovinae \\
\hline Bovine babesiosis & $\begin{array}{c}\text { Babesia bovis/B. bigemina/ } \\
\text { B. divergens }\end{array}$ & Bovinae \\
\hline $\begin{array}{c}\text { Bovine genital } \\
\text { campylobacteriosis (bovine } \\
\text { venereal campylobacteriosis) }\end{array}$ & $\begin{array}{c}\text { Campylobacter fetus subsp. } \\
\text { Venerealis }\end{array}$ & Bovinae \\
\hline Bovine viral diarrhoea & $\begin{array}{l}\text { Bovine viral diarrhoea virus } \\
\text { (BVDV) }\end{array}$ & Bovinae \\
\hline $\begin{array}{l}\text { Contagious bovine } \\
\text { pleuropneumonia }\end{array}$ & $\begin{array}{c}\text { Mycoplasma mycoides subsp. } \\
\text { Mycoides }\end{array}$ & Bovinae \\
\hline Haemorrhagic septicaemia & Pasteurella multocida & Bovinae \\
\hline $\begin{array}{c}\text { Infectious bovine } \\
\text { rhinotracheitis/infectious } \\
\text { pustular vulvovaginitis (IPV) }\end{array}$ & Bovine herpesvirus 1 (BoHV-1) & Bovinae \\
\hline Lumpy skin disease virus & Lumpy skin disease virus (LSDV) & Bovinae \\
\hline Theileriosis & Theileria annulata and T. parva & Bovinae \\
\hline Trichomonosis & Tritrichomonas foetus & Bovinae \\
\hline $\begin{array}{c}\text { Enzootic abortion of ewes } \\
\text { (ovine chlamydiosis) }\end{array}$ & Chlamydia abortus & Caprinae \\
\hline Contagious agalactia & Mycoplasma agalactiae (Ma) & Caprinae \\
\hline $\begin{array}{l}\text { Contagious caprine } \\
\text { pleuropneumonia }\end{array}$ & $\begin{array}{l}\text { Mycoplasma capricolum subsp. } \\
\text { capripneumoniae (Mccp) }\end{array}$ & Caprinae \\
\hline Nairobi sheep disease & Nairobi sheep disease virus (NSDV) & Caprinae \\
\hline $\begin{array}{c}\text { Peste des petits ruminants } \\
\text { virus }\end{array}$ & $\begin{array}{l}\text { Small Ruminant Morbillivirus } \\
\text { (SRMV) }\end{array}$ & Caprinae \\
\hline Salmonellosis & Salmonella abortusovis & Caprinae \\
\hline Sheep pox and goat pox & $\begin{array}{l}\text { Sheeppox virus (SPPV) and } \\
\text { goatpox virus (GTPV) }\end{array}$ & Caprinae \\
\hline African horse sickness (AHS) & $\begin{array}{l}\text { African horse sickness virus } \\
\text { (AHSV) }\end{array}$ & Equidae \\
\hline Equine rhinopneumonitis & Equid herpesvirus-1 & Equidae \\
\hline Equine viral arteritis (EVA) & Equine arteritis virus (EAV) & Equidae \\
\hline $\begin{array}{c}\text { Equine encephalomyelitis } \\
\text { (Eastern, Western, Venezuelan) } \\
\text { (EEE, WEE and VEE) }\end{array}$ & $\begin{array}{l}\text { Equine encephalomyelitis viruses } \\
\text { (Eastern, Western, Venezuelan) } \\
\text { (EEEV, WEEV and VEEV) }\end{array}$ & Equidae \\
\hline
\end{tabular}


Table A1. Cont.

\begin{tabular}{|c|c|c|}
\hline Name & Causative Agent & Disease Group \\
\hline Equine influenza & $\begin{array}{l}\text { Equine influenza viruses } \\
\text { (H7N7, formerly equi-1, and } \\
\text { H3N8, formerly equi2) }\end{array}$ & Equidae \\
\hline Classical swine fever virus & Classical swine fever virus (CSFV) & Suidae \\
\hline Nipah virus encephalitis & Nipah virus (NiV) & Suidae \\
\hline $\begin{array}{l}\text { Porcine reproductive and } \\
\text { respiratory syndrome (PRRS) }\end{array}$ & $\begin{array}{l}\text { Porcine reproductive and } \\
\text { respiratory syndrome virus } \\
\text { (PRRSV) }\end{array}$ & Suidae \\
\hline Porcine cysticercosis & Taenia solium & Suidae \\
\hline $\begin{array}{c}\text { Transmissible gastroenteritis } \\
\text { (TGE) }\end{array}$ & $\begin{array}{l}\text { Transmissible gastroenteritis virus } \\
\text { (TGEV) }\end{array}$ & Suidae \\
\hline Camelpox & Camelpox virus & Other diseases \\
\hline Leishmaniosis & $\begin{array}{l}\text { Leishmania species } \\
\text { (approximately } 20 \text { recognised) }\end{array}$ & Other diseases \\
\hline $\begin{array}{l}\text { Infectious salmon anaemia } \\
\text { virus (Inf. with) } \\
\text { (HPR-deleted or HPR0 } \\
\text { genotypes) }\end{array}$ & $\begin{array}{l}\text { Infectious salmon anaemia virus } \\
\text { (ISAV) }\end{array}$ & Diseases of fish \\
\hline $\begin{array}{l}\text { Koi herpesvirus } \\
\text { (Inf. with) }\end{array}$ & Koi herpesvirus (KHV) & Diseases of fish \\
\hline $\begin{array}{l}\text { Red sea bream iridovirus } \\
\text { (Inf. with) }\end{array}$ & Red sea bream iridovirus RSIVD & Diseases of fish \\
\hline $\begin{array}{l}\text { Salmonid alphavirus } \\
\text { (Inf. with) }\end{array}$ & Salmonid alphavirus (SAV) & Diseases of fish \\
\hline Avian infectious bronchitis & $\begin{array}{c}\text { Gammacoronavirus infectious } \\
\text { bronchitis virus (IBV) }\end{array}$ & Aves \\
\hline $\begin{array}{l}\text { Avian infectious } \\
\text { laryngotracheitis }\end{array}$ & Gallid alphaherpesvirus 1 & Aves \\
\hline Avian influenza & $\begin{array}{l}\text { Low and High pathogenicity } \\
\text { avian influenza viruses }\end{array}$ & Aves \\
\hline $\begin{array}{l}\text { Avian mycoplasmosis } \\
\text { (M.synoviae) }\end{array}$ & Mycoplasma synoviae & Aves \\
\hline $\begin{array}{c}\text { Avian mycoplasmosis } \\
\text { (Mycoplasma gallisepticum) }\end{array}$ & Mycoplasma gallisepticum & Aves \\
\hline Duck virus hepatitis & Duck hepatitis A virus (DHAV) & Aves \\
\hline Fowl typhoid & Salmonella Gallinarum & Aves \\
\hline $\begin{array}{l}\text { Infectious bursal disease } \\
\text { (Gumboro disease) }\end{array}$ & $\begin{array}{l}\text { Infectious bursal disease virus } \\
\text { (IBDV) }\end{array}$ & Aves \\
\hline Newcastle disease & Newcastle disease virus (NDV) & Aves \\
\hline Pullorum disease & Salmonella Pullorum & Aves \\
\hline Turkey rhinotracheitis & Avian metapneumovirus (Ampv) & Aves \\
\hline Myxomatosis & Myxoma virus (MYXV) & Leporidae \\
\hline Rabbit haemorrhagic disease & $\begin{array}{c}\text { Rabbit haemorrhagic disease } \\
\text { virus (RHDV) }\end{array}$ & Leporidae \\
\hline
\end{tabular}


Table A2. Information on animal vaccines production worldwide as submitted to the OIE by Member Countries. It is important to consider that not all the available vaccines on the market are reported as only the laboratories under national veterinary services are requested to provide information on the vaccines produced (e.g., vaccines produced by private industries might not be reported to the OIE).

\begin{tabular}{|c|c|c|c|c|c|c|}
\hline Disease & $\begin{array}{l}\text { Conjugate } \\
\text { Vaccine }\end{array}$ & $\begin{array}{c}\text { DNA } \\
\text { Vaccine }\end{array}$ & $\begin{array}{l}\text { Inactivated } \\
\text { Vaccine }\end{array}$ & $\begin{array}{c}\text { Live } \\
\text { Attenuated } \\
\text { Vaccine }\end{array}$ & $\begin{array}{l}\text { Recombinant } \\
\text { Vector } \\
\text { Vaccine }\end{array}$ & $\begin{array}{l}\text { Subunit } \\
\text { Vaccine }\end{array}$ \\
\hline African horse sickness & & & & $\times$ & & \\
\hline Anthrax & & & $\times$ & $\times$ & & \\
\hline Aujeszky's disease & $\times$ & & $\times$ & $\times$ & $\times$ & \\
\hline Avian infectious bronchitis & $\times$ & & $\times$ & $\times$ & $\times$ & \\
\hline Avian infectious laryngotracheitis & $\times$ & & $\times$ & $\times$ & $\times$ & \\
\hline Avian mycoplasmosis (M. gallisepticum) & & & $\times$ & $\times$ & & \\
\hline Bluetongue & & & $\times$ & $\times$ & & \\
\hline Bovine anaplasmosis & & & $\times$ & $\times$ & & \\
\hline Bovine babesiosis & & & $\times$ & $\times$ & & \\
\hline Bovine brucellosis & & & $\times$ & $\times$ & & \\
\hline Bovine viral diarrhoea & & & $\times$ & $\times$ & & \\
\hline Brucellosis (Brucella abortus) & & & & $\times$ & & \\
\hline Brucellosis (Brucella melitensis) & & & $\times$ & $\times$ & & \\
\hline Camelpox & & & $x$ & $\times$ & & \\
\hline $\begin{array}{l}\text { Caprine and ovine brucellosis } \\
\text { (excluding B. ovis) }\end{array}$ & & & $\times$ & $\times$ & & \\
\hline Classical swine fever & & & $\times$ & $\times$ & $\times$ & $\times$ \\
\hline Contagious agalactia & & & $\times$ & $\times$ & & \\
\hline Contagious bovine pleuropneumonia & & & & $\times$ & & \\
\hline Contagious caprine pleuropneumonia & & & $\times$ & $\times$ & & \\
\hline Duck virus enteritis & & & $\times$ & $\times$ & & \\
\hline Duck virus hepatitis & & & $\times$ & $\times$ & & \\
\hline Enterovirus encephalomyelitis & & & $\times$ & $\times$ & & \\
\hline $\begin{array}{l}\text { Enzootic abortion of ewes } \\
\text { (ovine chlamydiosis) }\end{array}$ & & & $\times$ & & & \\
\hline Equid herpesvirus-X (EHV-X) (Infection with) & & & $\times$ & & & \\
\hline Equine encephalomyelitis (Eastern) & & & $\times$ & $\times$ & & \\
\hline Equine encephalomyelitis (Western) & & & $\times$ & & & \\
\hline Equina influenza & & & $\times$ & $\times$ & & \\
\hline Equine rhinopneumonitis & & & $\times$ & & & \\
\hline Equine viral arteritis & & & $\times$ & & & \\
\hline Foot and mouth disease & & & $\times$ & $\times$ & & $\times$ \\
\hline Fowl cholera & & & $\times$ & $\times$ & & \\
\hline Fowl typhoid & & & $\times$ & $\times$ & & \\
\hline Haemorrhagic septicaemia & & & $\times$ & $\times$ & & \\
\hline Highly pathogenic avian influenza & & & $\times$ & $\times$ & $\times$ & \\
\hline $\begin{array}{l}\text { Highly pathogenic influenza A viruses } \\
\text { (infection with) (non-poultry incluiding } \\
\text { wild birds) }\end{array}$ & & & $x$ & & & \\
\hline
\end{tabular}


Table A2. Cont.

\begin{tabular}{|c|c|c|c|c|c|c|}
\hline Disease & $\begin{array}{l}\text { Conjugate } \\
\text { Vaccine }\end{array}$ & $\begin{array}{c}\text { DNA } \\
\text { Vaccine }\end{array}$ & $\begin{array}{l}\text { Inactivated } \\
\text { Vaccine }\end{array}$ & $\begin{array}{c}\text { Live } \\
\text { Attenuated } \\
\text { Vaccine }\end{array}$ & $\begin{array}{c}\text { Recombinant } \\
\text { Vector } \\
\text { Vaccine }\end{array}$ & $\begin{array}{l}\text { Subunit } \\
\text { Vaccine }\end{array}$ \\
\hline Infection with salmonid alphavirus & & $\times$ & & & & \\
\hline $\begin{array}{l}\text { Infectious bovine rhinotracheitis/infectious } \\
\text { pustular vulvovaginitis }\end{array}$ & $\times$ & & $\times$ & $\times$ & $\times$ & \\
\hline Infectious bursal disease (Gumboro disease) & $\times$ & & $\times$ & $\times$ & $\times$ & \\
\hline Infectious haematopoietic necrosis & & $\times$ & & & & \\
\hline Infectious pancreatic necrosis & & & $\times$ & & & $\times$ \\
\hline Infectious salmon anaemia & & & $\times$ & & & \\
\hline Japanese encephalitis & & & & $\times$ & & \\
\hline Low pathogenic avian influenza (poultry) & & & $\times$ & & & \\
\hline Lumpy skin disease & & & $\times$ & $\times$ & & \\
\hline Marek's disease & & & $\times$ & $\times$ & & \\
\hline Myxomatosis & & & & $\times$ & & \\
\hline Newcastle disease & & & $\times$ & $\times$ & $\times$ & \\
\hline Ovine epididymitis (Brucella ovis) & & & & $\times$ & & \\
\hline Peste des petits ruminants & & & $\times$ & $x$ & & \\
\hline $\begin{array}{l}\text { Porcine reproductive and respiratory } \\
\text { syndrome }\end{array}$ & & & $\times$ & $\times$ & $\times$ & $\times$ \\
\hline Pullorum disease & & & $\times$ & & & \\
\hline Rabbit haemorrhagic disease & & & $\times$ & $\times$ & & \\
\hline Rabies & & & $\times$ & $x$ & $\times$ & \\
\hline Red sea bream iridoviral disease & & & $\times$ & & & \\
\hline Rift Valley fever & & & $\times$ & $\times$ & & \\
\hline Rinderpest & & & $\times$ & $x$ & & \\
\hline Salmonellosis (S. abortusovis) & & & $\times$ & $\times$ & & \\
\hline Sheep pox and goat pox & & & $\times$ & $\times$ & & \\
\hline Theileriosis & & & & $\times$ & & \\
\hline Transmissible gastroenteritis & & & $x$ & $\times$ & & \\
\hline Trichomonosis & & & $\times$ & & & \\
\hline Turkey rhinotracheitis & & & $\times$ & $\times$ & & \\
\hline Venezuelan equine encephalomyelitis & & & $x$ & $\times$ & & \\
\hline Vesicular stomatitis & & & $\times$ & & & \\
\hline West Nile Fever & & & $x$ & & & \\
\hline
\end{tabular}

The most produced type is the inactivated vaccine (available for 56/67 diseases), followed by the live attenuated vaccine (available for 49/67 diseases), recombinant vector vaccine (available for 10/67 diseases), conjugate vaccine (available for 5/67 diseases), subunit vaccine (available for $4 / 67$ diseases), and DNA vaccine (available for $2 / 67$ diseases) (supplementary material: Table A2). Generally, live-attenuated vaccines are more heat sensitive to potency loss during storage and distribution, thus requiring particular attention to maintain the cold chain. Conversely, inactivated and subunit vaccines can be particularly freeze sensitive, while DNA vaccines are very stable and do not require a cold chain. 


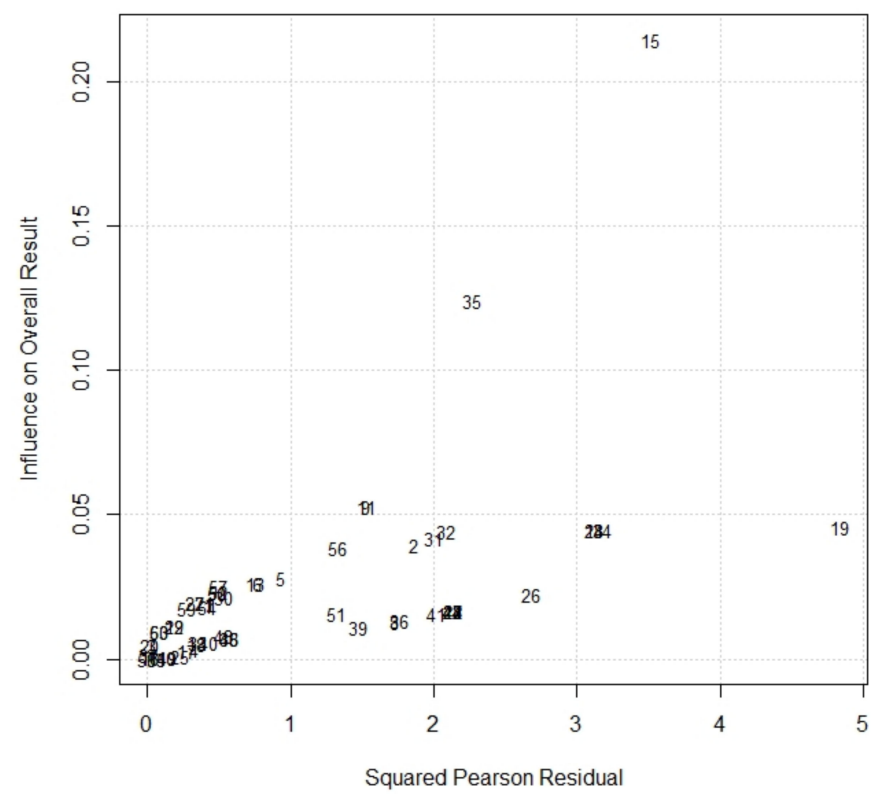

Figure A1. The Baujat Plot of roe deer studies. Study number 5 [90] could be an outlier which may distort the effect size estimate, as well as its precision.
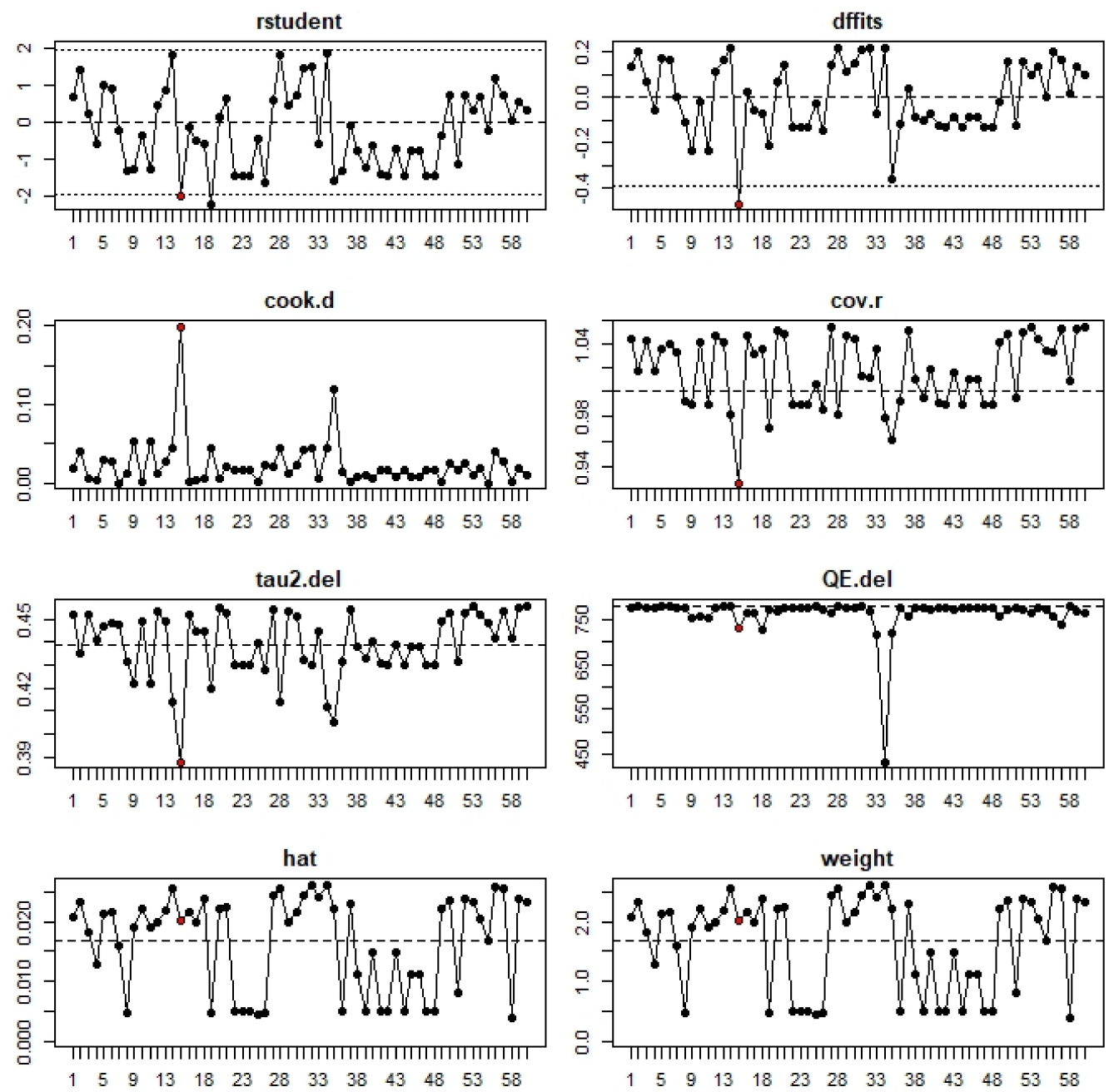

Figure A2. Influence analysis identifies study number 5 [90] as potential outlier. 


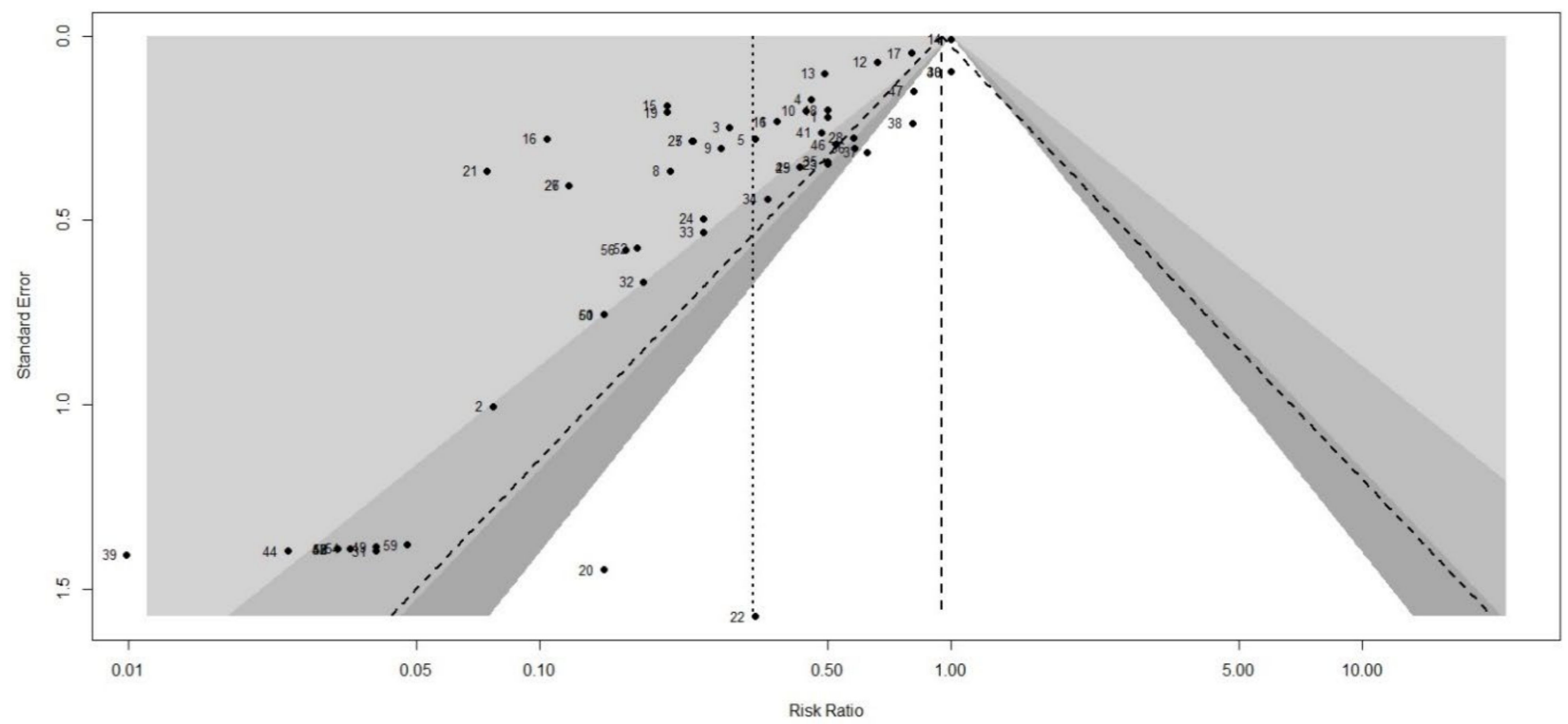

Figure A3. Funnel plot of the meta-analysis on vaccines efficacy.

\section{References}

1. People's Vaccine Alliance Open Letter: Former Heads of State and Nobel Laureates Call on President Biden To Waive Intellectual Property Rules for COVID Vaccines. Available online: https:/ / en.emergency.it/press-releases/former-heads-of-state-and-nobellaureates-call-on-president-biden-to-waive-intellectual-property-rules-for-covid-vaccines/ (accessed on 25 November 2021).

2. Capua, I.; Giaquinto, C. The unsung virtue of thermostability. Lancet 2021, 397, 1346. [CrossRef]

3. Global Health Summit The Rome Declarations. May 2021. Available online: https://global-health-summit.europa.eu/romedeclaration_en (accessed on 25 November 2021).

4. Wang, J.; Peng, Y.; Xu, H.; Cui, Z.; Williams, R.O. The COVID-19 Vaccine Race: Challenges and Opportunities in Vaccine Formulation. AAPS PharmSciTech 2020, 21, 225. [CrossRef]

5. Holm, M.R.; Poland, G.A. Critical aspects of packaging, storage, preparation, and administration of mRNA and adenovirusvectored COVID-19 vaccines for optimal efficacy. Vaccine 2020, 39, 457. [CrossRef] [PubMed]

6. Uddin, M.N.; Roni, M.A. Challenges of Storage and Stability of mRNA-Based COVID-19 Vaccines. Vaccines 2021, 9, 1033. [CrossRef]

7. Knoll, M.D.; Wonodi, C. Oxford-AstraZeneca COVID-19 vaccine efficacy. Lancet 2021, 397, 72-74. [CrossRef]

8. CDC Janssen COVID-19 Vaccine (Johnson \& Johnson). Available online: https://www.cdc.gov/vaccines/covid-19/info-byproduct/janssen/downloads/janssen-storage-handling-summary.pdf (accessed on 25 November 2021).

9. Chen, D.; Kristensen, D. Opportunities and challenges of developing thermostable vaccines. Expert Rev. Vaccines 2009, 8, 547-557. [CrossRef] [PubMed]

10. WHO. Global Vaccine Action Plan; WHO: Geneva, Switzerland, 2013.

11. Meeusen, E.N.T.; Walker, J.; Peters, A.; Pastoret, P.P.; Jungersen, G. Current status of veterinary vaccines. Clin. Microbiol. Rev. 2007, 20, 489-510. [CrossRef] [PubMed]

12. Paton, D.J.; de Clercq, K.; Greiner, M.; Dekker, A.; Brocchi, E.; Bergmann, I.; Sammin, D.J.; Gubbins, S.; Parida, S. Application of non-structural protein antibody tests in substantiating freedom from Foot-and-mouth disease virus infection after emergency vaccination of cattle. Vaccine 2006, 24, 6503-6512. [CrossRef]

13. OIE Manual of Diagnostic Tests for Aquatic Animals. Available online: https://www.oie.int/en/what-we-do/standards/codesand-manuals/aquatic-manual-online-access/ (accessed on 25 November 2021).

14. OIE. Manual of Diagnostic Tests and Vaccines for Terrestrial Animals; OIE: Paris, France, 2021.

15. Brandau, D.T.; Jones, L.S.; Wiethoff, C.M.; Rexroad, J.; Middaugh, C.R. Thermal stability of vaccines. J. Pharm. Sci. 2003, 92, 218-231. [CrossRef] [PubMed]

16. OIE. Chapter 4.18 Vaccination. In Terrestrial Animal Health Code; OIE: Paris, France, 2021; pp. 1-8.

17. Dumpa, N.; Goel, K.; Guo, Y.; McFall, H.; Pillai, A.R.; Shukla, A.; Repka, M.A.; Murthy, S.N. Stability of Vaccines. Am. Assoc. Pharm. Sci. 2019, 20, 42. [CrossRef] [PubMed]

18. Kristensen, D.; Chen, D.; Cummings, R. Vaccine stabilization: Research, commercialization, and potential impact. Vaccine 2011, 29, 7122-7124. [CrossRef]

19. OIE Rinderpest. Available online: https://www.oie.int/en/disease/Rinderpest/ (accessed on 8 August 2021).

20. Henderson, D.A. The eradication of smallpox-An overview of the past, present, and future. Vaccine 2011, 29, D7-D9. [CrossRef]

21. Matthias, D.M.; Robertson, J.; Garrison, M.M.; Newland, S.; Nelson, C. Freezing temperatures in the vaccine cold chain: A systematic literature review. Vaccine 2007, 25, 3980-3986. [CrossRef] [PubMed] 
22. Lee, B.Y.; Cakouros, B.E.; Assi, T.M.; Connor, D.L.; Welling, J.; Kone, S.; Djibo, A.; Wateska, A.R.; Pierre, L.; Brown, S.T. The impact of making vaccines thermostable in Niger's vaccine supply chain. Vaccine 2012, 30, 5637-5643. [CrossRef]

23. Lee, B.Y.; Wedlock, P.T.; Haidari, L.A.; Elder, K.; Potet, J.; Manring, R.; Connor, D.L.; Spiker, M.L.; Bonner, K.; Rangarajan, A.; et al. Economic impact of thermostable vaccines. Vaccine 2017, 35, 3135-3142. [CrossRef]

24. FAO. Livestock. Available online: http://www.fao.org/rural-employment/agricultural-sub-sectors/livestock/en/ (accessed on 7 August 2021).

25. Porphyre, T.; Rich, K.M.; Auty, H.K. Assessing the economic impact of vaccine availability when controlling foot and mouth disease outbreaks. Front. Vet. Sci. 2018, 5, 47. [CrossRef] [PubMed]

26. Knight-Jones, T.J.D.; Rushton, J. The economic impacts of foot and mouth disease-What are they, how big are they and where do they occur? Prev. Vet. Med. 2013, 112, 161-173. [CrossRef]

27. Boklund, A.; Halasa, T.; Christiansen, L.E.; Enøe, C. Comparing control strategies against Foot-and-mouth disease: Will vaccination be cost-effective in Denmark? Prev. Vet. Med. 2013, 111, 206-219. [CrossRef]

28. Berentsen, P.B.M.; Dijkhuizen, A.A.; Oskam, A.J. A dynamic model for cost-benefit analyses of foot-and-mouth disease control strategies. Prev. Vet. Med. 1992, 12, 229-243. [CrossRef]

29. WHO. Assessing the Programmatic Suitability of Vaccine Candidates for WHO Prequalification Immunization, Vaccines and Biologicals; WHO: Geneva, Switzerland, 2012.

30. OIE. Mission. Available online: https://www.oie.int/en/who-we-are/mission/ (accessed on 18 October 2021).

31. PAHO. Immunization. Available online: https://www.paho.org/en/topics/immunization (accessed on 25 November 2021).

32. FAO. Veterinary Vaccines Protect Humans as Well as Animals, says Director-General. Available online: https://www.fao.org/ news/story/it/item/1398970/icode/ (accessed on 25 November 2021).

33. Redding, L.; Weiner, D.B. DNA vaccines in veterinary use. Expert Rev. Vaccines 2009, 8, 1251-1276. [CrossRef] [PubMed]

34. Zhang, B.; Yuan, C.; Song, X.; Xu, L.; Yan, R.; Shah, M.A.A.; Guo, C.; Zhu, S.; Li, X. Optimization of Immunization Procedure for Eimeria tenella DNA Vaccine pVAX1-pEtK2-IL-2 and Its Stability. Acta Parasitol. 2019, 64, 745-752. [CrossRef] [PubMed]

35. WHO. Vaccine Efficacy, Effectiveness and Protection. Available online: https://www.who.int/news-room/feature-stories/ detail/vaccine-efficacy-effectiveness-and-protection (accessed on 6 October 2021).

36. Orenstein, W.A.; Bernier, R.H.; Dondero, T.J.; Hinman, A.R.; Marks, J.S.; Bart, K.J.; Sirotkin, B. Field evaluation of vaccine efficacy. Bull. World Health Organ. 1985, 63, 1055-1068. [PubMed]

37. R Core Team. A Language and Environment for Statistical Computing; R Foundation for Statistical Computing: Vienna, Austria, 2021.

38. Higgins, J.; Thompson, S. Quantifying heterogeneity in a meta-analysis. Stat. Med. 2002, 21, 1539-1558. [CrossRef]

39. Fanelli, A.; Battisti, E.; Zanet, S.; Trisciuoglio, A.; Ferroglio, E. A systematic review and meta-analysis of Toxoplasma gondii in roe deer (Capreolus capreolus) and red deer (Cervus elaphus) in Europe. Zoonoses Public Health 2021, 68, 182-193. [CrossRef]

40. Fanelli, A.; Tizzani, P.; Buonavoglia, D. A systematic review and meta-analysis of hepatitis E virus (HEV) in wild boars. Res. Vet. Sci. 2022, 142, 54-69. [CrossRef]

41. Peters, J.L.; Sutton, A.J.; Jones, D.R.; Abrams, K.R.; Rushton, L. Publication Bias in Meta-Analysis. J. Am. Med. Assoc. 2006, 295, 1-7. [CrossRef]

42. Abah, H.O.; Abdu, P.A.; Adamu, J. Newcastle disease virus antibody in serum and feather pulp of chickens vaccinated with thermostable vaccine coated on grains and brans in Zaria, Northern Nigeria. J. Vet. Med. Anim. Health 2017, 9, 264-272. [CrossRef]

43. Abdi, R.D.; Amsalu, K.; Merera, O.; Asfaw, Y.; Gelaye, E.; Yami, M.; Sori, T. Serological response and protection level evaluation in chickens exposed to grains coated with I2 Newcastle disease virus for effective oral vaccination of village chickens. BMC Vet. Res. 2016, 12, 150. [CrossRef]

44. Acharya, M.P.; Adhikari, S.K.; Awasthi, H.; Jha, A.; Singh, U.M. Field Verification Trial of ND I-2 Vaccine in Nepal. Nepal. Vet. J. 2019, 36, 15-22. [CrossRef]

45. Asl Najjari, A.H.; Nili, H.; Asasi, K.; Mosleh, N.; Rohollahzadeh, H.; Mokhayeri, S. Efficacy of thermostable I-2 Newcastle disease vaccine compared to B1 commercial vaccine in broiler chicken. Iran. J. Vet. Res. 2017, 18, 103-107. [CrossRef]

46. Awa, D.N.; Ngo Tama, A.C.; Njoya, A.; Jumbo, S.D.; Mefomdjo, P. The potential role of an inactivated thermostable vaccine in the control of Newcastle disease in traditionally free-roaming poultry in Central and West Africa. Trop. Anim. Health Prod. 2009, 41, 285-290. [CrossRef] [PubMed]

47. Balamurugan, V.; Sen, A.; Venkatesan, G.; Bhanuprakash, V.; Singh, R.K. Protective immune response of live attenuated thermo-adapted Peste des petits ruminants vaccine in goats. VirusDisease 2014, 25, 350-357. [CrossRef] [PubMed]

48. Riyesh, T.; Balamurugan, V.; Sen, A.; Bhanuprakash, V.; Venkatesan, G.; Yadav, V.; Singh, R.K. Evaluation of efficacy of stabilizers on the thermostability of live attenuated thermo-adapted Peste des petits ruminants vaccines. Virol. Sin. 2011, 26, 324-337. [CrossRef]

49. Daouam, S.; Ghzal, F.; Arkam, A.E.; Jazouli, M.; Ennaji, M.M.; Tadlaoui, K.O.; Oura, C.; Elharrak, M. Evaluation of the Safety and Efficacy of a Live Attenuated Thermostable Rift Valley Fever Vaccine in Sheep, Goats and Cattle. J. Vaccines Vaccinatio 2015, 6, 1000295. [CrossRef]

50. Daouam, S.; Ghzal, F.; Naouli, Y.; Tadlaoui, K.O.; Ennaji, M.M.; Oura, C.; El Harrak, M. Safety and immunogenecity of a live attenuated Rift Valley fever vaccine (CL13T) in camels. BMC Vet. Res. 2016, 12, 154. [CrossRef]

51. Dulal, P.; Wright, D.; Ashfield, R.; Hill, A.V.S.; Charleston, B.; Warimwe, G.M. Potency of a thermostabilised chimpanzee adenovirus Rift Valley Fever vaccine in cattle. Vaccine 2016, 34, 2296-2298. [CrossRef] [PubMed] 
52. Echeonwu, B.C.; Ngele, M.B.; Echeonwu, G.O.N.; Joannis, T.M.; Onovoh, E.M.; Paul, G. Response of chickens to oral vaccination with Newcastle disease virus vaccine strain I2 coated on maize offal. Afr. J. Biotechnol. 2008, 7, 1594-1599. [CrossRef]

53. Foster, H.A.; Chitukuro, H.R.; Tuppa, E.; Mwanjala, T.; Kusila, C. Thermostable newcastle disease vaccines in Tanzania. Vet. Microbiol. 1999, 68, 127-130. [CrossRef]

54. Habibi, H.; Nili, H.; Asasi, K.; Mosleh, N.; Firouzi, S.; Mohammadi, M. Efficacy and transmissibility of Newcastle disease I-2 vaccine strain against a field isolate of virulent ND virus (JF820294.1) in village chicken. Trop. Anim. Health Prod. 2015, 47, 73-78. [CrossRef]

55. Habibi, H.; Firouzi, S.; Nili, H.; Asasi, K.; Mosleh, N. Efficacy of thermostable Newcastle disease virus strain I-2 in broiler chickens challenged with highly virulent newcastle virus. Arch. Razi Inst. 2020, 75, 31-37. [CrossRef]

56. Henning, J.; Morton, J.; Pym, R.; Hla, T.; Meers, J. Evaluation of strategies to improve village chicken production-controlled field trials to assess effects of Newcastle disease vaccination and altered chick rearing in Myanmar. Prev. Vet. Med. 2009, 90, 17-30. [CrossRef] [PubMed]

57. Illango, J.; Olaho-Mukani, W.; Mukiibi-Muka, G.; Abila, P.P.; Etoori, A. Immunogenicity of a locally produced Newcastle disease I-2 thermostable vaccine in chickens in Uganda. Trop. Anim. Health Prod. 2005, 37, 25-31. [CrossRef] [PubMed]

58. Jeong, S.H.; Lee, D.H.; Kim, B.Y.; Choi, S.W.; Lee, J.B.; Park, S.Y.; Choi, I.S.; Song, C.S. Immunization with a thermostable Newcastle disease virus K148/08 strain originated from wild mallard duck confers protection against lethal viscerotropic velogenic Newcastle disease virus infection in chickens. PLoS ONE 2013, 8, e83161. [CrossRef] [PubMed]

59. Jones, L.; Giavedoni, L.; Saliki, J.T.; Brown, C.; Mebus, C.; Yilma, T. Protection of goats against peste des petits ruminants with a vaccinia virus double recombinant expressing the $\mathrm{F}$ and $\mathrm{H}$ genes of Rinderpest virus. Vaccine 1993, 11, 961-964. [CrossRef]

60. Khandelwal, A.; Renukaradhya, G.J.; Rajasekhar, M.; Sita, G.L.; Shaila, M.S. Immune responses to hemagglutinin-neuraminidase protein of Peste des petits ruminants virus expressed in transgenic peanut plants in sheep. Vet. Immunol. Immunopathol. 2011, 140, 291-296. [CrossRef]

61. Lankester, F.J.; Wouters, P.A.W.M.; Czupryna, A.; Palmer, G.H.; Mzimbiri, I.; Cleaveland, S.; Francis, M.J.; Sutton, D.J.; Sonnemans, D.G.P. Thermotolerance of an inactivated rabies vaccine for dogs. Vaccine 2016, 34, 5504-5511. [CrossRef]

62. Liu, M.; Guo, S.; Hu, S.; Xiao, Y.; Xu, Q.; Li, Z.; Bi, D.; Sun, M. Displaying the protein of Mycoplasma gallisepticum agglutinin on the cell surface of Bacillus thuringiensis with the S-layer protein. Vet. Microbiol. 2008, 130, 99-106. [CrossRef]

63. Liu, M.; Li, S.; Hu, S.; Zhao, C.; Bi, D.; Sun, M. Display of avian influenza virus nucleoprotein on Bacillus thuringiensis cell surface using CTC as a fusion partner. Appl. Microbiol. Biotechnol. 2008, 78, 669-676. [CrossRef]

64. Lv, F.; Lu, Y.; Hao, Z.1.; Zhao, Y.H.; Zhang, L.H.; Feng, L.; Chen, J.; Wang, L.1.; Rui, R.; Hou, J.B. Preparation and heat resistance study of porcine reproductive and respiratory syndrome virus sugar glass vaccine. Vaccine 2016, 34, 3746-3750. [CrossRef]

65. Mariner, J.C.; Van Den Ende, M.C.; House, J.A.; Mebus, C.A.; Salifou, S.; Stem, C. The serological response to a thermostable vero cell-adapted Rinderpest vaccine under field conditions in Niger. Vet. Microbiol. 1990, 22, 119-127. [CrossRef]

66. Mariner, J.C.; House, J.A.; Mebus, C.A.; Van Den Ende, M.C. The use of thermostable Vero cell-adapted Rinderpest vaccine as a heterologous vaccine against Peste des petits ruminants. Res. Vet. Sci. 1993, 54, 212-216. [CrossRef]

67. Mehrabadi, F.; Hajloo, A.; Shoushtari, A.; Tehrani, F.; Masoudi, S.; Abdoshah, M.; Amir Hajloo, S.; Shabani, M. Effectiveness of Thermostable Vaccine for Newcastle Disease Produced by the Razi Institute on Backyard Poultry in Iran during 2015. Arch. Razi Inst. 2020, 75, 1-7. [CrossRef]

68. Murr, M.; Hoffmann, B.; Grund, C.; Römer-Oberdörfer, A.; Mettenleiter, T.C. A novel recombinant Newcastle disease virus vectored DIVA vaccine against Peste des petits ruminants in goats. Vaccines 2020, 8, 205. [CrossRef]

69. Nega, M.; Moges, F.; Mazengia, H.; Zeleke, G.; Tamir, S. Evaluation of I2 thermostable Newcastle disease vaccine on local chickens in selected districts of western Amhara. J. Anim. Feed Res. 2012, 2, 244-248.

70. Nwanta, J.A.; Umoh, J.U.; Abdu, P.A.; Ajogi, I.; Egege, S.; Adeiza, A.A. Field trial of Malaysian thermostable Newcastle disease vaccine in village chickens in Kaduna State, Nigeria. Sokoto J. Vet. Sci. 2008, 3, 45-47.

71. Omony, J.B.; Wanyana, A.; Kirunda, H.; Mugimba, K.K.; Nakavuma, J.L.; Otim-Onapa, M.; Byarugaba, D.K. Immunogenicity and protection efficacy evaluation of avian paramyxovirus serotype-1 (APMV-1) isolates in experimentally infected chickens. Avian Pathol. 2017, 46, 386-395. [CrossRef] [PubMed]

72. Rahman, M.M.; Bhuiyan, A.R.; Parvin, R.; Giasuddin, M.; Haque, M.E.; Sayem, S.M.; Islam, M.R.; Chowdhury, E.H. Immune response of goats to thermostable PPR vaccine in Bangladesh. SAARC J. Agric. 2011, 9, 73-81.

73. Ruan, B.; Liu, Q.; Chen, Y.; Niu, X.; Wang, X.; Zhang, C.; Guo, M.; Zhang, X.; Cao, Y.; Wu, Y. Generation and evaluation of a vaccine candidate of attenuated and heat-resistant genotype VIII Newcastle disease virus. Poult. Sci. 2020, 99, 3437-3444. [CrossRef] [PubMed]

74. Shendy, M.; El-Dakhly, A.T.; Youssef, M.M. Preparation of a thermostable bovine ephermeral fever virus vaccine inactivated on the time of use. Egypt. J. Agric. Res. 2017, 95, 2.

75. Siddique, F.; Mahmood, M.S.; Hussain, I.; Deeba, F. Evaluation of efficacy of Vero cell-adapted, thermostable Newcastle disease vaccine in broilers. J. Appl. Poult. Res. 2017, 26, 145-153. [CrossRef]

76. Siddique, F.; Abbas, R.Z.; Iqbal, A.; Rabbani, M.; Rafique, A.; Hussain, I.; Ahmed, R.; Mahmood, M.S.; Lotfi, A. Development of humoral immune response to thermostable newcastle disease vaccine strain i-2 in ring-necked pheasant (Phasianus colchicus). Kafkas Univ. Vet. Fak. Derg. 2021, 27, 253-258. [CrossRef] 
77. Smith, T.G.; Wu, X.; Ellison, J.A.; Wadhwa, A.; Franka, R.; Langham, G.L.; Skinner, B.L.; Hanlon, C.A.; Bronshtein, V.L. Assessment of the immunogenicity of rabies vaccine preserved by vaporization and delivered to the duodenal mucosa of gray foxes (Urocyon cinereoargenteus). Am. J. Trop. Med. Hyg. 2017, 78, 752-756. [CrossRef]

78. Tan, L.; Wen, G.; Yuan, Y.; Huang, M.; Sun, Y.; Liao, Y.; Song, C.; Liu, W.; Shi, Y.; Shao, H.; et al. Development of a recombinant thermostable newcastle disease virus (Ndv) vaccine express infectious bronchitis virus (ibv) multiple epitopes for protecting against ibv and ndv challenges. Vaccines 2020, 8, 564. [CrossRef]

79. Tu, T.D.; Van Phuc, K.; Dinh, N.T.K.; Quoc, D.N.; Spradbrow, P.B. Vietnamese trials with a thermostable Newcastle disease vaccine (strain I2) in experimental and village chickens. Prev. Vet. Med. 1998, 34, 205-214. [CrossRef]

80. Verardi, P.H.; Aziz, F.H.; Ahmad, S.; Jones, L.A.; Beyene, B.; Ngotho, R.N.; Wamwayi, H.M.; Yesus, M.G.; Egziabher, B.G.; Yilma, T.D. Long-Term Sterilizing Immunity to Rinderpest in Cattle Vaccinated with a Recombinant Vaccinia Virus Expressing High Levels of the Fusion and Hemagglutinin Glycoproteins. J. Virol. 2002, 76, 484-491. [CrossRef] [PubMed]

81. Wambura, P.N.; Godfrey, S.K. Protective immune response of chickens to oral vaccination with thermostable live Fowlpox virus vaccine (strain TPV-1) coated on oiled rice. Trop. Anim. Health Prod. 2010, 42, 451-456. [CrossRef] [PubMed]

82. Wambura, P.N.; Kapaga, A.M.; Hyera, J.M.K. Experimental trials with a thermostable Newcastle disease virus (strain I2) in commercial and village chickens in Tanzania. Prev. Vet. Med. 2000, 43, 75-83. [CrossRef]

83. Wambura, P.N.; Kataga, S. Putative protective antibody response following oral vaccination of multi-age free ranging helmeted guinea fowls (Numida meleagris) with Newcastle disease virus strain I-2 coated on oiled rice. Trop. Anim. Health Prod. 2011, 43, 99-102. [CrossRef] [PubMed]

84. Wen, G.; Li, L.; Yu, Q.; Wang, H.; Luo, Q.; Zhang, T.; Zhang, R.; Zhang, W.; Shao, H. Evaluation of a thermostable Newcastle disease virus strain TS09-C as an in-ovo vaccine for chickens. PLoS ONE 2017, 12, e0172812. [CrossRef]

85. Zuo, X.X.; Zhao, Y.H.; Zhou, M.X.; Deng, B.H.; Hu, L.G.; Lv, F.; Lu, Y.; Hou, J.B. Live vaccine preserved at room temperature: Preparation and characterization of a freeze-dried classical swine fever virus vaccine. Vaccine 2020, 38, 8371-8378. [CrossRef]

86. Wen, G.; Hu, X.; Zhao, K.; Wang, H.; Zhang, Z.; Zhang, T.; Yang, J.; Luo, Q.; Zhang, R.; Pan, Z.; et al. Molecular basis for the thermostability of Newcastle disease virus. Sci. Rep. 2016, 6, 22492. [CrossRef] [PubMed]

87. Ahmadivand, S.; Soltani, M.; Behdani, M.; Evensen, Ø.; Alirahimi, E.; Soltani, E.; Hassanzadeh, R.; Ashrafi-Helan, J. VP2 (PTA motif) encoding DNA vaccine confers protection against lethal challenge with infectious pancreatic necrosis virus (IPNV) in trout. Mol. Immunol. 2018, 94, 61-67. [CrossRef] [PubMed]

88. Bande, F.; Arshad, S.S.; Bejo, M.H.; Omar, A.R.; Moeini, H.; Khadkodaei, S.; Wei, T.S.; Keong, Y.S.; Abba, Y.; Anka, I.A. Development and immunogenic potentials of chitosan-saponin encapsulated DNA vaccine against avian infectious bronchitis coronavirus. Microb. Pathog. 2020, 149, 104560. [CrossRef] [PubMed]

89. Bunning, M.L.; Fox, P.E.; Bowen, R.A.; Komar, N.; Chang, G.J.J.; Speaker, T.J.; Stephens, M.R.; Nemeth, N.; Panella, N.A.; Langevin, S.A.; et al. DNA vaccination of the American crow (Corvus brachyrhynchos) provides partial protection against lethal challenge with West Nile virus. Avian Dis. 2007, 51, 573-577. [CrossRef]

90. Cai, S.H.; Lu, Y.S.; Jian, J.C.; Wang, B.; Huang, Y.C.; Tang, J.F.; Ding, Y.; Wu, Z.H. Protection against Vibrio alginolyticus in crimson snapper Lutjanus erythropterus immunized with a DNA vaccine containing the ompW gene. Dis. Aquat. Organ. 2013, $106,39-47$. [CrossRef] [PubMed]

91. Chen, J.; Chen, Z.; Wang, W.; Hou, S.; Cai, J.; Xia, L.; Lu, Y. Development of DNA vaccines encoding ribosomal proteins (RplL and RpsA) against Nocardia seriolae infection in fish. Fish Shellfish Immunol. 2020, 96, 201-212. [CrossRef]

92. Citarasu, T.; Lelin, C.; Thirumalaikumar, E.; Michael Babu, M.; Vakharia, V.N. Macrobrachium rosenbergii nodavirus (MrNV)-CPRNA-2 DNA vaccine confers protective immunity in giant freshwater prawn Macrobrachium rosenbergii against MrNV infection. Fish Shellfish Immunol. 2019, 86, 319-326. [CrossRef]

93. Clapp, B.; Walters, N.; Thornburg, T.; Hoyt, T.; Yang, X.; Pascual, D.W. DNA vaccination of bison to brucellar antigens elicits elevated antibody and IFN- $\gamma$ responses. J. Wildl. Dis. 2011, 47, 501-510. [CrossRef]

94. Cui, J.; O'connell, C.M.; Hagen, C.; Sawicki, K.; Smyth, J.A.; Verardi, P.H.; Van Kruiningen, H.J.; Garmendia, A.E. Broad protection of pigs against heterologous prrsv strains by a GP5-mosaic DNA vaccine prime/GP5-mosaic rvaccinia (VACV) vaccine boost. Vaccines 2020, 8, 106. [CrossRef]

95. Dahiya, S.S.; Saini, M.; Kumar, P.; Gupta, P.K. Immunogenicity of a DNA-launched replicon-based canine parvovirus DNA vaccine expressing VP2 antigen in dogs. Res. Vet. Sci. 2012, 93, 1089-1097. [CrossRef]

96. Davis, M.R.; Langan, J.N.; Johnson, Y.J.; Ritchie, B.W.; Van Bonn, W. West Nile virus seroconversion in penguins after vaccination with a killed virus vaccine or a DNA vaccine. J. Zoo Wildl. Med. 2008, 39, 582-589. [CrossRef]

97. Eman, M.S.E.; Maha, A.N.G.; Zaki, F.F.; Saad, M.A.; Soliman, Y.A. A Novel DNA Vaccine Coding For H5 and N1 Genes of Highly Pathogenic Avian Influenza H5N1 Subtype. Indian J. Vet. Sci. Biotechnol. 2020, 15, 1-11. [CrossRef]

98. Fu, Y.; Chen, Z.; Li, C.; Liu, G. Protective immune responses in ducklings induced by a suicidal DNA vaccine of the VP1 gene of duck hepatitis virus type 1. Vet. Microbiol. 2012, 160, 314-318. [CrossRef]

99. Garver, K.A.; LaPatra, S.E.; Kurath, G. Efficacy of an infectious hematopoietic necrosis (IHN) virus DNA vaccine in Chinook Oncorhynchus tshawytscha and sockeye O. nerka salmon. Dis. Aquat. Organ. 2005, 64, 13-22. [CrossRef]

100. Gong, Q.; Kong, L.Y.; Niu, M.F.; Qin, C.L.; Yang, Y.; Li, X.; Ruan, M.D.; Tian, Y.; Li, Z.L. Construction of a ptfA chitosan nanoparticle DNA vaccine against Pasteurella multocida and the immune response in chickens. Vet. J. 2018, 231, 1-7. [CrossRef] [PubMed] 
101. Huang, J.; Shen, H.; Jia, R.; Wang, M.; Chen, S.; Zhu, D.; Liu, M.; Zhao, X.; Yang, Q.; Wu, Y.; et al. Oral vaccination with a DNA vaccine encoding capsid protein of duck Tembusu virus induces protection immunity. Viruses 2018, 10, 180. [CrossRef] [PubMed]

102. Kotla, S.; Vishanath, B.S.; H.J., D.; K., G.; V.V.S., S.; Reddy, G.R. DNA vaccine (P1-2A-3C-pCDNA) co-administered with Bovine IL-18 gives protective immune response against Foot and Mouth Disease in cattle. Vet. Microbiol. 2016, 193, 106-115. [CrossRef] [PubMed]

103. Liu, F.; Tang, X.; Sheng, X.; Xing, J.; Zhan, W. Construction and evaluation of an Edwardsiella tarda DNA vaccine encoding outer membrane protein C. Microb. Pathog. 2017, 104, 238-247. [CrossRef] [PubMed]

104. Liu, X.; Adams, L.J.; Zeng, X.; Lin, J. Evaluation of in ovo vaccination of DNA vaccines for Campylobacter control in broiler chickens. Vaccine 2019, 37, 3785-3792. [CrossRef]

105. Pasnik, D.J.; Smith, S.A. Immunogenic and protective effects of a DNA vaccine for Mycobacterium marinum in fish. Vet. Immunol. Immunopathol. 2005, 103, 195-206. [CrossRef] [PubMed]

106. Sisteré-Oró, M.; López-Serrano, S.; Veljkovic, V.; Pina-Pedrero, S.; Vergara-Alert, J.; Córdoba, L.; Pérez-Maillo, M.; Pleguezuelos, P.; Vidal, E.; Segalés, J.; et al. DNA vaccine based on conserved HA-peptides induces strong immune response and rapidly clears influenza virus infection from vaccinated pigs. PLoS ONE 2019, 14, e222201. [CrossRef] [PubMed]

107. Sun, Y.; Liu, C.S.; Sun, L. Construction and analysis of the immune effect of an Edwardsiella tarda DNA vaccine encoding a D15-like surface antigen. Fish Shellfish Immunol. 2011, 30, 273-279. [CrossRef] [PubMed]

108. Tarradas, J.; Álvarez, B.; Fraile, L.; Rosell, R.; Muñoz, M.; Galindo-Cardiel, I.; Domingo, M.; Dominguez, J.; Ezquerra, A.; Sobrino, F.; et al. Immunomodulatory effect of swine CCL20 chemokine in DNA vaccination against CSFV. Vet. Immunol. Immunopathol. 2011, 142, 243-251. [CrossRef] [PubMed]

109. Vaughan, K.; Del Crew, J.; Hermanson, G.; Wloch, M.K.; Riffenburgh, R.H.; Smith, C.R.; Van Bonn, W.G. A DNA vaccine against dolphin morbillivirus is immunogenic in bottlenose dolphins. Vet. Immunol. Immunopathol. 2007, 120, 260-266. [CrossRef]

110. Wang, H.; Zhu, F.; Huang, Y.; Ding, Y.; Jian, J.; Wu, Z. Construction of glutathione peroxidase (GPx) DNA vaccine and its protective efficiency on the orange-spotted grouper (Epinephelus coioides) challenged with Vibrio harveyi. Fish Shellfish Immunol. 2017, 60, 529-536. [CrossRef]

111. Wium, M.; Jonker, H.I.; Olivier, A.J.; Bellstedt, D.U.; Botes, A. DNA vaccines against Mycoplasma elicit humoral immune responses in ostriches. Front. Immunol. 2019, 10, 1061. [CrossRef]

112. Xing, J.; Xu, H.; Tang, X.; Sheng, X.; Zhan, W. A DNA vaccine encoding the VAA gene of Vibrio anguillarum induces a protective immune response in flounder. Front. Immunol. 2019, 10, 499. [CrossRef]

113. Xu, L.; Zhao, J.; Liu, M.; Ren, G.; Jian, F.; Yin, J.; Feng, J.; Liu, H.; Lu, T. Bivalent DNA vaccine induces significant immune responses against infectious hematopoietic necrosis virus and infectious pancreatic necrosis virus in rainbow trout. Sci. Rep. 2017, 7, 5700. [CrossRef]

114. Xu, H.; Xing, J.; Tang, X.; Sheng, X.; Zhan, W. Intramuscular administration of a DNA vaccine encoding OmpK antigen induces humoral and cellular immune responses in flounder (Paralichthys olivaceus) and improves protection against Vibrio anguillarum. Fish Shellfish Immunol. 2019, 86, 618-626. [CrossRef]

115. Yang, T.; Wang, H.N.; Wang, X.; Tang, J.N.; Gao, R.; Li, J.; Guo, Z.C.; Li, Y.L. Multivalent DNA vaccine enhanced protection efficacy against infectious bronchitis virus in chickens. J. Vet. Med. Sci. 2009, 71, 1585-1590. [CrossRef]

116. Yi, W.; Zhang, X.; Zeng, K.; Xie, D.F.; Song, C.; Tam, K.; Liu, Z.J.; Zhou, T.; Li, W. Construction of a DNA vaccine and its protective effect on largemouth bass (Micropterus salmoides) challenged with largemouth bass virus (LMBV). Fish Shellfish Immunol. 2020, 106, 103-109. [CrossRef]

117. Yu, N.T.; Zheng, X.b.; Liu, Z.X. Protective immunity induced by DNA vaccine encoding viral membrane protein against SGIV infection in grouper. Fish Shellfish Immunol. 2019, 92, 649-654. [CrossRef]

118. Yuan, D.; Qu, L.; Liu, J.; Guo, D.; Jiang, Q.; Lin, H.; Si, C. DNA vaccination with a gene encoding VP60 elicited protective immunity against rabbit hemorrhagic disease virus. Vet. Microbiol. 2013, 164, 1-8. [CrossRef] [PubMed]

119. Zhang, C.; Zhao, Z.; Liu, G.Y.; Li, J.; Wang, G.X.; Zhu, B. Immune response and protective effect against spring viremia of carp virus induced by intramuscular vaccination with a SWCNTs-DNA vaccine encoding matrix protein. Fish Shellfish Immunol. 2018, 79, 256-264. [CrossRef]

120. Zhu, Y.; Li, C.; Bi, Z.; Chen, Z.; Meng, C.; Wang, G.J.; Ding, C.; Liu, G. Protective immune responses in ducklings induced by a suicidal DNA vaccine of the sigma C gene of novel duck reovirus. Vet. Immunol. Immunopathol. 2015, 165, 88-92. [CrossRef] [PubMed]

121. Zhu, L.; Yang, Q.; Huang, L.; Wang, K.; Wang, X.; Chen, D.; Geng, Y.; Huang, X.; Ouyang, P.; Lai, W. Effectivity of oral recombinant DNA vaccine against Streptococcus agalactiae in Nile tilapia. Dev. Comp. Immunol. 2017, 77, 77-87. [CrossRef]

122. Joint FAO/IAEA Division of Nuclear Techniques in Food and Agriculture, A.P. and H.S. Improving Farmyard Poultry Production in Africa: Interventions and their Economic Assessment; Proceedings of a Final Research Coordination Meeting (IAEA-TECDOC-1489); International Atomic Energy Agency: Vienna, Austria, 2006.

123. Joint FAO/IAEA Programme Newcastle. Disease Control of Chicken Improves the Welfare of Rural Households in Africa. Available online: http:/ / www-naweb.iaea.org/nafa/news/2005-newcastle-vaccine.html (accessed on 25 November 2021).

124. Mahmood, M.S.; Siddique, F.; Hussain, I.; Ahmad, S.I.; Rafique, A. Thermostable vaccines for Newcastle disease: A review. Worlds. Poult. Sci. J. 2014, 70, 829-838. [CrossRef] 
125. Zhao, H.; Njeumi, F.; Parida, S.; Benfield, C.T.O. Progress towards eradication of Peste des petits ruminants through vaccination. Viruses 2021, 13, 59. [CrossRef]

126. USAID. Thermostable Peste des Petits Ruminants Vaccine Commercially Available for the First Time. Available online: https:/ / agrilinks.org/post/thermostable-peste-des-petits-ruminants-vaccine-commercially-available-first-time (accessed on 25 November 2021).

127. FAO. Lessons Learned from the Eradication of Rinderpest for Controlling other Transboundary Animal Diseases; FAO: Rome, Italy, 2012; ISBN 9789251073315.

128. Kristensen, D.D.; Lorenson, T.; Bartholomew, K.; Villadiego, S. Can thermostable vaccines help address cold-chain challenges? Results from stakeholder interviews in six low- and middle-income countries. Vaccine 2016, 34, 899-904. [CrossRef]

129. Lloyd, J.; Lydon, P.; Ouhichi, R.; Zaffran, M. Reducing the loss of vaccines from accidental freezing in the cold chain: The experience of continuous temperature monitoring in Tunisia. Vaccine 2015, 33, 902-907. [CrossRef]

130. Fomsgaard, A.; Liu, M.A. The key role of nucleic acid vaccines for one health. Viruses 2021, 13, 258. [CrossRef] [PubMed]

131. Dhama, K.; Mahendran, M.; Gupta, P.K.; Rai, A. DNA vaccines and their applications in veterinary practice: Current perspectives. Vet. Res. Commun. 2008, 32, 341-356. [CrossRef] [PubMed]

132. Farquhar, S.D.; Sims, S.M.; Wang, S.-J.; Morrill, K.S. A Brief Answer: Why is China's Aquaculture Industry so Successful? Environ. Manag. Sustain. Dev. 2017, 6, 234-241. [CrossRef]

133. Thacker, S.B.; Stroup, D.F.; Carande-Kulis, V.; Marks, J.S.; Roy, K.; Gerberding, J.L. Measuring the public's health. Public Health Rep. 2006, 121, 14-22. [CrossRef] [PubMed]

134. Knight-Jones, T.J.D.; Edmond, K.; Gubbins, S.; Paton, D.J. Veterinary and human vaccine evaluation methods. Proc. R. Soc. B Biol. Sci. 2014, 281, 20132839. [CrossRef]

135. Bozorgi, A.; Pazour, J.; Nazzal, D. A new inventory model for cold items that considers costs and emissions. Int. J. Prod. Econ. 2014, 155, 114-125. [CrossRef]

136. Liu, F.; Wu, X.; Li, L.; Ge, S.; Liu, Z.; Wang, Z. Virus-like particles: Promising platforms with characteristics of DIVA for veterinary vaccine design. Comp. Immunol. Microbiol. Infect. Dis. 2013, 36, 343-352. [CrossRef]

137. Ma, J.; Bruce, T.J.; Jones, E.M.; Cain, K.D. A review of fish vaccine development strategies: Conventional methods and modern biotechnological approaches. Microorganisms 2019, 7, 569. [CrossRef] [PubMed] 